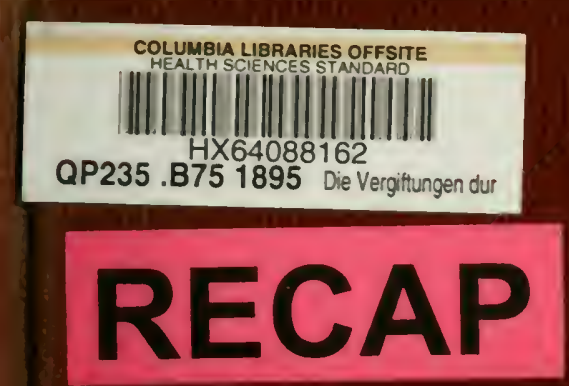


Cralumbia êtniurroity

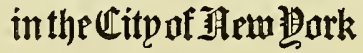

College of 3 弱stiants and Surgeons

Zibrary

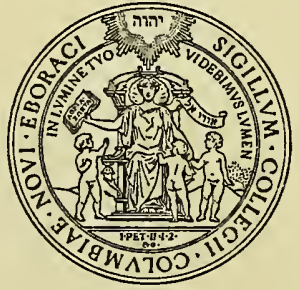



Digitized by the Internet Archive in 2010 with funding from Columbia University Libraries 



\section{DIE VERGIFTUNGEN}

\section{DURCH SCHLANGEN.}

MONOGRAPHISCH BEARBEITET

VUN

DR. M. BRENNING,

PIR IITT.

MIT EINES VORWOR'T VON PROF. DR. L. LEWIN.

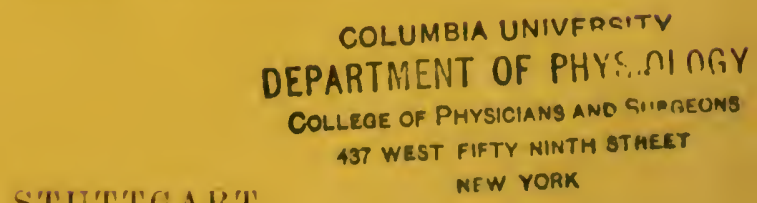

S'T'U'T'GAR'I.

NEW YORK

VERLAGVUN FERIINANI FNKE. 


\section{Organische Chemie für Aerzte.}

In zwölf Vorlesungen.

Von Privatdocent Dr. F. B. Ahrens.

8. 1894. geh. M. 3. -

$$
\text { 工 e h r b u c h }
$$

\section{Physiologie des thierischen Organismus,}

im Speciellen des Menschen.

Von

Prof. Dr. Bernstein.

Mit 271 Abbildungen. gr. 8. 1894. geh. M. 16.--

\section{Das zootomische Practicum.}

\section{Eine Anleitung}

zur Ausführung zoologischer Untersuchungen

für

Studirende der Naturwissenschaften, Mediciner, Aerzte und Lehrer.

Von

Prof: Dr. M. Braum.

Mit 122 Holzschnitten. 8. 1886. geh. M. 7.-

\section{Lehrbuch der Chemie} für

\section{MEDICINER。}

Unter Zugrundelegung des

${ }_{\text {}}$ Arzneibuches für das Deutsche Reichcc

von Dr. Bernhard Fischer.

Mit 46 Abbildungen. gr. 8. 1892. geh. H. 14.-

Lehrbuch der Toxikologie für Thierärzte.

Von Professor Dr. Eugen Fröhner.

gr. 8. 1890. geh. M. 6.- 


\section{DIE VERGIFTUNGEN}

\section{DURCH SCHLANGEN.}

MONOGRAPHISCH BEARBEITE'T

VON

DR. M. BRENNING,

1.IR. AI:T:T.

MI'T EINEM VORWOR'T VON PROF. DH. I. LEWIN.

S'TU'T'T':AR'T.

VFRルAG V(N FERJINAND ENKE.

$18.1 \%$. 
Gift und im menschlichen Körper erzeugten Eiweissgiften zu ziehen, und die Parallelisirung auch auf eine etwaige Immunisirung für solche Stoffe auszudehnen!

Zu einer Zeit, wo an eine Immunisirung gegen Eiweissgifte noch nicht gedacht wurde, habe ich bereits in meinen Vorlesungen auf die Thatsachen hingewiesen, die über die Impfung von Menschen mit Schlangengift, schwer zugänglich, hier und da in Reisewerken zerstreut, mitgetheilt wurden. Nunmelir ist das, was bisher nur deductiv vorgetragen werden konnte, experimentell begründet worden. Man hat Thiere durch Impfung gegen Schlangengift gefeit. Noch ist nicht Alles, was auf diesem Gebiete gefunden werden kann und muss, klargestellt. Die direct hierher gehörigen und damit in fernerem Zusammenhange stehenden Thatsachen älterer und neuerer Zeit bergen in sich viele Weiser für neue Wege der Forschung.

Es war ein Bedürfniss, einmal eine vollständige Darstellung der Schlangenfrage zu geben, und ich bin überzeugt, dass das, was hier mein Schüler, Herr Dr. Brenning, als ersten Abschnitt historisch-toxikologischer Studien aus meinem Laboratorium, zur Ausführung gebracht hat, eine Förderung der Forschungen auf diesem Gebiete wird veranlassen können.

\section{Lewin.}


Vorbemerkungen des Verfassers.

Die vorliegende Arbeit ist in der Absicht geschrieben worden, eine zusammenfassende Darstellung alles dessen zu geben, was rou den ältesten Zeiten an bis auf die Gegenwart über die Giftschlangen selbst, namentlich über ihren Giftapparat, n̈ber die Natur und die Wirkungsweise ihres Giftes, sowie ganz besonders über die zahllosen gegen dasselbe angewandten Gegenmittel geschrieben wurde. Eigene Messungen des Verhältnisses der Giftzahnlänge zu der Körperlänge sollen die in dieser Beziehung noch vorhandene Lücke ausfüllen helfen. Wie gross die Literatur über Giftschlangen und Schlangengift ist, kann man daraus ersehen, dass die von Weir Mitchell in seinem umfangreichen Werke über die Klapperschlange aufgestellte Bibliographie bis zum Jahre 1860 etwa 250 Titel aufweist, und seitdem sind noch gegen :300 Werke und Aufsätze hinzugekommen, welche ich, soweit Inöglich, in den Originalen für meine Arbeit benutzt habe. Der grösste Theil von diesen beschäftigt sich freilich nur mit der Anführung einzelner Fälle von Schlangenbiss und mit Berichten üher die günstige Wirkung von diesem oder jenem Heilnittel, indessen haben doch auch manche Schriften, wie die von Fontana, linssell, Weir Mitchell und namentlich 

I.

\section{Statistisches über Schlangenbisse.}

Es ist selbstverständlich unmöglich eine den thatsächlichen Verhältnissen entsprechende Schätzung der Häufigkeit der durch Giftschlangen erzeugten Schädigungen zn erzielen. Kommen schon nicht alle Verwundungen durch diese Thiere in Deutschland in ärztliche Behandlung, und werden von den durch Aerzte behandelten mindestens die Hälfte nicht literarisch verewigt, so ist an eine ärztliche Behandlung oder gar literarische Mittheilung solcher Vergiftungen in tropischen Gebieten - manche Theile Ostindiens ausgenommen - gar nicht zu denken.

Nicht minder unbestimmbar ist die Schätzung der Mortalität. Wie bei anderen Vergiftungen spielen auch hier nicht nur die individuellen Verhältnisse der Verletzten, nicht nur die Stelle, von der ans das Gift in den Körper gedrungen ist, sondern - was besonders erschwerend für die Beurtheilung des endlichen A usganges der Vergiftung ist - auch die Schlangenart sowie deren zeitlicher Zustand eine hervorragende Rolle. Dies muss bei der Beurtheilung der nachstehenden Angaben in Beriicksichtigung gezogen werden.

Was die europäischen Giftschlangen betrifft, so ist der Biss der Kreuzotter, entgegen der gewöhnlichen Meinung, selbst für Kinder selten tödtlich, und auch der Biss der südeuroppäischen Viper in der Regel nicht lebensgefährlich. So sah Fontana ${ }^{1}$ ) unter fi2 Fïllen von Vipernbiss nur zwei

1) Fontana, Traité sur les venins de la vipère. Florence 1781.

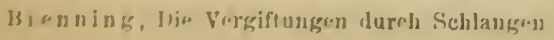


tödtlich verlaufen, und seit Fontana wurden ungefähr 100 Todesfälle durch Tipern in der Literatur reröffentlicht, von denen etwa die Hälfte auf Kinder fallen. In der Schweiz kamen in den Jahren 1877-86 7 Todesfälle durch Kreuzottern und Tipern ror, und in Deutschland wurden in einem Zeitraum ron 10 Jahren 216 Personen von Kreuzottern gebissen; ron den Verletzten starben 14, d. h. ca. 6,5\%. Nach Viaud Grand-Marais endeten von 316 in der Vendée und in Département Loire inférieure beobachteten Fällen 44 tödtlich, d. h. $11 \%$; nach einer anderen Statistik beträgt dagegen die Mortalität an Schlangenbissen im Département Loiret nur $1 \% 0^{1}$ ).

Im Durchschnitt wird man die Sterblichkeit an Bissen der europäischen Giftschlangen auf ungefähr 8,5\% annehmen können. Eine ganz andere Bedeutung für die Mortalität haben jedoch die Giftschlangen tropischer Länder und besonders diejenigen Ostindiens. Hier erreicht die $\mathrm{Zahl}$ der jährlichen Todesfälle an Schlangenbiss infolge der grösseren Zahl der Schlangen, ihrer grösseren Giftigkeit und ihres leichten Eindringens in menschliche Wohnungen und in die Schlafstätten eine erstaunliche Höhe. Nach den Berichten der englischen Regierang starben in Ostindien an Schlangenbiss :

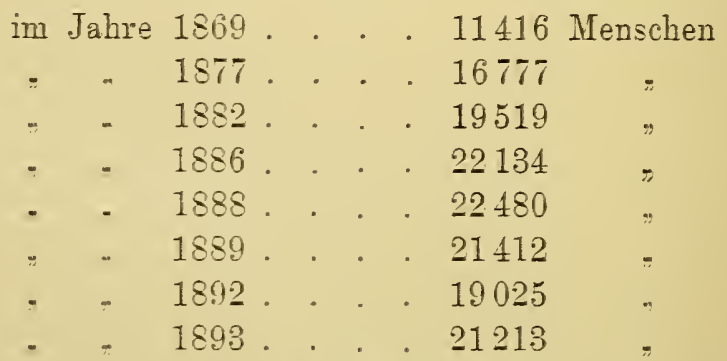

Trotzdem von der englischen Regierung in Jahre 1877 811 Pfund für 127295 getödtete Schlangen, 18821487 Pfund für 322421 Schlangen als Prämie gezahlt wurden, and ob-

1) Boullet, Etude sur la morsure de vipère. Paris 1867. 
gleich im Jahre 1888 sogar 578435 Giftschlangen rertilgt wurden, so hat sich doch in 20 Jahren die Zabl der durch sie ums Leben gekommenen Menschen rerdoppelt. Man hat berechnet. dass ron 100000 Einwohnern in Britisch-Indien jährlich mindestens $1 b^{b}$ an Schlangenbiss sterben. Was das Verhältniss der tödtlichen Bisswunden zu den nicht tödtlichen betrifft, so beobachtete Im la ch unter 306 Fällen 63 letale: dies würde also einer Mortalität ron $20.6 \%$ entsprechen, während. wie wir gesehen haben, in Europa ron den Gebissenen höchstens $8.5 \%$ zu Grunde gehen.

Viel schlimmer gestalten sich diese Verhältnisse noch auf manchen Inseln der ostasiatischen Meere, wo die Schlangenplage zur Verödung ron ganzen Districten, ja auf manchen Inseln zum Verlassen derselben genöthigt hat. Reisenden in jener Gegend ist die Frage bekannt, welche ron den Eingeborenen an den Weissen oft genug gestellt wird, ob er ein Schlangenmittel besitze. Selbst eine naturwissenschaftliche Durchforschung solcher Inseln ist mit Schwierigkeiten rerknüpft, da Eingeborene schwer oder gar nicht als Führer zu haben sind. 
II.

\section{Geschichte und Anatomie der Giftschlangen.}

Die Kenntniss der Gif́tschlangen reicht bis in das früheste Alterthum zurück. Die Bibel spricht von ihnen ebenso wie die altgriechische Mythologie, und Homer ${ }^{1}$ ) erzählt, dass Philoktetes, weil er von einer Hyder gebissen war, auf der Insel Lemnos von den Griechen zurückgelassen werden musste.

Herodot ${ }^{2}$ ) spricht von kleinen mit zwei Hörnern versehenen Schlangen, die um Theben in Aegypten vorkommen und von den Aegyptern für heilig gehalten werden sollen. Merkwürdigerweise erklärt er dieselben für ungefährlich, obgleich man sonst im Alterthum im Gegentheil in der Regel alle Schlangen, auch die wirklich unschädlichen, für giftig ansah, und obgleich die von ihm gemeinten Schlangen in der That eine giftige Art, nämlich den auch sonst den Alten wohlbekannten Cerastes aegyptiacus s. cornutus repräsentiren.

A usser dieser Schlange erwähnt H e r od ot noch geflügelte Schlangen, Riesenschlangen, und solche mit einem Horne auf dem Kopfe ${ }^{3}$ ).

Im Alterthum unterschied man vorziiglich zwei Arten von Giftschlangen, nämlich die Viper (Echis, Echidna) und die Aspis; erstere entspricht der in den Mittelmeerländern gemeinen Vipera ammodytes, der Sandviper, und letztere der ägyptischen Naja haje, durch die sich Cleopatra tödten liess. Der erste, der uns Genaueres über Schlangen berichtet, ist

1) Homer, llias II. 723.

2) Herodot, Histor. II. 74.

3) Herodot, Histor. II. 75, IV. 191-192. 
Aristoteles ${ }^{1}$ ). Nach ihm haben die Schlangen eine sehr lange Luftröhre und eine noch längere Speiseröhre. Der Anfang der ersteren liegt im Munde selbst, so dass die Zunge unter ihr zu liegen scheint. Letztere ist dünn, lang und schwarz, wird weit vorgestreckt und ist an der Spitze gespalten; die Spitzen sind so dünn wie Haare. Der Magen ist wie ein erweiterter Darm und dem des Hundes ähnlich. Der Darm ist lang, dünn und bis ans Ende einfach. Neben dem Schlundkopf liegt das kleine, lange und nierenförmige Herz; dann folgt die einfache, sehr lange, durch eine faserige Brücke gesonderte und rom Herzen weit entfernte Lunge. Auch die Leber ist lang und einfach, die Milz klein und drehrund. Die Gallenblase ist ähnlich wie bei den Fischen; die Wasserschlangen haben sie an der Leber, die übrigen Schlangen jedoch an den Gerlürmen. Alle haben ein sägeförmiges Gebiss. Die Zahl der Rippen beträgt 30. Die ausgestochenen Augen und der abgehauene Schwanz sollen wieder wachsen. Die Wirbelsäule ist grätenartig. Die Schlangen legen Eier, nur die Echidna bringt lebendige Junge zur Welt, erzengt aber auch zuvor in sich Eier. Das Ei ist wie das der Fische einfarbig und weichschalig. Die jungen Vipern werden in Häutchen geboren, die am dritten Tage zerreissen; zuweilen fressen sich die Jungen aber auch von selbst durch und schlüpfen aus. Die Eier der übrigen Schlangen hängen zusammen wie die Halsschnüre der Weiber; wenn sie die Eier in die Erde abgesetzt haben, brüten sie. Die Weibchen sind grösser als die Männchen.

Auch die Geschlechtsorgane beschreibt uns Aristoteles genauer; ebenso weiss er, dass sich die Schlangen häuten und einen Winterschlaf halten. Ausser der Viper und Aspis kennt ar auch die schon von Herodot erwähnte ägyptische Schlange mit einem hornartigen Auswuchs über den Auge, den Cerastes aegyptiacus.

Von anderen Autoren des Alterthums, die uns melır oder

J) Aristoteles, Hist. anim. II. 12, 10 u. a. O. 
weniger über Giftschlangen berichten, sind besonders zu erwähnen: Nikander, Dioscorides, Celsus, Plinius, Aelianus, Galenus, deren Mittheilungen im weiteren Verlaufe dieser Abhandlung noch gewürdigt werden sollen. Wie wenig in jenen Zeiten eine unbefangene naturwissenschaftliche Beobachtung zum Ausdruck kam, davon zeugen vor Allem Plinius und Aelian, die abgeschmackte Volksmärchen, in denen zumeist auch nicht einmal ein Kern von Wahrheit steckt, verewigt haben.

So meint Plinius, dass aus dem Rückenmarke menschlicher Leichen Schlangen entständen. Die letzteren hätten weder Wärme noch Schweiss noch Blut; frässen sie vor dem Bisse etwas Giftiges, so würden sie dadurch gefährlicher. Er kennt ausser Aspis und Hornschlangen auch Amphisbänen und Jacula; erstere sollen auch am Schwanze einen Kopf haben und vorwärts und rückwärts kriechen können, während die Jacula (auch Akontias genannt) sich wie Wurfspiesse fortschleudern sollen. In Indien soll es Riesenschlangen geben, die ganze Hirsche und Stiere verschlingen. Die schönste Schlange, die aber an Giftigkeit keiner anderen nachstehe, sei die im Wasser lebende Hyder. Plinius weiss, dass die Schlangen im Stande sind lange Zeit zu hungern, dass sie die Haut abstreifen und einen Winterschlaf halten; ferner spricht er von dem Kampf der Schlange mit dem Wiesel und Ichneumon.

Noch märchenhafter als die Schilderungen des Plinius sind diejenigen des Aelian, der ja auch eigentlich nur das berichtet, was er von anderen Leichtgläubigen gehört hat, und nichts selbst beobachtet zu haben scheint. So soll es nach ihm in Indien eine Purpurschlange mit weissem Kopf, aber ohne Zähne geben; sie beisst nicht, aber das Glied, das sie anspeit, fault ab. Die Schlangen sollen das Herz im Schlunde, die Galle in den Eingeweiden, die Hoden am Schwanze haben. Die Eier, die sie legen, sind lang und weich; das Gift ist in den Zähnen. Der Magen ist lang und dünn. Beim Fressen stellen sie sich aufrecht. 
Ausser den von Aristoteles und Plinius erwähnten Schlangen beschreibt A elian noch eine in Libyen und Arabien vorkommende "Dipsas", die einen brennenden Durst verursachen soll, ferner die Natter "Thermutis" in Aegypten, den "Hämorrhus", der theils feuerfarben theils tiefschwarz ist, und dessen Koopf mit starrenden Hörnern besetzt ist, die Schlange "Sepedon", die "Seps", welche die Farbe der Orte annimmt, auf denen sie sich aufhält, endlich auch Wasser-und Meerschlangen.

Es würde zu weit führen, wollte man hier alle mysteriösen Besclıreibungen von gehörnten, hundertköpfigen, geflügelten Schlangen und Drachen berücksichtigen, wie man sie, vielfach ron den wunderbarsten Abbildungen begleitet, in den Werken des Altertbums und besonders in denen des Mittelalters und Anfangs der Neuzeit findet.

Dagegen darf nicht unerwähnt gelassen werden, welche Vorstellungen die Alten von dem Bau des Giftapparates und von seiner Wirkungsweise hatten. Zwar wusste man schon in Alterthum, dass das Gift durch den Biss der Schlange in die Wunde gelangt, aber über den Ursprung des Giftes und über den Mechanismus beim Beissen war man doch noch sehr im Unklaren.

Nach Nikander ${ }^{1}$ ) ergiesst sich das Gift bei der Seps aus vier hohlen Zühnen, iber die eine Haut gebreitet ist, welche die Höhlung bedeckt.

Plinius ${ }^{2}$ ), dessen Beschreibung des Giftapparates der Wirklichkeit schon sehr nahe kommt, lïsst die Zähne der Aspis den Fischzähnen ähnlich sein; jedoch ständen im Oberkiefer noch jederseits zwei sehr lange Zähne, durch welche eine feine Röhre geht, aus der sie das Gift in die Wunde fliessen lassen. Diese gifttragenden Zälne sollen von einem dünnen Häutchen umgeben sein; wenn sie beisst, so wende sich letzteres um, und das Gift trete heraus; darauf zögen sich die Hünte wieder zusammen.

1) Nikander, 'Jheriaka 145, 182 ff.

2) Plinius, Hist. nat. XI. 62. 
Einige behaupten, wie Plinius erzählt, die Schlangen hätten auf jeder Seite nur einen Giftzahn, der krumm sei und sich nach dem Bisse zurücklehne; andere meinen, der Giftzahn breche leicht $a b$ und erneuere sich dann wieder. Die Zähne der Viper sollen sich im Zahnfleische verbergen; dieses, von Gift strotzend, lässt durch den Druck der Zähne das Gift in die Wunde fliessen. Der Sitz des Giftes soll die Gallenblase sein, von wo es durch besondere Adern unter der Wirbelsäule hin zum Maule gelange. Manche Autoren des Alterthums, wie Galen, glanbten, dass das Gift im ganzen Körper der Schlange vertheilt sei. Nenere Autoren, wie Mercurialis ${ }^{1}$ ) und $\operatorname{Redi}^{2}$ ) meinten, dass das Gift im ganzen Kopfe entstehe und durch besondere Gänge in die Zähne umhüllende Scheiden gelange.

Nach Gessner ${ }^{3}$ ) liegt es unterhalb der Zähne in einem kleinen Loche verborgen oder wird in einem kleinen Blättchen unter der Zunge gesammelt, ans welchem es nach dem Zerspringen desselben wie Speichel fliessen soll. Nach der Ansicht von Aldrovandus ${ }^{4}$ ) entleert es sich aus einem unter der Zunge liegenden Bläschen durch die Zahnhöhle.

Auch über die Zahl der Giftzähne herrschten lange Zeit Meinungsverschiedenheiten. So sollen sich nach Nikander ${ }^{5}$ ) beim Bisse der Echis zwei, bei dem der Echidna dagegen noch mehr Spuren von Zähnen zeigen. Mercurialis meint, dass bei der Aspis und Viper die Männchen zwei, die Weibchen aber vier Wunden machen.

Auch die Ansicht findet man vertreten, dass es nicht die Zähne, sondern die Zunge sei, welche das Gift führe. Lange Zeit wurde auch der Speichel der Schlangen für giftig gehalten, bis seine Unschädlichkeit von $\mathrm{Charas}^{6}$ ) nachgewiesen

1) Mercurialis, De venenis. 1548. lib. II. cap. 2.

$\left.{ }^{2}\right)$ Redi, Observationes de vipera. Opuscul. tom. II. p. 176 ff. 1729.

3) Gessner, De serpentibus. 1587.

4) Aldrovandus, Serpentum et draconum historia libri II. 1640.

4) Nikander, Theriaka $231 \mathrm{f}$.

6) Charas, Nouvelles expériences sur la vipère. Paris 1694. 
wurde, der auch die Speicheldrüsen bei den Schlangen entdeckte. Manclie glaubten sogar, dass die Viper nicht durch Beissen gefährlich werde, sonderu am Schwanze einen Stachel habe, mit dem sie steche.

Erst gegen Ende des vorigen Jahrhunderts gelangte man durch die Untersuchungen Fontana's, welchem das Verdienst gebührt zuerst eine richtige Beschreibung des Giftapparates, und zwar bei der Vipera aspis, geliefert zu haben, zu klareren Vorstellungen über diesen Gegenstand.

Die moderne Wissenschaft hat mit Scheere und Messer, mit Lupe und Mikroskop jeden Zweifel über die Anatomie der Gifteinrichtung völlig gelöst, so dass über diesen Punkt nunmehr rollständige Klarheit herrscht.

Das Thatsïchliche ïber den Giftapparat der Schlangen ist folgendes:

Alle giftigen Schlaugen, die man auch im Gegensatze zu den ungiftigen Schlangen Thanatophidii nennt, zeichnen sich dadurch aus, dass sie jederseits ausser der Speicheldrüse oberbalb des Mundwinkels eine besondere Giftdrüse besitzen, deren giftiges Secret mittelst eines Ausführungsganges jederseits zu der Basis eines meist gebogenen und sehr verschieden bis $\mathrm{zu} 3 \mathrm{~cm}$ langen Giftzahnes geleitet wird und von dort bei der Abtheilung der Proteroglyphen durch eine an der Vorderfläche des Giftrahnes befindliche Furche, bei den Solenoglyphen dagegen durch einen im Innern des Zahnes befindlichen Canal an die Spitze des Zahnes und beim Beissen von dort in die Wunde hinein gelangt. Die Lage der Giftzähne ist verschieden; bei manchen Schlangen finden sie sich ziemlich vorn im Oberkiefer, bei anderen so weit nach hinten, dass man in das Maul den \%eigefinger legen kann, ohne dass der Zahn diesen zu verwunden vermag. Das Gift wird nur in den beiden Giftrrüsen gebillet und findet sich in keinem anderen Organe der Schlange; daher sind auch alle Theile derselben ausser den Giftdrüsen mit ihren Ausführungsgïngen ungiftig. Der Form nach sind die Giftdrüsen theils knopfförmig, theils platt zusammengedrïckt, theils cylindrisch oder röhrenförmig; ihrem 
Bau nach gehören sie zu den acinösen Drüsen. Bei der Mehrzahl der Giftschlangen liegen sie zwischen Oberkiefer und Quadratbein unter und hinter dem Auge; bei einigen reichen sie dagegen bis weit auf den Rücken, und bei Callophis (Elaps) intestinalis und $\mathrm{C}$. bivirgatus liegen sie sogar innerhalb der Bauchhöhle als langgestreckte, gelb gefärbte Körper dicht neben einander und sind $1 / 4$ bis $1 / 2$ so lang wie das ganze Thier. Drüsen und Ausführungsgänge sind von quergestreiften Muskeln umgeben, um das Gift herauszupressen. Die Giftzähne sitzen anfangs frei beweglich im Oberkiefer, verwachsen aber später mit ihm; dicht hinter ihnen folgen zwei bis sechs Reservezähne, die zum Ersatz der ersten Giftzähne nach ihrer Abnutzung oder zufälligen Ausbrechen dienen.

In der Ruhe oder beim Fressen liegen die Giftzähne, mit ihrer Spitze nach hinten gerichtet, in einer Scheide oder einem Sack verborgen, der durch Erweiterung des Ausführungsganges an der Wurzel des Zahnes und durch eine Duplicatur des Zahnfleisches oder der Lippenschleimhaut gebildet wird. Wenn die Schlange zum Beissen den Rachen öffnet, so richten sich die Zähne durch Verschieben des Quadratbeines durch einen Muskel, der an der Schädelbasis entspringt und sich am hinteren Theile des Gaumenbogens ansetzt, derart auf, dass die obere Oeffnung des Giftzahnes auf die Mündung des Drüsenausführungsganges passt; darauf wird der Giftsack durch den Musculus pterygoideus externus in die Höhe gezogen und durch Contraction der Schläfenmuskeln zusammengepresst, wodurch sich das Gift aus ihm entleert und in die Zähne gelangt.

Manche Schlangen, wie Naja tripudians und Bungarus fasciatus, haben keinen beweglichen Oberkiefer, weshalb die Giftzähne bei denselben nicht erectil sind ${ }^{1}$ ). Bei einzelnen Schlangen (Meerschlangen) finden sich hinter den Giftzähnen anch gewöhnliche solide Zähne im Oberkiefer.

Trotz der scheinbaren anatomischen Uebereinstimmung

1) Fayrer, Edinb. Med. Journ. 14. May. p. 999.1869. 
liegen für die toxikologische Betrachtung in dem bisher Mitgetheilten doch zahlreiche, recht bedentungsvolle Verschiedenheiten, die erklärlich machen, weshalb die Giftwirkung verschiedener Schlangen, abgesehen von der Verschiedenartigkeit des Giftes selbst, sich oft verschieden darstellen kann.

Die Gefährlichkeit der Bisswunden hängt nämlich $a b$ :

1. Von der Grösse der Schlange resp. ihrer Giftdrüsen. Es giebt Trigonocephalus-Arten, bei denen die Giftdrüsen die Grösse einer menschlichen Parotis erreichen. Je grösser die Giftdrüse ist, desto grösser ist auch die darin enthaltene Giftmenge.

2. Von der Kraft der Expulsion; diese ist bei den Schlangen, welche ihre Drüsen in Leibe haben, wegen der Mitwirkung der Bauchmuskulatur grösser als bei denen, die ihre Giftdrüsen im Kopfe zu liegen haben und sie nur durch Contraction der Temporalmuskeln entleeren.

3. Von der Länge des Giftzahues und der davon abhängenden Tiefe des Bisses. Der Giftzahn ist z. B. bei Vipera Berus 11/2"', bei Trigonocephalus mutus etwa $1^{1 / 4} \mathrm{~cm}$ lang.

4. Von der Oertlichkeit des Bisses. Am gefährlichsten sind solche Wunden, welche direct Gefässe oder sehr gefüssreiche Körpertheile, besonders das Gesicht, sowie solche Bisse, welche Körpertheile mit kleinem Umfange treffen, da in diesem Falle die Giftzähne mehr senkrecht und dadurch tiefer eindringen.

5. Von dem Zustande, in dem sich die Schlange befindet. Eine in der Gefangenschaft lebende, die lange Zeit nicht gebissen hat, ist viel geführlicher als eine frei lebende Schlange, ebenso ist eine Schlange gefährlicher, wenn sie gereizt ist, weil sie dann mit grösserer Energie beisst.

6. Von der Jahreszeit; an heissen Tagen sind die Bisswunden gefiihrlicher als bei kühler Temperatur.

7. Von dem Zustande des Gebissenen; kräftige Personen sind im Allgemeinen weniger geführdet als schwache. Ferner soll es günstig sein, wenn der Gebissene sich in einem Zu- 
stande der Erregung befindet, da das Schlangengift depressorisch auf die Nerven wirkt.

8. Von dem Alter der Schlangen. Die indianischen Aerzte behaupten nämlich, dass nur der Biss der jungen Klapperschlangen tödte, und dass die Intensität der Wirkung ihres Giftes dem Alter proportional abnehne; an gefährlichsten sollen die drei- bis achtjährigen sein. Dasselbe glauben die brasilianischen Neger ${ }^{1}$ ).

Was die Menge des bei einem Biss entleerten Giftes betrifft, so liefert ein ausgewachsenes Exemplar von Vipera ammodytes durchschnittlich $0,06 \mathrm{~g}$ Giftflüssigkeit; Kreuzottern geben $0,022 \mathrm{~g}$, Klapperschlangen $0,5 \mathrm{~g}^{2}$ ). Bei rasch wiederholtem Beissen erschöpft sich der Giftvorrath schnell, so dass oft schon der fünfte Biss ungiftig ist. Nach viermonatlichem Winterschlaf ist noch ein ganz actives Gift vorhanden. Alle Organe der Schlangen, ausser den Giftdrüsen und Ausführungsgängen derselben sind ungiftig. Muscarin und Pilocarpin wirken auf die Giftproduction nicht ein, eben so wenig Atropin. Die stärksten Schläge des Magnetelektromotors, die man durch die Giftdrüsen eben getödteter Schlangen treten liess, bewirkten keine Giftabsonderung. Dagegen scheint Nahrungsenthaltung ein zeitweiliges Versiegen des Giftes resp. die Production eines nur wenig oder gar nicht wirkenden Drüsensaftes zu veranlassen. Die in Laboratorium geborenen Thiere geben schon am ersten Lebenstage ein ganz actives Gift.

1) N a phegyi, Philad. med. a. surg. Recorder. XVIII. 12. p. 249. March 1868.

$\left.{ }^{2}\right)$ Feoktistow, Experimentelle Untersuchungen über Schlangengift (Inaug.-Dissert. Dorpat 1888). 
III.

\section{Systematik der wichtigsten Giftschlangen.}

Bei der folgenden Besprechung der an häufigsten vorkommenden Giftschlangen habe ich, dem Zwecke dieser Arbeit entsprechend, weniger die zoologischen Eigenthümlichkeiten und Kennzeichen als vielmeln die Differenzen in der Giftwirkung und Gefährlichkeit der einzelnen Arten berücksichtigen zu müssen geglaubt.

Da ein Moment, worauf es bei der Beurtheilung dieser Frage, wie schon oben erwähnt, vorzüglich ankommt, nämlich die Länge der Giftzähne, bisher eine verhältnissmässig geringe Beachtung gefunden hat, so habe ich mich auf Veranlassung von Herrn Prof. Lew in der Mühe unterzogen, eine grosse Zahl der in der zoologischen Sammlung des Küniglichen Museums für Naturkunde zu Berlin befindlichen Giftschlangen daraufhin zu untersuchen, und füge die gefundenen Resultate den betreffenden Species bei.

Man theilt die Giftschlangen in zwei Abtheilungen ein:

I. Viperina oder Solenoglypha; dieselben haben im Oberkiefer jederseits einen in Innern von einem Kanal durchbohrten Giftzahn und hinter ihm keine soliden Zälne.

II. Colubrina venenosa oder Proteroglypha; diese haben im Oberkiefer an ihrer vorderen Seite mit einer Längsfurche versehene Giftzähne; hinter denselben befinden sich entweder gar keine oder doch nur kleine solide Zähne.

\section{Solenoglypha.}

1. Crotalidac: Jederseits \%wischen Auge und Nasenloch befindet sich eine tiefe Grube. Die wichtigste Gattung 
dieser Familie, deren Arten zu den gefährlichsten Giftschlangen gehören und sehr lange und starke Giftzähne haben, ist die Gattung Crotalus, die dadurch ausgezeichnet ist, dass alle Arten derselben an der Spitze des Schwanzes eine meist aus neun Hornringen bestehende Klapper besitzen. Crotalus durissus Daud., die nordamerikanische Klapperschlange, ist die häufigste Giftschlange der Vereinigten Staaten. Sie kommt bis zum 46. Grad n. Br. vor und wird selten über $1,5 \mathrm{~m}$ lang. Ein von mir untersuchtes Exemplar hatte bei einer Gesammitlänge von $110 \mathrm{~cm}$ sehr kräftige, stark gekrümmte Giftzähne von $10 \mathrm{~mm}$ Länge.

C. cerastes Hallow in Californien und Mexico.

C. adamanteus Pall. findet sich im südlichen Nordamerika und wird über $2 \mathrm{~m}$ lang.

C. miliarius L. hat ungefähr dasselbe Verbreitungsgebiet wie die vorige Art.

C. horridus Daud., die südamerikanische Klapperschlange, die Cascavela der Brasilianer, kommt in Südamerika und auf den Antillen vor. Zwei von mir gemessene Exemplare massen 93 resp. $160 \mathrm{~cm}$, ihre Giftzähne 10 resp. $13 \mathrm{~mm}$; dieselben sind ebenfalls stark und gekrümmt. Sie soll bei jedem Biss 1,5 g Gift entleeren und fast stets den Tod bringen, wenn die Giftzähne tief eindrangen. Der Biss durchdringt das dickste Zeng und die stärksten Stiefel.

Zu den Crotaliden gehört ferner die Gattung Lachesis; statt der Klapper findet sich hier vor dem Schwanzende eine Anzahl dorniger Schuppenreihen.

Lachesis rhombeata Pr. Neawied (Lachesis muta Daud., Crotalus mutus L.), die Surucucú oder der „Buschmeister" der holländischen Colonisten von Surinam, bewohnt die heissen Urwälder der südamerikanischen Ostküste, besonders von Guyana, wirnd über $3 \mathrm{~m}$ lang und ist die grösste Giftschlange. Länge des Giftzahnes $20 \mathrm{~mm}$ (bei $175 \mathrm{~cm}$ Gesammtlänge). Sie soll, wie mir von glaubwürdiger Seite in Brasilien versichert wurde, beim Nahen eines Menschen sich gegen denselben zum Beissen emporrichten. 
Die Gattung Trigonocephalus hat einen spitzen Schwanz ohne Klapper oder Dornen; der Kopf ist dreieckig und besitzt ein grosses Scheitelschild.

Trigonocephalus contortrix Holbrook, die Mocassinschlange, lebt im östlichen Nordamerika und wird $1 \mathrm{~m}$ lang.

T. piscivorus Lacép., lebt ebenfalls in Nordamerika, besonders in Louisiana und Nordcarolina und wird 1,5 m lang. Sie wird mehr gefürchtet als die Klapperschlange, weil sie im Gegensatz zu letzterer, welche nur beisst, wenn sie gereizt ist, direct den Menschen angreifen soll. Giftzähne an einem Kopfiskelet $7 \mathrm{~mm}$ lang.

T. halys Dum., im westlichen Asien, z. B. häufig an den Uferu des Kaspischen Meeres. Länge $65 \mathrm{~cm}$.

T. rhodostoma Reinw., auf Java und in Siam sehr gefürchtet, weil ihr Biss in weniger als einer Viertelstunde tödten soll, und weil sie vielfach in die Besitzungen eindringt. Giftzahn $12 \mathrm{~mm}$ lang.

T. Blomhoffii Boie, in Ostasien, besonders in Japan. Sie verursacht oft tödtliche Vergiftungen. Länge des Giftzahns $5-7 \mathrm{~mm}$ bei $55-69 \mathrm{~cm}$ Totallänge.

Die Gattung Bothrops ist ähnlich der vorigen, hat aber am Kopfe jederseits ein grosses Supraciliarschild.

Bothrops lanceolatus Wagl., die Lanzenschlange, kommt auf den Antillen, besonders auf Martinique sehr häufig vor und ist daselbst sehr gefürchtet. Sie verursacht unter den ca. 150000 Einwohnern der Insel jährlich ca. 50 Todesfälle. Der längste von $\mathrm{Rufz}^{1}$ ) gemessene Giftzahn dieser Schlange war ca. $25 \mathrm{~mm}$ lang (bei einer Totallänge von $190 \mathrm{~cm}$ ). Im Pariser Museum soll sich sogar ein Exemplar mit einem 1.) Linien (etwa $34 \mathrm{~mm}$ ) langen Giftzahn befinden. Eine von mir gemessene Schlange hatte bei einer Gesammtlänge von 1.j) $\mathrm{cm}$ einen $15 \mathrm{~mm}$ langen Giftzahn.

B. Jararací Neuw., die Jararacá, ist die häufigste

') $\mathrm{R} \cup \mathrm{f} \%$, Finquite sur le serpont (Fer de lance) de la Martiniqur. Paris 185\%. ए. 67. 
Giftschlange Brasiliens. Sie wird 1,8 $\mathrm{m}$ lang und dem Menschen dadurch besonders gefährlich, dass sie ihn, ohne irgendwie gereizt zu sein, zuweilen aus freien Stücken angreifen und sogar verfolgen soll. Uebrigens ist sie die einzige Schlange, von welcher letzteres mit Sicherheit constatirt ist. Unter 100-200 Einwohnern stirbt in manchen Gegenden jährlich einer durch den Biss dieser Schlange.

B. atrox Dum., die Labaria der Colonisten, Sororaima der Macusis, lebt in Brasilien und Guyana, und zwar besonders in den dichten Urwäldern. Sie ist ebenfalls sehr gefürchtet, ihr Biss tödtet oft schon in weniger als 24 Stunden. Bei drei Exemplaren des Berliner Museums betrug die Länge der Giftzähne 4, 9, $12 \mathrm{~mm}$, die Totallänge der betreffenden Schlangen $38,75,85 \mathrm{~cm}$.

B. viridis Dum., in Ostasien. Giftzahn an einem Kopfskelet der Schlange $6 \mathrm{~mm}$ lang.

Weniger wichtige Arten der Gattung Bothrops sind noch:

B. formosus Schl. auf Sumatra.

B. nigromarginatus Dum. auf Ceylon.

B. Jararacussú in Brasilien.

B. Neuwiedi Wagl. und

B. Castelnaudi Dum., ebenfalls in Brasilien.

B. bilineatus Dum., in Brasilien und auf den Antillen.

B. pictus Tschudi in Peru.

B. Boussingaulti Dum. in Ecuador.

B. alternatus Dum. in Südamerika.

B. Lansbergi Schl. in Mittel- und Südamerika.

Trimeresurus Riukiuanus Hilg., dieHabu-Schlange, ist auf den Liu-kiu-Inseln derartig gefürchtet, dass ganze Dörfer verlassen werden, wo die Schlange sehr zunimmt; ihr Biss soll schon nach wenigen Stunden, spätestens in zwei Tagen den Tod nach sich ziehen. Die Schlange wird etwa $2 \mathrm{~m}$ lang.

T. erythrinus Cant. in Ostasien. Giftzahn $8 \mathrm{~mm}$, Totallänge $80 \mathrm{~cm}$.

T. gramineus Shaw. in Indien wird weniger gefürchtet, da ihr Biss nur Localerscheinungen verursachen soll. 
Tropidolaemus sumatranus Rafft, auf den Sundainseln und in Ostindien. Giftzahn $11 \mathrm{~mm}$, Totallänge $75 \mathrm{~cm}$.

T. semiannulatus, Giftzahn $4 \mathrm{~mm}$ lang.

T. Hombroni Dum. auf den Philippinen.

Hypuale nepa Laur. auf Ceylon und in Ostindien.

Peltocolor macrolepis Bedd. in Indien.

Atropos acontia Gray auf Japan und Borneo.

A. undulatus in Mexico.

2. Viperidae. Diese Familie unterscheidet sich von den Crotalidae dadurch, dass sich zwischen Auge und Nasenloch keine Grube befindet.

Die Giftzähne sind zwar bei den meisten Viperiden bedeutend kleiner als bei den Crotaliden, erreichen jedoch bei einzelnen ebenfalls eine bedeutende Länge und Stärke.

Die Arten der Gattung Cerastes haben den Scheitel des Kopfes mit warzigen Schuppen bedeckt, welche sich über den Augen zu hornartigen Fortsätzen erheben.

Cerastes aegyptiacus Wagl. ist die von den Alten so oft erwähnte, und von Herodot für ungefährlich gehaltene Hornviper; sie lebt in Nordafrika, besonders in Aegypten und in der Wüste, und findet sich auch in Arabien. Giftzahn if $\mathrm{mm}$, Totallänge $51 \mathrm{~cm}$.

Cerastes lophophrys Dum., die Helmbuschviper, hat über jedem Auge ein Büschel kleiner Hornfäden; sie lebt am Cap der guten Hoffnung.

Cerastes caudalis Smith in Südafrika.

Cerastes persicus Dum. in Persien.

Bei der Gattnng Vipera sind die Schuppen auf dem Scheitel des Kopfes glatt.

Vipera aspis Merr. (Vipera Redii Fitz), die Redi'sche Tiper, wird $6.5-7.5 \mathrm{~cm}$ lang und findet sich im südwestlichen Europa, besonders in Südfrankreich, Italien, in der Schweiz, seltener in Südtirol, Kärnthen, Illyrien, Dalmatien; in Deutschland kommt sie nur bei Metz und in Baden vor. Sie ist kenntlich an der etwas aufgeworfenen Schnanze und an den vier lieihen schwarzer grosser llecken auf dem Rücken, welche 
aber kein Zickzackband bilden. Die Mortalität der Verwundung durch diese Viper verhält sich wie 1:25. Bei jedem Biss werden $0,15 \mathrm{~g}$ Gift entleert. Giftzahn $5 \mathrm{~mm}$ bei $50 \mathrm{~cm}$ Totallänge.

Vipera ammodytes Dum. und Bibr., die Sandviper, wird $65-95 \mathrm{~cm}$ lang; sie ist die von den meisten alten Autoren als Viper, von Dioscorides als Kenchros bezeichnete, gefährlichste aller europäischen Giftschlangen und ist in allen Mittelmeerländern, besonders in Dalmatien und Griechenland gemein, findet sich aber auch in Kärnthen, Steiermark, Südungarn, Tirol. Sie hat über der Schnauzenspitze eine weiche, hornartige Verlängerung. In Bezug auf die Mortalität verhält sie sich ungefähr wie die vorige. Giftzahn $5 \mathrm{~mm}$, Totallänge $51 \mathrm{~cm}$.

Vipera rhinozeros Schl., in Gabun, soll einen schnellen Tod verursachen. Giftzahn an einem Kopfskelet im Berliner Museum $30 \mathrm{~mm}$ lang, sehr stark und von bedeutender Krümmung.

Vipera nasicornis Shaw. in Guinea und an der Goldküste.

Vipera atropos Schl. in Südafrika, Giftzahn $7 \mathrm{~mm}$, Totallänge $42 \mathrm{~cm}$.

Vipera latastei Bosc. lebt in Spanien und Portugal.

Vipera lebetina L. auf der Insel Milo und in Afrika.

Die Gattung Pelias, die von Vielen auch zur Gattung Vipera gezählt wird, hat vorn auf dem Kopfe ein grösseres centrales Schild, das von kleineren Schilden umgeben ist.

Pelias berus Merr. (Vipera berus Dand.), die gemeine Kreuzotter, wird $50-70 \mathrm{~cm}$ lang, findet sich in ganz Europa ausser in den nördlichsten und südlichsten Theilen, sowie in Asien. Sie ist leicht kenntlich durch das auf dem Rücken befindliche schwarze Zickzackband. Auf ihre verhältnissmässig geringe Giftigkeit ist bereits in der Einleitung hingewiesen worden. Bei jedem Biss entleert sich etwa $0,1 \mathrm{~g}$ Gift; ihre Giftzähne sind etwa $3-4 \mathrm{~mm}$ lang.

Variationen von Vipera berus sind die von den Alten 
als Prester oder Dipsas beschriebene Vipera prester L., die sogen. Höllennatter, und die Kupferschlange, Vipera cliersea $\mathrm{L}$.

Von aussereuropäischen Viperiden sind noch zu nennen:

Clotho arietans Gr., die Puffotter in Südafrika, deren Biss häufig schnell tödtet. Giftzähne von drei Exemplaren des Museums, deren Länge 27-34 cm betrug, 7-8 mm lang. Die Zähne an einem Kopfskelet waren sogar 12 (rep. 14) mm lang.

Daboia Russelii Gthr., die Katuka Rekula Poda oder Bora Siah Chunder der Eingeborenen in Ostindien. Sie verursacht nächst der Brillenschlange die meisten Todesfälle daselbst, ist aber noch weit mehr gefürchtet als diese, weil sie, wenn sie auch langsamer in ihren Bewegungen ist als die Brillenschlange und weniger häufig beisst, so doch desto sicherer den Tod verursacht. Lünge dcs Giftzahnes $14 \mathrm{~mm}$, Totallänge $110 \mathrm{~cm}$.

Echis carinata Merr. ebenfalls in Indien (Horatta $\mathrm{Pam})$. Sie steht an Gefährlichkeit hinter den meisten anderen Giftschlangen Indiens zurück. Länge $60 \mathrm{~cm}$.

Echis chlorechis Schl, an der Goldküste.

\section{Proteroglypha.}

Die Giftzähne der Proteroglyphen sind bedeutend kleiner als die der Solenoglyphen.

1. Elapidae. Körper fast cylindrisch, Nasenlöcher seitlich gerichtet.

Bei der Gattung Elaps sind die Schuppen der Rückenmittellinie nicht besonders ausgezeichnet, die unteren Schwanzschilder zweireihig und der Kopf flachgedrückt.

Elaps corallinus Wied, Korallenschlange, $65-70 \mathrm{~cm}$ lang, in Südamerika. Giftzahn ca. $2 \mathrm{~mm}$ lang. Trotz der Kleinheit der Zähne ist das Gift dieser Schlange so wirksam, dass ınan schon eine Stunde nach dem Bisse den Torl eintreten sal.

E. lenniscatus Schl. in Südamerika. 
E. fulvius L. in Nordamerika.

E. frontalis Dum. in Südamerika. Länge $85-90 \mathrm{~cm}$, Giftzähne 2-4 mm.

E. bivirgatus Schl. auf Java. Giftzähne $3 \mathrm{~mm}$ lang.

Die Gattung Naja hat einen hohen, vierkantigen Kopf; die vorderen Rippen sind verlängert, und der Hals ist ausdehnbar.

Die wichtigste Schlange dieser Gattung ist Naja tripudians Merr., Cobra de Capello, die ostindische Brillenschlange. Sie wird $11_{4}-2 \mathrm{~m}$ lang und findet sich ausser in Ostindien auch auf Java und in Südchina. Sie ist diejenige Giftschlange, welche in Indien wegen ihres ausserordentlich häufigen Vorkommens daselbst und ihrer leichten Reizbarkeit und davon abhängigen Geneigtheit zum Beissen die meisten Opfer fordert. Bei jedem Biss sollen ca. $2 \mathrm{~g}$ Gift entleert werden. Zwei von mir untersuchte Brillenschlangen besassen bei einer Totallänge von 105 resp. $118 \mathrm{~cm}$ Giftzähne von nur 4 resp. $5 \mathrm{~mm}$ Länge.

Naja haje Merr., die Aspis der Alten, die Schlange der Cleopatra oder ägyptische Brillenschlange, ist 1,6-2,25 m lang und lebt in West- und Nordafrika. Giftzahn $6 \mathrm{~mm}$ lang bei einer Totallänge von $174 \mathrm{~cm}$.

Naja angusticeps Smith. in Gabun. Giftzähne bei einem $3 \mathrm{~m}$ langen Exemplar $7 \mathrm{~mm}$, an einem Kopfskelet $8 \mathrm{~mm}$ lang.

Naja sputatrix Boie auf Banka. Giftzähne $4 \mathrm{~mm}$ lang. Naja regalis Schl. an der Goldküste.

Naja nigricollis Reinh. in Guinea, Sierra Leone und an der Goldkïste.

Seped on ha emachates Merr. in Südafrika ist fast ebenso giftig wie Naja tripudians und $\mathrm{N}$. haje.

Bei der Gattung Pseudechis sind die unteren Schwanzschilder voru einreihig, hinten zweireihig.

Pseudech is porphyricus Wagl., 2,5 m lang, Schwarze Schlange (black suake), in Australien. Sie verursacht oft schnellen Tod, Giftzahn $5 \mathrm{~mm}$ lang. 


\section{- $21-$}

Bei der Gattung Bungarus sind die Schuppen der Ruickenmittellinie besonders ausgezeichnet, gross und sechsseitig; After- und untere Schwanzschilder sind nicht getheilt.

Bungarus coeruleus Daud., Krait oder Gedi Paraguda der Eingeborenen, ist $80 \mathrm{~cm}$ lang und gehört zu den gefährlichsten Schlangen Ostindiens und Javas. Giftzähne kleiner als bei Naja tripudians, nämlich $2 \mathrm{~mm}$ bei einer Totallänge von $106 \mathrm{~cm}$.

Bungarus annularis Daud. (B. fasciatus Schn.). Sankni oder Bungarum Pamah der Eingeborenen, 1,6 bis $2 \mathrm{~m}$ lang, auf Ceylon, in Ostindien und in China, ist weniger gefährlich.

Die Gattung Dinophis (Dendraspis) hat grosse dreieckige Schuppen auf der Rückenmittellinie und getheilte Afterund untere Schwanzschilder.

Dinophis Jamesonii Traill. lebt auf Bäumen in Westafrika, besonders an der Goldküste.

Atractaspis Bibroni Smith in Westafrika. Giftzähne 5 $\mathrm{mm}$, Totallänge $70 \mathrm{~cm}$.

Ophiophagus elaps Gth., 4-5 m lang, Sunkerchor der Indier, findet sich in Indien, auf den Andamanen, den Sunda-Inseln, Neu-Guinea. Sie ist nach Fayrer vielleicht die grösste und gefährlichste Giftschlange Ostindiens und vermag einen Elephanten in 3 Stunden zu tödten. Sie soll ebenfalls den Menschen angreifen.

Causus rhombeatus Wagl. in Süd- und Westafrika. Vier von mir gemessene Exemplare hatten Giftzähne von 1 1/2, $2,3,4 \mathrm{~mm}$ Länge bei einer Totallänge von $21,39,42$, $57 \mathrm{~cm}$.

Callophis intestinalis Gth. in Indien ist dadurch ausgezeichnet, dass sich bei dieser Schlange die Giftdrüsen in der Bauchhöhle befinden. Sie ist relativ wenig gefährlich, ihr Giftzahn auch nur ca. $3 / 4 \mathrm{~mm}$ lang bei einer Totallänge von $37 \mathrm{~cm}$.

Callophis japonicus gebört zu den wenigen in Japan vorkommenden Giftschlangen. 
Hoplocephalus curtus Schl., Tigerschlange, in Australien. Ihr Biss tödtet ziemlich häufig.

H. superbus Gthr., large scaled oder diamond snake, in Australien, ist weniger giftig.

Acanthophis antarctica, death adder, Todesnatter, ist die gefährlichste aller australischen Schlangen. Giftzahn $3 \mathrm{~mm}$ bei $35 \mathrm{~cm}$ Totallänge, $6 \mathrm{~mm}$ an einem Kopfskelet.

Diemansia superciliaris Fisch., brown snake, in Australien. Giftzähne an einem Kopfskelet $2 \mathrm{~mm}$.

Im Allgemeinen sind von den australischen Giftschlangen, deren Zahl 208 beträgt, die meisten für den Menschen vollkommen ungefährlich.

2. Hydrophidae. Die Meer- oder Seeschlangen haben einen seitlich zusammengedrückten Körper und Schwanz; die Nasenlöcher sind nach oben gerichtet. Sie sind die am wenigsten gefährlichen Giftschlangen und haben auch die relativ kleinsten Giftzähne.

$\mathrm{Platurus}$ fasciatus Latr. in Chinesischen und Indischen Meere. Giftzahn $1 \mathrm{~mm}$ bei $75 \mathrm{~cm}$ Totallänge.

P. laticaudatus L. Giftzähne $2 \mathrm{~mm}$ bei $90 \mathrm{~cm} \mathrm{To-}$ tallänge.

Hydrophis cyanocincta Gthr. im Meere von Ceylon bis Japan. Giftzähne $2-3 \mathrm{~mm}$ bei $45-75 \mathrm{~cm}$ Totallänge. Hydrophis pelamoides Schl. im Indischen Meere.

Pelamis bicolor Daud. ist die gemeinste Seeschlange und kommt von Madagaskar bis zum Golf von Panama vor. Giftzähne sehr fein, $1^{1 / 2} \mathrm{~mm}$ bei $50 \mathrm{~cm}$ Totallänge. Sie vermag unter Umständen einen Menschen in 4 Stunden zu tödten. doch gehören Todesfälle nach ihrem Bisse zu den Ausnahmefällen.

Manche Seeschlangen, wie z. B. Platurus fasciatus, sollen nicht einmal dann beissen, wenn man sie in die Hand ninmmt.

Aus der vorstehenden Betrachtung der einzelnen Giftschlangen scheint hervorzugehen, dass die Länge des Gift- 
zahnes eine wesentliche Rolle bei der Beurtheilung des Giftigkeitsgrades der einzelnen Arten spielt. Am gefährlichsten wären danach die Crotaliden, dann folgen die Viperiden und Elapiden, und am ungefährlichsten sind die Hydrophiden. Dieselbe Reihenfolge in der Gefährlichkeit hat übrigens auch Fayrer ${ }^{1}$ ) für die ostindischen Giftschlangen aufgestellt, und zwar ebenfalls mit Bezugnahme auf die Länge der Giftzähne.

Was nun die Abtheilung der Colubriformia (Aglyphodontia, Opistoglypha) betrifft, welche nicht mehr zu den eigentlichen Giftschlangen gezählt werden, so besitzen manche Gattungen derselben, nämlich Scytale, Dipsas, Dryophis, Langaha, Psammophis, Coelopeltis, Homalopsis, Tachymenis und zuweilen auch Calamaria und Geophis im Oberkiefer jederseits hinter einer Reihe von soliden Hakenzähnen einen Furchenzahn und werden deshalb als Serpentes suspecti bezeichnet. Nachdem aber bereits Duvernoy bei verschiedenen Opistoglyphen, und nenerdings auch Jourdain ${ }^{2}$ ) bei Coelopeltis insignitus eine kleine Giftdrüse entdeckt hat, deren Ausführungsgang mit den hinteren Furchenzähnen in Verbindung steht, so unterliegt es wohl keinem Zweifel, dass schliesslich bei allen diesen „verdächtigen Schlangen" eine Giftdrüse nachgewiesen werden wird, und dass dieselben somit eigentlich zu den Giftschlangen gehören. Jourdain ist sogar der Meinung, dass alle Schlangen im Besitze von Giftapparaten, wenn auch von verkümmerten, sind. Wie weit sich diese Ansicht bestätigen wird, muss dahingestellt bleiben, jedenfalls ist zu hoffen, dass wenigstens die "Serpentes suspecti" in absehbarer Zeit dieses unbestimmten Charakters entkleidet und als giftige oder ungiftige Schlangen erkannt werden. Diese Frage ist wahrscheinlich auch für den Menschen nicht ohne Bedeutung; zwar tödten die meisten dieser Schlangen ihre Opfer nicht durch Beissen, sondern

1) Ea y rer, Edint. Med. Journ. 14. May 1869. p. 997.

${ }^{2}$ ) Jo u rdain, Compt. rend. de l'Acad. des sciences. T. 118. 1894. p. 207. 
durch Umschlingen, und wenn sie einmal wirklich beissen, so thun sie dies in der Regel nur mit den ungiftigen Vorderzähnen. Sperrt man aber z. B. einer Coelopeltis absichtlich die Kiefer weit aus einander und schiebt das Glied des zu beissenden Thieres ganz weit hinein, so dass dann auch die Giftzähne eindringen können, so sterben kleine Säugethiere und Vögel schon sehr kurze Zeit nach dem Biss. Es geht daraus hervor, dass auch diese Schlangen ein durchaus wirksames Gift zu produciren vermögen. Hierfür scheint auch der Umstand zu sprechen, dass die ebenfalls zu den "Verdächtigen" gehörende Langaha-Schlange vou den Eingeborenen von Madagaskar wegen ihrer Giftigkeit gefürchtet sein soll ${ }^{1}$ ).

1) Gmelin, Allgem. Geschichte der thierischen und mineralischen Gifte. 2. Aufl. Erfurt 1811. S. 78. 


\section{Die Natur des Schlangengiftes.}

Ueber die Natur des Schlangengiftes finden sich bei den Alten nur wenige Bemerkungen. Nach Aelian soll die indische Purpurschlange zwei Arten von Gift, eine schwarze und eine dem Bernstein gleichende, enthalten. Gessner sagt vom Schlangengift, es sei kalt und trocken und werde nur bei grosser Trockenleit erzeugt, weswegen Einige meinten, die Galle sei das Gift der Schlangen. Auch Plinius erzählt, dass die besten Autoren die Galle für das Gift der Schlange hielten.

Mead ${ }^{1}$ fand im Viperngift äusserst zarte, spitze, sehr beständige Krystalle und erklärte dieselben für das wirksame Prinzip des Giftes.

Dass man lange Zeit den Speichel der Schlange als giftig ansah, habe ich bereits erwähnt.

Entsprechend der Bedentung des Gegenstandes hat unsere \%eit ganz besonders eifrig an der Aufklärung des Schlangengiftes gearbeitet. Ist hier auch jetzt dem weiteren Forschen, wie die folgenden Zeilen es lehren werden, eine gewisse natürliche Schranke gezogen worden, so kann man doch den Zuwaclss an Erkenntniss begrüssen und vor Allem sich freuen, dass ein Wust von falschen Angaben nummehr endgültig beseitigt ist.

Die ergebnissreichsten Untersuchungen stellten Mitchell und Reichert ${ }^{2}$ ) an. Sie benutzten zu ihren Versuchen be-

1) Mead, Le vipera. Opera medica. Vol. II. 1749.

2) Weir Nitchell, Rescarches upon the venom of the Rattlesnake (Smithsonian contributions to knowledge. Philad. 1860. 4\% ). Americ. 
sonders die Gifte folgender amerikanischer Schlangen: Crotalus adamanteus, Cr. durissus und Ancistrodon piscivorus (Mocassinschlange), sowie das getrocknete Gift der indischen Cobra.

Die physikalischen Eigenschaften der Schlangengifte sind bei allen Giften fast die gleichen.

Die Farbe variirt von blass Smaragdgrün bis Orangeund Strohgelb. Auch das Gift der Surucucú soll eine grünliche Färbung haben, das der Jararacá dagegen wasserklar sein und mit Kalilauge eine carminrothe Farbe annehmen ${ }^{1}$ ). Das spezifische Gewicht des Giftes schwankt zwischen 1030 und 1077. Durch langen Aufenthalt in der Drüse wird es concentrirter. Das eingetrocknete Gift bleibt ausserordentlich lange wirksam, da es z. B. in einem Falle nach 16 jährigem, in einem anderen sogar nach 22 jährigem Aufbewahren noch nichts von seiner Giftigkeit eingebüsst hatte. Ebenso hält sich Viperngift, wenn gut verschlossen, über 18 Monate lang ${ }^{2}$ ) und war sogar noch wirksam, nachdem es mehrere Jahre in der Höhlung des Giftzahnes gewesen war. Auch selbst längere Zeit in Spiritus aufbewahrte Giftschlangen können noch gefährlich werden, wie der Fall eines Assistenten am Petersburger Museum beweist, welcher sich durch unvorsichtige Manipulation mit einer solchen Schlange eine tödtliche Verletzung durch deren Giftzahn zuzog. In Glycerinlösung bleibt das Gift lange Zeit wirksam. Wässrige Lösungen des Schlangengiftes dagegen zersetzen sich schnell und werden bald unwirksam. Das Gift ist klebrig (bei der Viper wie Harz) und trocknet sehr langsam. In völlig trockenem Zustande gleicht es getrocknetem Eiweiss und bildet es dünne, gelbe, durchscheinende Lagen. Die Krystalle, welche Me a d im Viperngift gefundem haben wollte, sind nichts Anderes als zahllose Risse, welche diese Lagen durchkreuzen. Das frische Gift

med. chir. Rev. V. p. 269-311. March 1861. - Weir Mitchell and Reichert, Researches upon the venom of poisonous serpents (Smithsonian contrib. Wash. 1886).

1) v. Tschudi, Reisen durch Südamerika. III. 1867.

2) Mangili, Annales de Chimie et de Physique. Florence 1817. 
ist geruch- und geschmacklos. Einige Autoren wollen allerdings einen scharfen, ätzenden Geschmack daran wahrgenommen haben. Das Gift zersetzt sich, wenn lange feucht gehalten, unter Ammoniakentwickelung und riecht dann furchtbar, ist aber auch dann häufig noch giftig.

Unter dem Mikroskope zeigt sich im frischen Gifte häufig ausser einigen Epithelzellen und Speichelkörperchen eine granulirte Masse; daron erwiesen sich bei genauerer Untersuchung die grösseren Granula als Körper von albuminoider Natur, die kleineren als Mikrokokken. Die letzteren spielen aber sicher keine Rolle in der Wirksamkeit des Giftes trotz der gegentheiligen Ansicht Lacerda's, der im Gifte von Bothrops-Arten Bacterien entdeckt zu haben glaubte ${ }^{1}$ ). Neuere Untersuchungen ${ }^{2}$ ) ergaben, dass frisc hes Schlangengift überhaupt keine Organismen enthält, es sei denn, dass solche aus der Mundhöhle der Schlange stammen oder durch irgend einen Zufall hineingeriethen. Krystalle, die denen der phosphorsauren Ammoniak-Magnesia ähnlich sahen, wurden im Gifte von Crotalus confluentus gefunden; sie sind aber offenbar auch nur die Folge beginnender Zersetzung des Giftes. In getrockueten Viperngifte fehlte jede Krystallisation; es stellt eine amorphe, in Wasser völlig lösliche Substanz dar. Auch etwaigen im Gifte befindlichen Krystallen darf also kein Einfluss auf die Wirksamkeit desselben zugeschrieben werden, wie man es früher zuweilen that.

Eine $20 \%$ ige wässerige Lösung des eingetrockneten Viperngiftes soll in der Wirkung auf Thiere ganz dem ursprünglichen Gifte entsprechen ${ }^{y}$ ).

Die Reaction des Schlangengiftes ist nach Angabe der meisten Untersucher sauer; das Cobra-Gift wird jedoch von neueren Autoren ${ }^{4}$ ) für neutral erklïrt.

') La cerda, Compt. rend. de l'Acad. des sc. Déc. 1878.

2) Fredet, Union méd. 'T. XXV. 1878. - M. Ka ufmann, Du venin de la vipère. P’aris 1889.

$\left.{ }^{3}\right)$ Karlinski, Fortschritte der Medicin. VIII. 16. 1890.

4) Feoktistow, Experimentelle Untersuchungen iber Schlangen- 
Klapperschlangengift beginnt bei $41^{\circ}$ C. zu gerinnen und ist bei $53^{\circ} \mathrm{C}$. beinahe fest; es löst sich in kaltem Wasser ohne Rückstand auf. Das Viperngift ist in absolutem Alkohol, Alkalien und Oelen gar nicht, in kaltem Wasser schlecht, in verdünntem Alkohol besser, in kochendem Wasser gut löslich ${ }^{1}$ ). Es wird durch Mineralsäuren gefällt; die Niederschläge sind im Ueberschuss des Fällungsmittels löslich; auch Tannin fällt das Gift. Mit Eisenchlorid, Silbernitrat, Platinchlorid, Eisen- und Kupfersulfat giebt es ebenfalls Niederschläge. Dasselbe Verhalten zu den Mineralsäuren zeigt auch Klapperschlangengift; mit Essigsäure liefert letzteres keinen, mit Tannin einen dichten weissen Niederschlag, der in Wasser und im Ueberschuss der Säure unlöslich, aber in Ammoniak löslich ist. Chlorwasser bringt einen dichten Niederschlag hervor, ebenso Jodlösung und Jodkali einen solchen, der im Ueberschuss des Reagens sich anflöst. Kali und Natron haben keinen sichtbaren Einfluss anf das Gift, ebenso Ammoniak und Kalkwasser. Mit Sublimat entsteht ein dicker weisser Niederschlag. Natrium sulfuricum und Magnesium sulfuricum bringen einen voluminösen weissen Niederschlag hervor, der sich im Ueberschuss von Wasser auflöst. Alkohol bewirkt einen schweren, flockigen Niederschlag, der auch nach dem Trocknen in Wasser löslich ist.

Die Frage, welchem Bestandtheile das Schlangengift seine Wirkung verdankt, lässt sich jetzt mit Sicherheit beantworten. Es sind nicht Mikroorganismen, welche die Giftwirkung hervorrufen. Auch die Ansicht, dass es im Schlangengift enthaltene Cyanverbiudungen sein könnten, hat sich nicht bestätigt; Mitchell konnte niemals im Klapperschlangengift Rhodankalium nachweisen, dem man auch bei Bissen anderer Thiere die Giftwirkung zuschrieb. Eben so

gift. Inaug.-Diss. Dorpat 1888. - Kanthak, Journ. of the Physiol. 1892. p. 272. - Calmette, Annales de l'institut Pasteur. 1892. IX. p. 168.

1) L e Gag e, Journ. de Chim. méd. 5. sér. IV. Avril 1868. 
wenig bilden Alkaloide das wirksame Prinzip im Schlangengift. Die vermeintlichen Alkaloide $\mathrm{Najin}$ und Elaphin, die Gautier ${ }^{1}$ ) im Naja-Gifte entdeckt haben wollte, sind nichts anderes als Zersetzungsproducte.

Das Schlangengift ist eine Eiweisssubstanz. Im $\mathrm{Klapperschlangengift} \mathrm{sind} \mathrm{wenigstens} \mathrm{zwei} \mathrm{eiweiss-}$ artige Substanzen, eine, die sowohl durch Kochen als auch durch Alkohol gerinnt, und eine, die nur durch Alkohol coagulirt wird, neutral reagirt und das eigentlich wirksame Prinzip des Giftes bildet. Mitchell nannte diese letztere Substanz Crotalin. Schon früher hatte Prinz Lucien Bonaparte, der übrigens im Jahre 1843 überhaupt die erste chemische Untersuchung von grösserem Werte, die bis dahin über Schlangengift gemacht war, anstellte, aus dem Viperngift durch Alkoholbehandlung als wirksames Prinzip das Viperin oder Echidnin dargestellt.

Bei den späteren gemeinsam mit Reichert angestellten, den neuesten Anschauungen nicht mehr ganz entsprechenden, aber doch erwähnenswerthen Versuchen Mitchell's zeigte es sich, dass die eiweissartigen Substanzen im Schlangengift den Charakter der Globuline und Peptone haben. Es gelang ihnen, drei Arten von giftigen Globulinen zu isoliren:

1. Ein Globulin, das durch starke Verdünnung des Giftes mit Wasser füllbar war und den Myosin im Verhalten gegen Salzlösungen sehr ähnlich sah.

2. Ein Globulin, das im Filtrat des vorigen durch Kupfersulfat gefüllt wurde.

3. Ein Globulin, das durch Dialyse abscheidbar war.

Das Filtrat von diesem letzten Globulinkörper coagulirte nicht mehr beim Kochen, gab aber noch alle Farbenreactionen der Eiweisskörper. Mitchell und Reichert nannten diesen Körper "Giftpepton". Das relative Verhältniss zwischen Glohulin und Pepton ist je wach der Schlangenart verschieden. So enthält das getrocknete Gift der Klapperschlange ca. $24 \%$

') Gautier, Tiull. de l'Acad. do mél. 2. sér. X. p. 9:0. 1881. 
Globulin und $75 \%$ Pepton, das der Mocassinschlange ca. $8 \%$ Globulin und $92 \%$ Pepton.

Ausser diesen Eiweisskörpern sind nach MitchellReichert's Untersuchungen im Schlangengift noch vorhanden: ein Farbstoff, Spuren von Fett und Salze, besonders Chloride und Phosphate.

Die chemische Zusammensetzung des Giftes bei den anderen Schlangenarten, namentlich bei den indischen und europäischen, ist im Wesentlichen eine ähnliche wie die bei dem Gifte der amerikanischen Schlangen.

Ueberall bilden Eiweisskörper, die sogenannten Toxalbumine, die wirksame giftige Substanz. Zwar behaupten einige Autoren, dass im Schlangengift, speziell in dem der Brillenschlange, Ptomaïne enthalten seien ${ }^{1}$ ), indessen fehlen im frischen Gifte Ptomaïne ebenso wie auch Alkaloide gänzlich. Die Wirkung des Giftes der Brillenschlange beruht auch nicht auf Cobrasäure (die vermeintlichen Krystalle, denen der Name Cobrasäure gegeben wurde, bestehen aus Gyps), sondern auf der Gegenwart folgender Eiweisskörper $\left.{ }^{2}\right)$ :

1. Globulin. Es ist immer vorhanden und wirkt tödtlich durch Asphyxie.

2. Syntonin, das durch Magnesiumsulfat zusanimen mit dem Globulin gefällt wird. Es dialysirt in gewissem Grade durch Pergamentpapier. Die giftige Wirkung des sauren Dialysates beruht auf diesem Eiweisskörper, der aber weniger stark wirkt als Globulin.

3. Serum-Albumin, das ebenfalls giftig ist und Apoplexie bewirkt.

4. In einigen Proben zeigten sich Spuren von Hemialbumose und zweifelhafte Spuren von Pepton; letztere sind wohl als zufällig zu betrachten.

Das Gift der indischen Viper (Daboia Russelii) enthält:

1) Fayrer, Med. Times and Gaz. Febr. 2. 1884.

$\left.{ }^{2}\right)$ Wolf enden, Journ. of physiol. VII. 327. 
1. Globulin, das melı vorherrscht als in Cobra-Gift.

2. Serum-Albumin in kleiner Menge.

3. Einen Eiweisskörper, der viele Eigenschaften einer A l b u mose besitzt.

Walre Peptone kommen darin nicht vor, und wahrscheinlich waren anch die ron Weir Mitchell und Reichert als Peptone bezeichneten Substanzen in den Giften der amerikanischen Schlangen in Wirklichkeit Albumosen.

Auch das Cobra-Gift soll als wirksamen Bestandtheil eine Albumose (Protoalbumose) enthalten, welche dieselbe toxische Wirkung hat wie das Gift selbst ${ }^{1}$ ); ausser dieser ist wahrscheinlich noch eine Heteroalbumose darin vorhanden.

Das Globulin Mitchell's ist vielleicht nichts Anderes als ein Gemisch ron Heteroalbumose und Dysalbuminose und entsteht nur secundär nach gewissen Manipulationen irn Schlangengifte. So scheint andauerndes Erhitzen die Protoalbumose in jene beiden Körper zu zerlegen, die wohl harmlos sind.

Auch in dem Gifte der australischen Schlange Pseudechis porphyriacus sind die einzigen giftigen Bestandtheile primäre Albumosen ${ }^{2}$ ).

Das Gift der europäischen Giftschlangen soll enthalten ${ }^{3}$ ):

1. Eine Art Ptyalin (nach Lucien Bonaparte -Viperin" oder "Echidnin").

2. Albumin und Schleim.

3. Eine in Alkohol lösliche Substanz.

4. Gelben Farbstoff.

5.) Fett.

6. Chlorüre und Phosphate wie der Speichel (kein Rhodankalium).

1) Kanthack, Journ. of l'hysiol. XIII. 3 and 4. p. 272.1892.

2) (:. F. Martin, Jonrn. of Physiol. XV. 1893. p. 380.

$\left.{ }^{3}\right)$ I, Gage, Journ. de Cliim. méd. 5. scer. IV. p. 178. Avril 1868. 
Das Viperin stellt dem Tannin ähnliche Schüppchen dar, es enthält Stickstoff, reagirt neutral, färbt Kupferoxydhydrat violett und wird von Bleiessig nicht gefällt; es ist geschmacklos. Man gewinnt es durch Alkoholbehandlung aus dem Schlangengift. Es entspricht offeubar ganz dem Crotalin Mitchell's und besteht aus mehreren, wahrscheinlich den Eiweisskörpern verwandten Substanzen ${ }^{1}$ ).

Aus allen Untersuchungen ergiebt sich also das Eine mit Sicherheit, dass das Gift sowohl der europäischen als auch der ausländischen Giftschlangen als wirksames Prinzip Eiweissstoffe enthält. Welcher Art dieselben sind, ist als noch nicht definitiv festgestellt zu betrachten.

Es dürfte interessiren, an dieser Stelle darauf hinzuweisen, dass merkwürdigerweise auch in einer Pflanze, nämlich in den Samen von Abrus precatorius, dem bekannten Jequirity, ein Stoff, das Abrin, enthalten ist, welcher ebenso wie das Schlangengift aus zwei Eiweisskörpern besteht, von denen der eine zu den Globulinen gehört, während der andere eine Albuminose ist. Er erzeugt, wie auch Schlangengift häufig, bei subcutaner Injection Gastroenteritis mit blutigen Ausleerungen. Diese Aehnlichkeit des Abrins mit den Schlangengifte dürfte vielleicht noch einmal für die Therapie des Schlangenbisses Bedeutung erlangen.

Unschädlichwerden des Schlangengiftes.

Die Gifte der amerikanischen Schlangen ertragen im getrockneten Zustande eine Temperatur von $110^{\circ}$ C. 30 Minuten lang, ohne eine Abschwächung ihrer Wirkung zu erleiden. In wässrigen Lösungen bis zu $76,5^{\circ} \mathrm{C}$. erhitzt, erfährt das Gift von Crotalus adamantinus eine beträchtliche Schwächung. Bei den peptonreicheren Giften anderer Schlangen (z. B. der Mocassinschlange) ist die Abschwächung durch Kochen lange nicht so energisch. Bei nur 10 Minuten langem Kochen

1) M. Ka ufmann l. c. 
wirkt das Gift oft noch sehr stark. Das Gift der Lanzenschlange wird zerstört, wenn man es eine Minute lang auf $100^{\circ}$ erhitzt. Von den indischen Schlangengiften wird das der Daboia durch Erwärmen auf $80^{\circ}$ unwirksam, Cobra-Gift dagegen nach Fayrer noch nicht ganz bei einstündigem Erhitzen anf $107^{\circ}$, wohì aber bei zweistündigem.

Calmette ${ }^{1}$ ) jedoch fand, dass schon 20 Minuten langes Erhitzen auf $98^{\circ}$ die Virulenz des Cobra-Giftes zerstörte, während auf $90^{\circ}$ erhitztes Gift bereits nicht mehr local entzündend wirkte. Das Gift von Hoplocephalus curtus verliert seine toxischen Wirkungen erst, wenn man es mindestens 15 Minuten lang bei $100-102^{\circ}$ erhitzt, das von Pseudechis porplyyicus bei $99-100^{\circ}$, das der Kreuzotter bei $95-97^{\circ}$ oder bei noch geringeren Hitzegraden. Die Resistenz der einzelnen Gifte gegen Hitze ist also verschieden, und selbst das Gift einer bestimmten Schlangenart verhält sich in dieser Hinsicht nicht immer gleich.

Wenn man Viperngift 20-25 Secunden lang sieden, dann wieder erkalten lüsst und es nun Thieren einimpft, so zeigt es sich, dass jetzt keine örtlichen Erscheinungen mehr auftreten und die Allgemeinsymptome schwächer sind als nach Einimpfung eines nicht in dieser Weise behandelten Giftes. Auch bewirkt erhitztes Gift Erhöhung der Temperatur, während nicht erhitztes diese meist erniedrigt. Vielleicht sind zwei verschieden wirkende toxische Substanzen im Gifte enthalten, eine entzündungserregende ( $\mathrm{Echidnase}$ ), die durch Hitze zerstört wird, und eine allgemein wirkende, und Hypothermie verursachende ("Echidnotoxin"), welche durch Erlitzen nicht zerstört wird ${ }^{2}$ ).

Hohe Kältegrade (bis zu $-15^{\circ} \mathrm{C}$.) und selbst wochenlanges (iefrierenlassen vermögen die Wirkung des Schlangengiftes nicht $\% u$ schädigen.

') Calmette, Annales de l'institut Pasteur. 1892. IX. ए. 160. 18.34. I. 275 .

3) P'hinalix et Hertrand, Compt. rend. de l'Acad. rles seiences. T. CXVHI. 1894. p. $2=8$.

Brenning, the Vergiftungen threh Schlangen. 


\section{$-34-$}

Von chemischen Mitteln vermögen Alkohol, Terpentinöl, Silbernitrat, Ammoniak, Kali oder Natron die Wirkungen des Klapperschlangengiftes weder zu alteriren noch aufzuheben, wenn nicht diese Reagentien von ätzender Stärke sind. Eben so wenig zerstören Mineralsäuren, Chlorwasser oder Jod das Gift. Dagegen wird dasselbe durch Pepsin oder Trypsin seiner Giftigkeit beraubt.

Bei Filtration durch Thierkohle werden die giftigen Eiweisskörper durch diese zurückgehalten; das eiweissfreie Filtrat ist ungiftig.

Cobra-Gift wird schon nach 5-10 Minuten durch $10 \%$ ige Kali- oder Natronlauge wirkungslos, bei längerer Einwirkung auch durch Chlorwasser, Jodtrichlorid, Kaliumpermanganat; weniger wirksam sind Carbolsäure und Pankreatin. Silbernitrat, Sublimat, Gerbsäure, Alkohol heben die Wirkung dadurch auf, dass sie die Albumose fällen; ziemlich wenig wirksam sind Citronensäure, Pepsin und selbst das so oft als eines der besten Mittel gegen Schlangenbiss empfoblene Ammoniak.

Es scheint demnach, als ob das Gift der Brillenschlange weniger widerstandsfähig gegen Chemikalien ist als das der Klapperschlange. 
V.

\section{Die Wirkung des Schlangengiftes und die Symptomatologie der Vergiftung.}

Es lässt sich denken, dass bei der Jahrtausende alten Geschichte der Vergiftungen durch Schlangengift, entsprechend der Zeitbildung und der individuellen Schärfe der Auffassung, die verschiedenartigsten Ansichten über die Wirkung des Schlangengiftes zu Tage getreten sind.

Im Alterthume finden wir neben einzelnen wahren die übertriebensten und vom krassesten Aberglauben beeinflussten Vorstellungen über die Symptome des Schlangenbisses verbreitet. So sagt A ristoteles, wer von der Hyder gestochen sei, gebe sogleich einen üblen Geruch von sich, Vergessenheit überfalle ihn, und tiefe Dunkelheit verbreite sich über seine Augen, Wahnsinn folge darauf und heftiges Zittern; am dritten Tage sterbe er.

Der Biss der Aspides tödtet nach Plinius ${ }^{1}$ ) durch Schlaf und Erstarrung. Wenn das Gift in eine alte Wunde komme, so tödte es nicht so schnell; verschluckt schade es nicht. Eine Schlange soll üherhaupt nur giftig sein, wenn sie in dem laufenden Monat durch Einwirkung des Mondes aufgereizt sei. Nach Dioskorides schwillt beim Vipernbiss der ganze Körper an; dann folgen Schaudern, Frost, Stupor, Schwere des Kopfes, galliges Erbrechen, Schluchzen, Fieber, Athemnoth, zuweilen Gelbsucht. Die Ge-

1) Plinius, Hist. nat. 28, 42. 
bissenen seien bald blass, bald grün, bald gelb, je nach ihrem Temperament; bei den Biliösen ergiesse sich die Galle in das Blut und es entstehe bleiche und gelbe, bei den Melancholikern grüne und schwarze Färbung. Am gefährlichsten sei der Biss in nuichternem Zustande und von einer nüchternen Schlange, im Sornmer bei grosser Hitze, und wenn die Schlange gereizt sei. Der Tod erfolge sicher, wenn Synkope eintritt, Blut aus der Nase fliesst, die Lippen grünlich, die Nägel kalt werden und der ganze Leib zittert, und zwar meist innerhalb sieben Stunden, selten noch am dritten Tage. Durch den Biss der Hornviper sollen an der verwundeten Stelle eine harte Geschwulst und Pusteln entstehen; es erscheine dasn'hst eine bald schwarze, bald gelbliche Jauche, und der ganze Körper werde dunkelgelb. Der Tod trete unter Ohnmachten und Convulsionen ein.

Galen ${ }^{1}$ ) erzählt, dass denjenigen, der von der Dipsas gebissen ist, ein brennender Durst befalle; er müsse unaufhörlich trinken, bis er zerplatze. Auch Nikander und A elian sprechen von dieser Wirkung des Dipsas-Bisses.

Nach Aelian soll die Libysche Aspis den, der sich ihrem Anhauche aussetzt, wenn sie den Hals aufbläst, der Sehkraft berauben. Die indische Purpurschlange soll nicht beissen, sondern speien und bewirken, dass die getroffenen Glieder abfaulen. Sie soll zwei Arten von Gift haben, ein bernsteinartiges und ein schwarzes. Wer das erstere verschluckt, den ergreift zuerst ein heftiger Krampf, dann verdreht er die Augen, das Gehirn fliesst ihm durch die Nase herab, und er stirbt je nach der Menge des Giftes schnell oder nach einiger Zeit. Nimmt er von dem schwarzen Gift aus der todten Schlange, so fängt er an zu eitern und stirbt nach einem bis zwei Jahren an der Auszehrung. Nach dem Biss der Natter soll Sticken, Krampf und Schluchzen eintreten. Wer eine Wasserschlange berühre, sterbe ohne Biss durch die faulende Kraft derselben. Das Gift der Aspis bleibe nicht

1) Galen, Theriaca ad Pis. c. 8. 
oben. sondern schleiche in die inneren Gänge hinab; es tödte, wenn man es aussaugt, ohne Wasser nachzutrinken, und zwar ohne Schmerz, indem es ganz unvermerkt Zahnfleisch und Mund verzehre (auch Plutarch ${ }^{1}$ ) sagt, der Biss der Aspis sei nicht schmerzhaft, sondern mild). Die von der Echis Gebissenen sollen Zuckungen bekommen, nicht aber die von der Echidna Gebissenen. Die Bissstelle der Echidna soll weiss, die der Echis schwarzblau sein, und die des Hänorrhus sofort blau werden. Der Gebissene bekomme Herzwels und profuse Diarrhöe. In der ersten Nacht fliesse Blut aus Nase, Hals und Ohren mit einem galligen Gifte. Der Urin sei blutig. Alte Narben brächen auf. War der Haemorrbus ein weibliches Exemplar, so komme Blut aus den Fingernägeln, und das Gift verbreite sich in das Zahnfleisch, wobei sich viel Blut ergiesse und die Zähne ausfielen. Die Bisswunde des Sepedon fresse um sich und faule nach unten; das Gift dringe durch den ganzen Körper mit grosser Schnelligkeit. Selbst das Haar faule weg und schwinde, Augenbrauen und Wimpern fielen aus, Dunkel bedecke die Augen und diese bekämen Flecken. Das Gift der Schlange Seps verursache sogleich Fäulniss und tödte schnell. In Indien soll es geflügelte Schlangen geben, deren Urin, wem er anf den Leib fällt, Fäulniss verursache. Der Biss der Schlange Prester mache träge und schwer beweglich, dann vergesslich und schwer athmend, er hemme die Urinentleerung, die Haare fallen aus, und es folgen Sticken, Krampf und Tod.

Bedeutende Fortschritte in der Auffassung und Darstellung der Symptomatologie sind in späteren Jahrhunderten zu beobachten, wenn wir auch hier noch manche übertriebene Berichte in Folge des weit verbreiteten Aberglaubens verzeichnet finden. Um nur eins zu erwähnen, so glaubte man noch bis weit in die Neuzeit hinein fest an die sogen. Fascinationskraft der Schlangen, vermöge welcher sie im Stande sein sollten, durch ihren Blick nicht nur Thiere, son-

1) Plutarch, Vit. Anton. c. 71 . 
dern auch Menschen zu bezaubern und fest an den Boden zu bannen, so dass sie unfähig wären, zu entfliehen.

Manche Autoren indessen liefern uns bereits ziemlich objective und der Wahrheit entsprechende Schilderungen.

So führt Gessner als Symptome des Schlangenbisses an: hitziges Fieber, Unruhe, Erstarrung oder Erschlaffung des ganzen Leibes, Unempfindlichkeit desselben, heftige Schmerzen an der Wunde, Röthung oder Schwarz- und Blaufärbung des gebissenen Gliedes.

Nach Mercurialis bewirken die Aspides Gesichtsstörung, Gesichtsschwellung, geringen Schmerz, Taubheit, andere Schlangen dagegen Stupor, Blässe, Herzklopfen, Frost und häufiges Gähnen. Das Herz scheine am ersten afficirt zu werden, dann Leber und Gehirn. Die Vipern sollen Blutungen und einen Tumor hervorrufen, der erst roth, dann schwarz oder grün werde.

Selbstverständlich lag es nahe, um bindende Schlüsse bezüglich der Angriffspunkte des Giftes an Organen und Organfunctionen zu erlangen, das Verhalten der Thiere für eine solche Erkenntniss mit heranzuziehen.

Hier wurden Ergebnisse gezeitigt, denen eine allgemeinere Bedeutung zuzuschreiben ist.

Die interessanteste Frage auf diesem Gebiete war zweifellos die, wie sich Giftschlangen selbst gegen ihr eigenes Gift oder das anderer Species verhielten.

Hier sind nun die widersprechendsten Ansichten zu Tage getreten, und es scheint, dass die einzelnen Schlangenarten in dieser Hinsicht Unterschiede aufweisen. Nach einigen Beobachtungen sollen Giftschlangen durch ihre eigenen Bisse sterben, nach anderen dagegen nicht. Die Klapperschlangen starben bei den Versuchen Weir Mitchell's alle ausser einer einzigen durch ihre eigenen Bisse.

Ebenso gehen Lanzenschlangen zu Grunde, wenn man ihnen ihr eigenes Gift einspritzt ${ }^{1}$ ). Dagegen ist die Brillen--

1) Tricard, Arch. de méd. navale. LXI. 1894. p. 357. 
schlange immun gegen Injection von $2 \mathrm{cg}$ ihres Giftes ${ }^{1}$ ), und auch die Kreuzotter scheint gegen ihr eigenes Gift unempfindlich zu sein ${ }^{2}$ ). Nach noch nicht veröffentlichten Untersuchungen ron L. Lewin trifft dies letztere selbst für mehrere tagstiber veranlasste Selbstbisse zu; doch schien ihm die Schlange danach eimen auffallenden Zustand von Erschlaffung, die an Muskelschwäche erinnerte, aufzuweisen. Gegenseitige Bisse ron Giftschlangen, die ein und derselben Art angehören, sollen in der Regel ohne Einfluss auf die Schlangen sein, wenigstens wird dies von verschiedenen Vipern Europas und Afrikas, sowie auch ron Trigonocephalus piscivorus und den ostindischen Giftschlangen behauptet. Auch hierbei konnte Lewin feststellen, dass wenige Bisse, die eine Kreuzotter der anderen versetzte, scheinbar wirkungslos waren, dass aber eine grössere Zahl das gebissene Thier allgemeine Befindensänderung aufweisen liess. Dass sich dagegen Giftschlangen verschiedener Art gegenseitig tödten können, ist sicher constatirt. So sah man z. B. durch den Biss der Brillenschlange andere Giftschlangen sterben ${ }^{3}$ ). Indessen sollen nach Fayrer Giftschlangen auch gegen Bisse anderer Arten relativ wenig empfindlich sein, und nur selten soll eine Cobra oder eine Daboia einen Bungarus coeruleus tödten und umgekehrt. Nur Bungarus fasciatus zeigt eine starke Empfänglichkeit gegen Cobra-Gift.

In Bezug auf die nicht giftigen Schlangen ist im Allgemeinen die Ansicht verbreitet, dass sich dieselben den Giftschlangen gegenüber wie alle anderen Thiere verhalten, also durch sie getödtet werdeı. Nenere Untersuchungen auf diesem Gebiete haben aber das interessante Resultat geliefert, dass auch manche von den $\% u$ den giftlosen Schlangen gerechnete Arten gegen Viperngift immun sinl. Schon Fontana hatte die Beobachtung gemacht, dass Ringelnattern

j) Cialmette, Compt. rend. de la soc. de biol. 9. sér. 'T. VI. 1834. p. 11.

2) L en z, Schlangenkunde. 1832.

$\left.{ }^{3}\right)$ Russell, Account of Indian serpents. 1796. 1. 56. 
ohne Gefahr zahllose Bisse der Viper, sowie auch Einimpfungen von deren Gifte vertragen. In letzter Zeit wurden nun diese Versuche von französischen Forschern ${ }^{1}$ ) wiederholt, und es zeigte sich dabei, dass eine Ringelnatter (Tropidonotus natrix) von $50 \mathrm{~cm}$ Länge eine intraperitoneale Injection von $5 \mathrm{mg}$ trockenen Viperngiftes ertrug, eine Dosis, welche 15-20 Meerschweinchen zu tödten vermag. Ausser Tropidonotus natrix sollen auch T. viperinus, Elaphis A esculapii, Coronella laevis und Rhinechis scalaris gegen Viperngift immun sein ${ }^{2}$ ).

Eine Erklärung dieser wunderbaren natürlichen Immunität giftiger und nicht giftiger Schlangen gegen das Gift der ersteren hat man dadurch zu geben versucht, dass man auch bei letzteren die Existenz eines Giftapparates und eine nahe Beziehung des Giftes zu dem Blute annahm. Wie Claude Bernard für die Leber ein gewisses Verhältniss ihres Secretes zu der Zusammensetzung des Blutes nachgewiesen hat, so ist es auch möglich, dass die wirksamen Stoffe des Schlangengiftes von den Giftdrüsen aus durch „interne Secretion" derselben in das Blut gelangen, mit diesem den ganzen Organismus imprägniren und so eine Gewöhnung des letzteren an selbst grössere Giftdosen bedingen. Verschiedene Beobachtungen scheinen auch in der That darauf hinzuweisen, dass sich im Blute der Schlangen toxische Substanzen befinden, welche denen des giftigen Drüsensecretes analog sind. So scheint das Blut der Brillenschlange in hohem Grade giftig zu sein; $2 \mathrm{ccm}$ frischen Cobrablutes, in die Bauchhöhle eines Kaninchens von $1 \frac{1}{1} 2 \mathrm{~kg}$ eingespritzt, tödten dasselbe in sechs Stunden; spritzt man eine gleiche Dosis defibrinirten Cobrablutes einem Kaninchen in eine Vene, so tritt der Tod schon in drei Minuten ein. Bei subcutaner Blutinjection sind die auftretenden Vergiftungssymptome dieselben,

1) Phisalix et Bertrand, Arch. de physiol. 5. sér. T. VI. 2. 1894. p. 423.

2) Jourdain, Compt. rend. de l'Acad. des sciences. T. CXVIII. 1894. p. 207. 
wie bei Injection reinen Giftes. Für Frösche, Fische und eine kleine ungiftige Natternart zeigt sich das Cobrablut nicht giftig; diese Thiere sind iibrigens auch gegen Cobragift selbst wenig empfindlich ${ }^{1}$ ). Aehnliche Erfahrungen wie mit dem Blute der Cobra hat man auch mit dem der Viper gemacht.

Besonders erwähnenswerth sind Versuche mit dem Blute der Ringelnatter. Spritzt man ${ }_{3 / 4} \mathrm{ccm}$ Blutserum von Tropidonotus natrix oder $T$. viperinus Meerschweinchen ein, so erfolgt der Tod in weniger als sechs Stunden unter den gleichen Symptomen wie nach Viperngift. Dieselbe Wirkung würden etwa ${ }_{1}^{3} 0 \mathrm{mg}$ trockenen Viperngiftes haben. Im Blute der Natter scheint also eine wenigstens ebenso grosse Menge analoger toxischer Substanzen vorhanden $\mathrm{zu}$ sein, wie in dem der Viper. Es hat sich nuu weiter herausgestellt, dass die Oberlippendrüsen der Ringelnatter ein sehr actives Gift absondern, dessen Eigenschaften ganz den im Blute derselben befindlichen toxischen Substanzen entsprechen. Wenn man z. B. einen Auszug aus diesen Drüsen einen Sperling unter die Haut bringt, so stirbt dieser unter unzweifelhaften Vergiftungssymptomen ${ }^{2}$ ). Alle anderen Organe der Natter, namentlich auch die unteren Speicheldrüsen, sind dagegen ungiftig. Aus diesen Versuchen kann man schliessen, dass, ähnlich wie bei den eigentlichen Giftschlangen die toxischen Substanzen aus den Giftdrüsen in das Blut gelangen, so auch bei den Nattern und anderen nicht zu den giftigen gezählten Schlangen Giftstoffe aus den Oberlippendrüsen durch „interne Secretion" derselben vom Blute aufgenommen werden und so auch diesen Schlangen Immunität gegen das Viperngift verleihen. Wie weit sich diese Immunität auch gegen Gifte anderer Schlangen erstreckt, scheint noch nicht untersucht worden zu sein.

Die übrigen Reptilien, sowie auch die Amphibien,

') Calmette, Compt. rend. de la soc, de biol. 9. sér. 'T. VI. 1894. 1. 11.

2) I'lanchard, Compt. rend. de la soc. de biol. 9. sér. 1894. p. 85. 
Fische und die wirbellosen Thiere hielt man früher nach den negativ ausgefallenen Versuchen Fontana's für völlig unempfindlich gegen Schlangengift. Indessen hat es sich doch gezeigt, dass das Gift der Kreuzotter wenigstens für Blindschleichen, Eidechsen, Salamander und Frösche tödtlich ist. Trotzdem kann man allgemein sagen, dass Kaltblüter weniger durch Schlangengift afficirt werden, und dass der Tod in der Regel langsamer bei ihnen eintritt als bei Warmblütern. Von letzteren sind Vögel am empfindlichsten. So starben Tauben oft schon wenige Minuten nach dem Biss. Je kleiner ein Thier ist, desto empfindlicher pflegt es in der Regel gegen Schlangengift zu sein. Was die Säugethiere betrifft, so ist es bekanntlich ein weit verbreiteter Glaube, dass dem Igel die Bisse der Kreuzotter nicht schaden, und auch Lenz behauptet, dass Igel und Iltisse durch Kreuzotterbisse nicht afficirt würden. Indessen hat es sich jetzt doch herausgestellt, dass künstliche Inoculation des Giftes für Igel tödtlich ist, und auch Herr Professor Lewin sah zwei Igel, welche er, den einen in der Aethernarkose, durch Kreuzottern in die Schnauze beissen liess, nach einem kurzen Stadium der Erregung unter soporösen Erscheinungen in fünf resp. neun Tagen zu Grunde gehen. Der Igel ist also wohl sicher nicht immun gegen Schlangengift. Aehnliche Immunität schrieb man früher dem wilden Schweine, dem Mungo, dem Ichneumon und anderen Thieren zu; doch bei allen ist die vermeintliche natürliche Immunität wohl nur durch äussere Umstände bedingt, welche, wie beim Igel die Stacheln, beim Schweine die dicke Haut, ein Eindringen der Giftzähne in blutführende Theile erschweren. Ganz junge Säugethiere sind infolge der geringeren Entwickelung der Nervencentren weniger empfindlich. Auch wirbellose Thiere sind, so weit sie ein Nervensystem besitzen, nicht unempfänglich für Schlangengift.

Die Gefahr, welche der Schlangenbiss dem Menschen bringt, wird im Allgemeinen sehr überschätzt. An dem Biss der europäischen Giftschlangen sterben nur sehr wenige Men- 
schen, und auch von den von der Klapperschlange Gebissenen sollen nach Mitchell $/ / s$ ron selbst genesen.

Gefährlicher ist jedoch der Biss sïdamerikanischer und ostindischer Schlangen, von denen manche Arten durch ihren Biss fast immer den Tod herbeifüliren.

Schon Celsus, Plinius und Galen wussten, dass Sclilangengift nur dann schadet, wenn es, wie beim Bisse der Schlangen, in Wunden gelangt, dass es aber, wenn innerlich genommen, unschädlich ist. Verschiedene Untersucher haben dies später durch Thierversuche und Versuche an sich selbst bewiesen.

Das Gift wird also von der unverletzten Schleimhaut des Magendarmcanals entweder gar nicht oder doch so langsam resorbirt, dass meistens keine Vergiftung erfolgt.

Nach Mitchell-Reichert tritt eine Resorption -des Klapperschlangengiftes in Magen nur in den Zwischenpausen der Verdauung, aber nie während derselben ein, da es, -wie schon erwähnt, durch Pepsin zerstört wird. Dagegen ist constatirt worden, dass Najagift selbst bei 48stündiger Vermischung nit Magensaft nicht nur nicht zerstört wird, sondern dass sich bei Thierversuchen seine Wirkung dadurch sogar um das Doppelte des Normalen verstärkt zeigte ${ }^{1}$ ). Für die Naja und für die ostindischen Schlangen überhaupt wurde die Wirksamkeit des Giftes sowohl vom Magen als von der Conjunctiva aus bestimmt nachgewiesen.

Ein Arat, dem etwas Najagift ins Auge gekommen war, bekam eine heftige Entzündung und Augenschwäche ${ }^{2}$ ). Auch in älteren Krankengeschichten findet sich Augenentzündung und Blindheit als Folge des Hineingerathens von Schlangengift ins Auge.

Wenn aber behauptet wird, dass es geführlich sei, Schlangenbisswunden auszusaugen, weil das Gift, auch wenn in den Ifund gelangt, rasch resorbirt werde, so haben wahrschein-

1) Gautié, Bull. de l'Acad. de méd. 2. sér. X. p. 950. 1881.

2) Fayrer, Med. Times and Gazette. Fehr. 2. 1884. 
lich in den betreffenden Fällen kleine, nicht wahrnehmbare Verletzungen der Mund- oder Rachenschleimhaut vorgelegen.

Auch Calmette sah keine Resorption vom Verdauungscanal aus eintreten.

Ein Forscher ${ }^{1}$ ) hat sogar von Vipern gebissenen Tauben wiederholt die Wunden ohne Nachtheil ausgesogen, obgleich er blutendes Zahnfleisch hatte, und nach $\mathrm{Husemann}$ können selbst grössere Giftmengen ohne Nachtheil verschluckt werden. Dagegen ist eine Absorption des Giftes von der Trachea, den Bronchien und der Lunge aus möglich; denn zwei Tauben, denen man Gift durch die Glottis in die Bronchien einbrachte, starben, und ihre Lungen zeigten Blutextravasate. Ferner beobachtete man, dass ein Hund sogar starb, als ihm etwas Brillenschlangengift auf die Oberfläche des Gehörorganes gebracht worden war ${ }^{2}$ ).

Das Gift wird bei Fröschen auch von der unverletzten Haut, bei Warmblütern vom Peritoneum aus, jedoch langsam, resorbirt ${ }^{3}$ ).

Oertliche Symptome nach dem Schlangenbiss.

Dieselben sind bei den verschiedensten Giftschlangenarten im Wesentlichen die gleichen.

Zunächst folgt auf den Biss in der Regel sogleich ein heftiger stechender Schmerz an der Bissstelle, welcher allmählich an Intensität zunimmt. Alsbald entsteht an dem betreffenden Theile fast stets eine Anschwellung, welche sich häufig schon in sehr kurzer Zeit nicht nur über das ganze gebissene Glied, sondern auch, je nach der Stelle des Bisses, auf Schulter, Hals, Kopf, Zunge, oder auf den Unterleib, in manchen Füllen sogar über den ganzen Körper aus-

1) Viaud Grand·Marais, Gaz. des Hôpitaux, 26. 1870.

$\left.{ }^{2}\right)$ Bellanger, Journ. de Chimie méd. III. 590.

$\left.{ }^{3}\right)$ Feoktistow l. 
breitet. In zwei Fällen barsten die Hautvenen des gebissenen und stark angeschwollenen Gliedes an nehreren Stellen ${ }^{1}$ ).

Auch die L y m phdrüsen und $L$ y $\mathrm{m}$ h g efässe pflegen mehr oder weniger stark geschwollen zu sein. Während die Bisswunde selbst sich bald bleigran färbt, nimmt die Umgebung derselben und oft das ganze Glied entweder eine blasse oder häufiger eine blanrothe Färbung an und ist dabei eigenthümlich glänzend und gespannt. Die Lymphgefässe machen sich oft als dunklere, zuweilen fast bleifarbene Streifen besonders bemerkbar. Die Bisswunde ist in der Regel so klein, dass eine Blutung ans derselben entweder ganz fehlt oder doch nur sehr unbedeutend ist; in ihrer Umgebung entsteht eine heftige Entzündung aller Weichtheile, die sich rasch centralwärts, besonders längs der Lymphgefässe, ausbreitet und sich bis zur intensivsten, das ganze Glied einnehmenden eitrig en $\mathrm{Phl}$ e g m o ne steigern kann. Oeffnungen und Fistelgänge bilden sich, und mitunter bedecken brandartige Blasen nicht nur die Umgebung der Bissstelle, sondern auch das ganze Glied, das in manchen Fällen steinhart, völlig unbeweglich und bei der geringsten Ber ührung enorm schmerzhaft ist.

Aus gemachten Einschnitten entleert sich dann weniger Blut als übelriechende, schleimartige, gelbliche Flüssigkeit. Einige Beobachter nahmen an der Bissstelle ein Knistern, herrührend ron Gasansammlung in Unterhautgewebe, wahr. Zuweilen geht der Schmerzhaftigkeit eine Gefühllosigkeit um die Wunde herum voraus. In seltenen Fällen verfällt das ganze Glied dem Brande.

Von diesen Symptomen sind natürlich in der Regel nur einzelne vorhanden; Schmerz, Schwellung und Verfärbung pflegen jedoch nie zu fehlen.

1) Renggger, Neckel's Archiv f. Anatomie u. Physiologie. 1829. S. 271. 
Resorptive Vergiftungssymptome.

Neben lokalen Symptomen kommen nun noch eine Reihe von Allgemeinwirkungen zur Beobachtung. Dieselben erscheinen schon sehr früh, meistens bereits nach einigen Minuten. Dahin gehören eine eigenthümliche Beängstigung und Unruhe, Schwindel, Eingenommensein des Kopfes, Kopfschmerzen, Uebelkeit, Erbrechen, zuweilen von grün gefärbtem Wasser oder von Blut, kaltes Schandern, Fieber, heftiger Durst, Durchfall oder Verstopfung ${ }^{1}$ ), in schweren Fällen Schluchzen, unwillkürliches Stöhnen und Gelbsucht. Fast stets macht sich eine mehr oder weniger grosse Schwäche bemerkbar. Das Gesicht ist eingefallen, blass oder livide und ebenso wie der ganze Körper mit kaltem, klebrigem Schweisse bedeckt. An Stelle des letzteren tritt mitunter nach einiger Zeit ein warmer Schweiss, den man, jedoch mit Unrecht, als Krisis angesehen hat. Zuweilen ist dagegen auch die Haut völlig trocken. Die Augen sind starr und glänzend oder matt und trübe und in die Höhlen zurückgesunken, die Pupillen dilatirt, seltener verengt und reactionslos, die Extremitäten fühlen sich kalt an, der Puls ist zuweilen so schwach, dass er kaum fühlbar ist, dabei meist beschleunigt und unregelmässig. Die Athmung ist erschwert und ebenfalls beschleunigt. Die Zunge ist häufig mit gelben Massen belegt. Zuweilen beobachtet man auch copiöse Harnentleerungen, während in der Regel die Harnmenge, entsprechend der Herabsetzung des Blutdruckes, eher vermindert zu sein scheint.-Der Harn enthält in einigen Fällen Eiweiss.

Von Störungen der Empfindung stellt sich, abgesehen von der Schmerzhaftigkeit resp. Gefühllosigkeit an der Bissstelle und in dem betroffenen Gliede, in manchen Fällen Reissen und Ziehen in allen Gliedern, sowie eine starke Empfindlichkeit am ganzen Körper ein, von der auch alle

1) Nach Weir Mitchell ist Verstopfung die Regel, während Durchfall nur eintritt, wenn sich die Vergiftung lange Zeit hinzieht. 
Muskeln betroffen werden köunen, so dass danu jede Bewegung schmerzhaft wird; in anderen Fällen dagegen kommt es zu einer vollständigen Anästhesie des ganzen Körpers, welche an dem gebissenen Gliede, auch wenn der Fall in Genesung endet, noch dauernd zurückbleiben kann. In einem Falle sah man heftige Schmerzen in der Stirn und in den Augenhöhlen eintreten.

Wichtiger sind die nach Sehlangenbiss auftretenden Bewe gungss törungen. Sie bestehen anfangs theils in leichtem Zittern am ganzen Körper, theils in Convulsionen der Extremitäten, und zwar besonders der Beugemuskeln derselben. Der Gang eines Gebissenen wird infolge dessen mitunter stark schwankend. Nach Weir Mitchell sollen Krämpfe ein seltenes Symptom des Schlangenbisses sein. Später komınt es zu einer Lähmung der Extremitäten, so dass diese oft völlig unbeweglich werden.

Die Krämpfe können sich auch auf andere Muskeln ausdehnen. So sollen Convulsionen des Keblkopfes und Schlundes ein constantes Symptom beim Biss der Brillenschlange bilden ${ }^{1}$ ). Auf Krämpfen der betreffenden Muskeln beruhen auch folgende Symptome: Verzerrungen des Gesichtes, Trismus, Opisthotonus, Schluckbeschwerden, unverständliche Sprache, Aphasie, Zusammenschnüren der Kehle, Schluchzen, asthmatische Beschwerden, Tenesmus, Strangurie. Infolge der nachfolgenden Lähnuung treten an Stelle dieser Symptome zum Theil die entgegengesetzten, also Lähmung des Unterkiefers, der Zunge, des Gaumens, Kehlkopfes, der Darm- und Blasenschliessmuskeln.

Nach Bissen der ostindischen Brillenschlange soll Ptosis ein häufiges Symptom sein. Auch Accommodationslähmung ist heobachtet worden. Während in der ersten Zeit nach dem Biss in der Regel ein eigenthümlich unruhiges Wesen, Schlaflosigkeit und zuweilen sogar die heftigsten Delirien zur Beobachtung kommen, so tritt dagegen später häufiger Schlafsucht und völlige Apathie bei dem Gebissenen ein. Von

1) Asiatic Resparches. Vol. II. 1799. 
Störungen der Sinnesorgane ist noch Blindheit zu erwähnen, die schon von den Autoren des Alterthums als Symptom des Schlangenbisses angeführt wird und unter Umständen dauernd bestehen bleiben kann, sowie vorübergehende T a ubheit.

Die Reflexe gehen meist verloren.

Von vasomotorischen Störungen treten als ein sehr wichtiges und sehr häufiges Symptom Blutungen aus Nase, Ohren, Augen, Mund, Magen, Darm und Blase auf. Auch in der Haut und in fast allen inneren Organen kommen in manchen Fällen Hämorrhagieen vor. Hämaturie lässt sich übrigens auch auf experimentellem Wege durch Schlangengift bei Hunden hervorrufen. Als selteneres Symptom ist endlich noch Speichelfluss zu erwähnen.

Während die Temperatur anfangs erhöht ist, pflegt sie später zu sinken.

Zuweilen bemerkt man ein langes Bestehenbleiben von Hautröthung nach Streichen mit dem Fingernagel; dies sowie die anhaltende Pupillenerweiterung, die andauernd erhöhte Pulsfrequenz, das Auftreten von Albuminurie weisen auf eine vasodilatatorische Wirkung des Giftes hin ${ }^{1}$ ).

Der Symptomencomplex eines voll der Surucucú Gebissenen soll dem des intensivsten Scorbuts entsprechen, während dem Bisse der Jararacá die. Erscheinungen eines Typhus im vorgerückteren Stadium folgen sollen. Der Biss von Bothrops atrox erzeugt vorwiegend örtliche Läsionen.

Das Eindringen von viel Gift in eine Vene ist wohl in der Regel als tödtlich zu betrachten, oder führt doch wenigstens die schwersten Zufälle herbei. So wurde eine kräftige Frau von einer Kreuzotter in einen Varixknoten gebissen; es trat sofort nach dem Biss Ohnmacht und Bewusstlosigkeit ein, der Körper wurde eiskalt und livide, es erfolgte Erbrechen und Abgang blutiger Massen aus dem Mastdarme,

1) Schilling, Deutsche Medicinal-Zeitung. 1888. S. 867 . 
und 6 Stunden nach dem Bisse kam es zum Abort eines fünfmonatlichen Fötus ${ }^{1}$ ).

In einem anderen Falle erkrankte ein Kind, nachdem es an die Brust der gebissenen und krank gewordenen Mutter gelegt war: die letztere starb, während das Kind gerettet wurde ${ }^{2}$. Es scheint hiernach, dass das Schlangengift anch im Stande ist in das Brustdrüsensecret ïberzugehen.

Nachwirkungen des Schlangengiftes.

Eigenthümliche chronische Wirkungen des Schlangenbisses beobachtete man in Australien. So wurde ein Gebissener melancholisch und beging schliesslich Selbstmord, und eine gebissene Frau wurde Säuferin und gebar ein idiotisches Kind.

In einem Falle sah man Blödsinn mit partieller Lähmung der unteren Extremitäten und der Harnblase zurückbleiben. Von sonstigen Nachkrankheiten kommen zuweilen grosse, dauernde Schwäche, kachelitischer Zustand, krätzeartige Ausschläge, Neigung zu ödematösen Geschwülsten, Drïsenschwellungen am gebissenen Theile, allgemeine Wassersucht, Nasenbluten vor: in manchen Fällen entwickelt sich eine ausgesprochene hämorrhagische Diathese. Häufig beobachtet man ein eigenthümliches periodisches A uftreten gewisser Affectionen, so von neuralgischen Schmerzen an der Bissstelle, von einer tieberhaften Lymphangitis, die von der Narbe ihren Ausgang nimmt, ron Exanthemen, Schmerzen in den Fingern und krampfartiger klexion derselben. Besonders oft sielit nuan ein periorisches Wiederaufbrechen der alten Bissstelle, verbunden mit langdauernden Eiterungen. Die Vernarbung dauert überhaupt, besonders bei Bissen tropischer Giftschlangen, oft sehr lange und kann sich sogar über mehrere Jahre hinziehen; die Narbe bleibt aber auch dann meist sehr dünnhäntig, etwas aufgeschwollen und blau gefürbt, entzündet sich bei der geringsten Veranlassung und bricht danı wieder

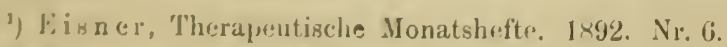

2) l.owthur, Madras (Quart. Journ. of med. sc. Vol. V. 1. 742. lirenning, hie Vrrgiftungr'll durch Schlangen. 
auf. Zuweilen werden an der Wunde schliesslich die Knochen vom Perioste entblösst, werden nekrotisch und fallen heraus. Bei Hunden wurden nach Schlangenbissen periodische Anscliwellungen der Bissstelle wahrgenommen.

An diesen Folgezuständen kann, wenn der Gebissene nicht gleich nach dem Bisse zu Grunde geht, sogar noch nach Jahren der Tod erfolgen.

Das Schlangengift scheint theils durch die Haut und Nieren theils auf der Magenschleimhaut ausgeschieden und dadurch wenigstens theilweise unschädlich gemacht zu werden ${ }^{1}$ ). Bei seinem Durchgang durch die Leber soll es ebenso wie Nicotin, Hyoscyamin und Curarin durch dieselbe zerstört werden ${ }^{2}$ ).

1) Alt, Münch, med. Wochenschr. XXXIX. 41. 1892.

2) La utenbach, Philad. med. Times. VII. p. 387. May 26. 1877. - Dujardin-Beaumetz, Bull, de l'Acad. de méd. 2. sér. X. p. 954.1881. 


\section{Ursachen und Mechanismus der Giftwirkungen und des Todes.}

Wenn wir von einer alten Angabe absehen, wonach dem Schlangengifte selbst gar keine Bedeutung zukommt, sondern nur der starke Reiz, den die Schlange beim Biss auf Haut und Nerven äussere, als Todesursache aufgefasst wird ${ }^{1}$ ), so waren die meisten Autoren bis in die neueste Zeit hinein der Ansicht, der Tod erfolge durch „Blutzersetzung" oder „Blutvergiftung*. Wenn auch bereits Mercurialis ${ }^{2}$ ) erwähnt, dass das Herz zuerst, dann Leber und Gehirn afficirt zu werden scheinen, und zu Anfang dieses Jahrhunderts die Ansicht ausgesprochen wurde, dass das Gift nicht durch Einwirkung auf das Blut, sondern auf das Nervensystenı, und zwar besonders auf das Rückenmark, den 'Tod herbeifïhre ${ }^{3}$ ), so ist doch erst in neuester Zeit nachgewiesen worden, dass in acuten Fällen eine Blutzersetzung überhaupt nicht vorhanden ist, und dass auch in chronischen Fiallen nicht diese das Wesentliche ist, sonderu dass der $\mathrm{Haupteffect}$ des Giftes darin besteht, die vitale Kraft des Herzens und des Athuungscentrums herabzusetzen. Später stellte man auf experimentellem Wege fest, dass das Schlangengift ein sich über die ganze motorische Sphäre des Centralnervensystems verbreitendes Gift ist. Alle Vergiftungs-

1) Friccius, Pardoxa medica. V'Il.

2) Mercurialik, De venenis. $15 \times 4$.

3) Rengger I. C. 
erscheinungen lassen sich demnach auf Parese und Paralyse motorischer Nervenzellen zurückführen. Die scheinbare Verschiedenheit der Wirkungen des Giftes einzelner Schlangenarten beruht wahrscheinlich darauf, dass diese Wirkungen sich mit verschiedener Intensität auf einzelne Gruppen jener Zellen concentriren. Am meisten scheinen die Medulla oblongata, der Plexus cardiacus und die Splanchnici zu leiden; daher ist fast stets Athmungs- oder Herzlähmung die Todesursache. Aus der Splanchnicuslähmung lassen sich manche abdominalen Symptome (Erbrechen, Icterus etc.) erklären. Die Lähmung der Extremitäten hat ihren Grund in einer aufsteigenden Rückenmarksparalyse, der eine Reizung, entsprechend den anfänglichen Convulsionen, vorausgehen kanu. An die Rückenmarkslähmung schliesst sich eine solche der Medulla oblongata und des Gehirns. Anf die motorischen Nervenendigungen wirkt das Gift nicht ein, eben so wenig auf den Muskel als solchen, obschon man an den quergestreiften Muskelfasern in der Nähe der Injectionsstelle des Giftes stellenweise einen granulösen Zerfall der Bowmanschen Scheiben beobachtete. Die Muskeln bleiben aber stets direct elektrisch reizbar, und es tritt keine Veränderung der Muskelcurve ein, ausser wenn die Muskeln direct mit Gift behandelt werden. Die Herzenden des N. vagus werden sehr früh gelähmt, ebenso die intracardialen Hemmungsganglien. Das Vaguscentrum wird im Anfang gereizt. Das Respirationscentrum wird ebenfalls anfangs gereizt, dann aber gelähmt. Die motorischen Ganglien und die Muskulatur des Darmes werden nicht tangirt. Der Blutdruck wird stark herabgesetzt, und zwar unter Lähmung der peripheren Endigungen der Nervi splanchnici. Vom Sinken des Blutdrucks hängt der bei schwangeren Thieren oft eintretende Abort, sowie die Verminderung der Harnabsonderung ab. Wahrscheinlich ist das Sinken des Blutdrucks die Folge einer depressorischen Wirkung des Giftes auf die vasomotorischen Centra der Medulla oblongata, das spätere Wiederansteigen desselben die Folge einer peripheren Reizung der Capillaren, 
und der schliessliche dauernde Abfall die Folge der abnehmenden Kraft der Herzschläge.

Auch ïber den Einfluss des Giftes auf die Herzthätigkeit liegen genauere Beobachtungen vor. Nach Injection der genuinen Gifte wird die Pulsfrequenz meist etwas beschleunigt, noch mehr nach Durchschneidung der Nn. ragi. Waren diese und das Rückenmark durchschnitten, so tritt meist gar keine Pulsbeschlemigung ein, woraus man schliessen kann, dass auch die Accelerationscentra des Rückenmarkes durch das Gift erregt werden. Der anfänglichen Vermehrung der Pulszahl folgt eine Verminderung.

Waren die Vagi vor der Injection durchschnitten, so bewirken die Globuline des Schlangengiftes im Gegensatze zu dem genuinen Gifte keine Pulsbeschleunigung. Waren die Tagi und das Rückenmark durchtrennt, so stellt sich nach der Globulininjection eine directe Abnahme der Herzschlïge ein durch die schädliche Wirkung der Globuline auf das Herz. Die Resultate mit den isolirten Giftpeptonen stimmen ganz mit denjenigen nach Injection des genuinen Giftes iberein: auch diese Peptone schädigen das Herz direct. Die injicirten Gifte rufen ferner mit Ausnahme des sogenannten "KupferGift-Globulins" eine deutliche Steigerung der Respirationsfrequenz hervor, und zwar am stärksten das Pepton. Nach Durchschneidung beider Vagi bleibt dieselbe aus, und es stellt ich vielmehr eme Verminderung der Athemthätigkeit ein. I) ie Beschleunigung bei intactenı Vagus ist zu erklären durch eine Frregung der peripheren Vagusendigungen durch das Gift, das aber auf das Athmungscentrum depressorisch wirkt.

Es bloibt nun noch eine Erscheinung zu besprechen, nämlich die nach Schlangenbiss so häufig auftretenden $\mathrm{Blu-}$ tungr!n. Man führte dieselben früher fälschlich allein anf die ahnorm veründerte Beschaffenheit des inficirten Blutes zurück. Vach Borbachtungen an mit Gift bepinselten Froschmesenterium krommen dieselben jedoch dadurch zu Stande, dass das (ift rinen Erweichnngaprocess an den Gefïsswandungen hervorruft, worlurch plitzlich Unmengen rother Blntkörperchen 
nebst reichlichem Serum per diapedesin aus den Gefässen auswandern. Von einer Ruptur der letzteren ist nichts zu bemerken; ihr Endothel wird trübe und sieht rauh aus. Vor der Diapedese sah man eine auf örtliche Lähmung der vasomotorischen Nervenendigungen und vielleicht auch der Gefässganglien zu beziehende enorme Ausdehnung der Gefässe an der mit Gift bepinselten Stelle eintreten. Eine Stase braucht in den Gefässen dabei nicht vorauszugehen. Weisse Blutkörperchen wandern nur sehr vereinzelt aus. Diese Capillardilatation und die mit ihnen verbundenen Blutungen sind am stärksten am Herzen, im Verdauungstractus und in den Nieren. Vielleicht ist sogar die durch die Apoplexie des gastrointestinalen Apparates und der Nieren hervorgerufene Anämie der übrigen Organe an der Todesursache betheiligt. Sie tritt allerdings zurück hinter der Lähmung der Herz- und Athmungsthätigkeit. Bein Vipernbiss soll die letztere stets vor der ersteren erlöschen. Die schwache Reizbarkeit des Diaphragmas und der diaphragmatischen Nerven uach dem Tode scheint eine lähmende Wirkung des Giftes auf diesen Muskel anzudeuten.

Das bisher Gesagte gilt von der weitaus grössten Zahl der bekannten Schlangengifte, namentlich von denen der europäischen und amerikanischen Schlangen. Ein etwas abweichendes Verhalten scheinen indessen die ostindische Brillenschlange und die australischen Schlangen zu zeigen.

Das Gift der ersteren soll nämlich in kleinen Dosen ausschliesslich eine Lähmung der intramuskulären Nervenendigungen, besonders frühzeitig auch derjenigen des Zwerchfells, erzeugen, die sich von derCurarelähmung durch die bei grösseren Giftdosen eintretende schwere Schädigung der Muskelsubstanz unterscheidet ${ }^{1}$ ). Das Rückenmark und die vasomotorische Sphäre zeigen bei Vergiftung durch Cobra-Gift ein verschiedenes Verhalten. Während nämlich bei einigen Versuchen beide, ebenso wie auch die sensible Sphäre, gar nicht vom

1) Ragotzi, Virchow's Archiv. 122. 2. S. 201. 1890. 
Gifte beeintlusst wurden, so konnte man bei anderen eine deutliche Herabsetzung der Erregbarkeit des Rückenmarkes, sowie eine anffallende Blutdrucksenkung in Folge einer Liihmung des peripherischen vasomotorischen Apparates wahrnehmen ${ }^{1}$ ). Bei rascher intravenöser Injection grösserer Giftmengen werden nicht die hemmenden Vagusendigungen, sondern nur der Herzmuskel afficirt. Die Blutkörperchen werden biconvex, und ihre Schädignng giebt sich durch Uebertritt von Oxyhämoglobin in die Galle zu erkennen. Auch liessen sich besonders in den Lungen Thrombosirungen durch multiple intravitale Blutgerinnungen nachweisen.

Dass diese Veränderungen des Blutes jedoch nicht das Wesentliche sind, und dass das Blut mit den Vergiftungserscheinungen nichts zu thun hat, wurde dadurch zur Evidenz bewiesen, dass bei Fröschen, bei denen das Blut, durch $0,7^{\circ}$ oige Kochsalzlösung ersetzt worden war, dennoch genau die gewöhnlichen Vergiftungssymptome auftraten. Das Cobra-Gift schädigt vielmehr direct das Nervensystem, und es ist jetzt mit Sicherheit festgestellt, dass die eigentliche Todesursache hierbei eine nach einem kurdauernden Erregungsstadiun eintretende Lähmung der Athmungscentren ist.

Die acuten Symptome nach dem Biss der a ustralisclien Schlangen sollen wesentlich verschieden sein von dem nach dem Cobrabiss anftretenden ${ }^{2}$ ). Letzterer veranlasst Schmerz an der Bissstelle, sowie Schwellung und Blutextravasate $11 m$ dieselbe herum. Der Biss der Tigerschlange dagegen verursacht keine locale Schwellung und nur sehr geringen Schmerz, aber in wenigen (höchstens 30) Minuten verliert der Gebissene die Spontanbeweglichkeit in Folge Lähmung der motorischen Centra, und sehr bald darauf folgen Sopor und tödtliches Coma. Manchmal kehrt das Bewusstsein wieder, aber der Tod erfolgt doch noch an Herzschwäche. Der I3iss der

1) Vollmer, Archiv f. experim. P'ath.u. Pharm. XXXI. 1. S.1. 1892.

$\left.{ }^{3}\right)$ A. Miill $r$, Austral. Ined. Journ. May 15. 1888, und Austral. med. (ja\%. VIII. 2. 3. 5. Nov. 15, I)ec. 15. 1888. Febr. 15. 1889. 
Schwarzen Schlange bringt selten Coma, lähmt aber in hohem Grade die motorischen und vasomotorischen Centra und den ganzen Sympathicus. Die Gehfähigkeit ist fast stets verloren, die Arme aber bleiben relativ frei, der Tod erfolgt meist an Herzschwäche. Beim Biss der Braunen Schlange liegen die Symptome zwischen denen der beiden vorigen Schlangen; es entstehen hier complete Muskelparalyse, tiefes Coma und Herzschwäche, die bald zum Tode führt.

Bei den australischen Giftschlangen scheint also im Gegensatz zum Cobrabiss stets Lähmung der Herzthätigkeit die Todesursache $z u$ sein.

Auch die australischen Schlangengifte, wenigstens das der Schwarzen Schlange (Pseudechis porphyricus), scheinen keinen directen Einfluss auf die rothen Blntkörperchen des Menschen zu haben; dieselben zeigten sich bei Behandlung des Blutes mit dem Gift ganz unverändert, und die weissen verloren nur ihre amöboide Bewegung ${ }^{1}$ ).

Die Zeit, welche bis zum Eintritt des Todes vergeht, ist in den einzelnen Fällen sehr verschieden. Nach Fayrer sterben in weniger als 2 Stunden 22,96\%, zwischen 2-6 Stunden nach dem Biss 24,53\%, zwischen 6-12 Stunden $23,05 \%$, zwischen $12-24$ Stunden $9,36 \%$ und nach mehr als 24 Stunden 21,10\%. Ein sehr rascher Tod scheint besonders dem Bisse der Brillenschlange zu folgen. Man hat hier Fälle beobachtet, wo die Gebissenen fast augenblicklich nach dem Bisse, wie vom Blitze getroffen, bewusstlos niederstïrzten and schon nach wenigen Minuten todt waren. In der Regel erfolgt der Tod jedoch erst nach mehreren Stunden oder Tagen, in manchen chronisch verlaufenden Fällen sogar erst nach Monaten und Jahren, und zwar hier mehr durch allgemeine Erschöpfung in Folge fortwährenden Aufbrechens und Eiterung der Wunde, durch Blutverluste, Lungenödem, oder durch allgemeine Wassersucht.

1) C. J. Martin, Journ, of Physiol. XV. 1893. p. 380. 
VII.

\section{Pathologisch-Anatomisches über die Vergiftung durch Schlangenbiss.}

Die Leiche eines an Schlangenbiss Gestorbenen pflegt, in Gegensatz zu der gewöhnlichen Ansicht, nicht schneller in Füulniss überzugehen als andere Leichen; dagegen soll eine schnelle und intensive Todtenstarre eintreten. Die Section ergiebt in der Regel hauptsächlich zahlreiche Blutextravasate in fast allen Organen, besonders in denen des Verdauungscanals. Der Panniculus adiposus und das Unterhautgewebe sind in der Ungebung der Bissstelle hänfig bis zwischen die Muskelfasern hinein in eine schleimartige, höchst widerlich riechende Masse umgewandelt. Das Blut ist gewöhnlich dunkelroth und flüssig. Wie schon erwähnt, zeigt dasselbe in acuten und primären Fällen von Vergiftung durch Schlangenbiss fast gar keine Veränderung; namentlich sind die rothen Blutkörperchen dabei durchaus normal. Einige Untersucher fanden neben den normalen biconcaven scheibenfürmigen auch kugelförmige oder biconvexe rothe Blutkörperchen. Bei mehr subacutem Verlaufe nehmen dieselben häufig eine zackige Gestalt an und verlieren ilıre Hähigkeit, Geldrollen \%u bilden; auch sollen sie in manchen Fällen kleiner und blasser werden. Wenn man ausserhalb des Körpers viel Schlangengift zun Blute hinzusetzt, so werden die rothen und weissen Blutkörpercluen aufgrelöst, das Blut nimmt eine Picrocarminfarbe an und gicbt in mässign dicken Schichten gar kein Alsorptionsspectrum. Bei gewöhnlichen Vergiftungsfällen ist jedroch der normale Hämoglobinstreifen erhalten. Nur ein- 
mal wurde bisher nach Schlangenbiss der Blutfarbstoff verändert gefunden. Auch ein Mangel der Bizzozzero'schen Blutplättchen wurde wahrgenommen. Was die dunkle Farbe des Blutes betrifft, so glaubte man früher, dass dieselbe vom Gifte selbst herrühre, indessen scheint die dem Tode vorangehende Apnoe die Ursache davon zu sein. Fast alle Forscher stimmen darin überein, dass die Gerinnungsfähigkeit des Blutes durch Schlangengift herabgesetzt oder ganz aufgehoben wird. Nach Fayrer bewirken jedoch die Gifte von Naja und Bungarus Gerinnung, die von Echis und Daboia dagegen Verflüssigung des Blutes. In einer Versuchsreihe ${ }^{1}$ ) war die Gerinnungstendenz des Blutes meistens schon eine Minute nach der Injection des Giftes unter der Norm; in einzelnen Fällen jedoch kam eine anfängliche, vorübergehende Erhöhung der Gerinnungstendenz zum Vorschein, gefolgt von einer sehr bald darauf eintretenden Herabsetzung derselben. Da letztere niemals fehlte, so ist wohl anzunehmen, dass in allen Fällen beide Phasen der Blutveränderung vorhanden waren. In allen Versuchen fanden sich schliesslich die Leucocyten beträchtlich vermindert. Die vorübergehende Erhöhung der Gerinnungsfähigkeit war, wie alle Versuche ergaben, die nothwendige Folge jeder plötzlichen Steigerung des Leucocytenumsatzes in circulirenden Blute. Herabgesetzt wird sodann die Gerinnungstendenz dadurch, dass das Gift das Protoplasma der farblosen Blutkörperchen so angegriffen und verändert hat, dass die betreffenden Bestandtheile desselben ihre Spaltbarkeit einbüssten.

Eine eigenthümliche und wohl falsch gedeutete Beobachtung über die Veränderung des Blutes durch Cobra-Gift wurde von einem englischen Arzte gemacht ${ }^{2}$ ). Danach soll nämlich, wenn ein Mensch von der Cobra gebissen ist, organische, keimfähige Materie in das Blut desselben gelangen

1) Heidenschild, Untersuchungen über die Wirkung des Giftes der Brillen- und der Klapperschlange. Inaug.-Diss. Dorpat 1886.

2) Halford, Brit. med. Journ. July 20. 1867. p. 43. 
und sich zu Zellen weiter entwickeln, welche auf Kosten des bei der Inspiration anfgenommenen Sanerstoffes in kürzester Zeit auf viele Millionen anwachsen und das Blnt functionsunfähig machen. Sie haben im Durchschnitt einen Durchmesser von ${ }_{1} 1700$ " mnd enthalten einen 1/2800" grossen Nucleus; letzterer schliesst wieder noch kleinere Molekïle der erwähnten keimförmigen Materie in sich.

Ein bei Zusatz ron Magentaroth an einer Stelle der Peripherie dieser Zellen anftretender rother Fleck unterscheidet sie von Lymph- und Eiterkörperchén. Ihre Vermehrung scheint durch Kerntheilung stattzufinden; sie sind noch mehrere Tage nach dem Tode der Thiere im Blute zu finden und sollen dasselbe vor cadaveröser Fäulniss schïtzen. Sie wurden für belebte kleinste Organismen gehalten. Diese Zellen sollen sich schon zwei Stunden nach dem Biss aus einer in Blute entstandenen granulirten, nebelartigen Masse entwickelt haben, welche letztere wieder sich in wenigen Minuten über die ganze Blutmasse des gebissenen Thieres verbreitet. Das Blut von vier jungen, aus dem Uterus einer gebissenen trächtigen Katze entfernten Kätzchen enthielt dieselbe oben beschriebene keimfähige Materie wie das der Katze; also müssen die kleinsten Partikel der genannten Materie auch die feinsten Poren thierischer Membranen durchdringen kömnen.

Diese Körper waren wahrscheinlich nichts weiter als umgewandelte Lencoryten.

Bei nach mehrfach wiederholten Vergiftungen жu Grunde gegangenen Hunden fand man eine Degeneration der Hinterstrïnge des Rückenmarkes, in denen an einzelnen Stellen die Axencylinder fast völlig geschwunden waren.

Wie man sieht, sind also die pathologisch-anatomischen Veränderungen, welche nach Schlangenbissen eintreten, nur sehr unbedentend und lassen keinen Schluss auf den Augriff'spunkt des Giftes zu. 


\section{Therapie des Schlangenbisses.}

\section{Die Schlangenbeschwörer.}

Es dürfte wohl kaum eine Krankheit geben, gegen welche so viele, theils erprobte, theils aus mystischen und abergläubischen Vorstellungen hervorgegangene Mitteỉ empfohlen worden sind, wie bei der Vergiftung durch Schlangenbiss. Ich kann davon absehen, alle jene Einsalbungen des Körpers, Räucherungen, Ausstreuen von stark riechenden Substanzen, besonders von Pflanzen, wodurch man glaubte die Schlangen von sich fernhalten und so einem Bisse überhaupt aus dem Wege gehen zu können, zu erwähnen. Was aber der Besprechung werth ist, das sind die sogenannten Schlangenbeschwörer. Schon im Alterthume gab es. besondere Menschenklassen, die sich speziell mit der Abrichtung von Giftschlangen und mit der Heilung von Bissen derselben beschäftigten. So werden verschiedentlich die am Hellespont wohnenden Ophiogenen erwähnt, deren Ahnherr, wie Strabo (XIII, p. 588) erzählt, ein aus einer Schlange verwandelter Held gewesen sein soll. Sie heilten den Schlangenbiss durch Anrühren und trieben, wie man glaubte, das Gift durch Auflegen der Hände aus dem Körper.

Den Ophiogenen entsprachen in Italien die Marsier, die vom Sohne der Circe herstammen sollten, und die nach ihrem Könige Psillo benannten Psillier oder Psyllen in Afrika. Plutarch erzählt, dass Cato in seinem Heere in Afrika viele Psyllen hatte, um die etwa vorkommenden Schlangenbisswunden durch dieselben aussaugen zu lassen. 
Nach Nikander genügt in leichten Fällen schon Bestreichen der Wunde mit dem Speichel derselben, in schweren soll der Psyllier sich den Mund mit Wasser spülen und dasselbe dann dem Gebissenen zu trinken geben; nimmt aber das Gift überhand. so solle er nackt bei dem erwundeten liegen. A elian meinte, dass giftige Thiere einem Psyllen nicht schaden, sondern , erschlafft" und entkrifftet würden, bis derselbe vorüber gegangen sei. Nach Damokrates können die Psyllen aber doch gebissen werden, und gebrauchen daun zur Heilung Alexipharmaka. Anch Aelian selbst erzählt einen Fall, wo ein Gaukler in Rom, der sich absichtlich hatte beissen lassen und das Gift ausgesogen hatte, starb, weil das zum Nachtrinken bestimmte Wasser in böser Absicht umgestossen war. Celsus schreibt den Psyllen keine besondere Wissenschaft. sondern nur gewohnte Kühnheit zu, und meint, dass andere Leute eben so gut die Wunden aussangen können, ebenso Galen. Dieser erklärte die angebliche Immunität der Gaukler dadurch, dass sie die Schlangen zu stetigem Beissen zwängen und dadurch das Gift abschwächten, oder dass sie ihnen einen Teig vorwürfen, der die Oeffnungen der Giftzähne verstopfe.

Nach Gessner werfen die Gaukler den Schlangen hartes Fleisch vor, in das sie durch Hineinbeissen das Gift entleeren.

Bei den Mohamedanern werden bei Schlangenbissen die Sayetten, meist Nachkommen Mahomets, zu Hülfe herbeigerufen. Diese machen unter Hersagen einiger Koranverse an der Bissstelle einen leichten Einschnitt, sangen die Wunde kräftig aus, legen gekanten línoblauch darauf und benetzen unter bestïndigem Segensprechen Lippen und Zunge des Gebissenen mit ihrem Speichel ').

Nach Anıerika wurde die Kunst des Schlangenbeschwijrens von den Negern aus Afrika gebracht. Nach den von

') limelin, Allgemrine Geschichte der thierischen und mineralischen Gift:. 2. Aufl. Firfurt 1811. S. 29. 
Sack ${ }^{1}$ ) in Surinam gemachten, aber mehr als skeptisch gedeuteten Beobachtungen soll die Kunst der Schlangenzauberer darin bestehen, dass sie mit der grössten Schnelligkeit die Schlange an einem Theile, wahrscheinlich den Nieren, exgreifen und festhalten, an dem sie sehr empfindlich sind, und sie dadurch in Furcht setzen und unschädlich machen. Der Beschwörer entfernte während der ganzen Dauer seiner Prodiction die Hand nicht von der Stelle, wo er die Schlange zuerst erfasst hatte. Gegen das Versprechen, nie aus einer geborstenen Kalabasse zu trinken, erbot sich der Mann, auch Sack gegen das Schlangengift zu schützen. Nach gegebenem Versprechen machte jener an beiden Armen und Beinen dieses Reisenden einen leichten Einschnitt und rieb ihm ein schwarzes Pulver ein, das aus der Asche von drei Pflanzenarten bestehen sollte. Hierin bestand das Verfahren, das ohne bestimmte Beweise nicht als Gaukelei aufzufassen ist, sondern vielleicht eine wirkliche Impfung darstellt.

R. Schomburgk ${ }^{2}$ ) erwähnt, dass die Neger Klapperschlangen, ohne ihnen die Fänge auszureissen, so abzurichten versteben, dass sie sich ihnen ruhig um die Arme schlingen, ohne sie zu beissen.

Zur grössten Sicherheit scheinen es aber die indischen Schlangenbeschwörer gebracht zu haben. Nach Forbes ${ }^{3}$ ) haben dieselben ein festes Vertrauen zu dem Nutzen ihrer Gegengifte und räumen nur ein, dass diese, wenn nicht zeitig genug angewandt, wirkungslos bleiben können, oder dass vielleicht ein in dem Verwundeten vorhandener Krankheitsstoff die Wirkung beeinträchtigt. Forbes sah zwei Wurzeln, mit denen der gebissene Theil über der Bisswunde schnell, aber gelinde bestrichen wird, um zu verhüten, dass das Gift höher steige. Die Pflanzen scheinen von den indischen

1) v. Sack, Beschreibung einer Reise nach Surinam. 1821. Bd. II. S. $125 \mathrm{ff}$.

2) R. Sch o mburgk, Reisen in Britisch-Guyana. 1847/48. II. p. $129 \mathrm{ff}$.

3) Forbes, British-Burma. Isondon 1878. 
Schlangenbeschwörern ans Birma mitgebracht zu sein. Die Beschwörer in Britisch-Birma verlassen sich ganz auf die Wirkung eines Arzneimittels, das sie an Rnmpf und Gliedern einimpfen. Wenn sie gebissen sind, so tätowiren sie den ganzen Körper nit der Medicin. Der Schüler eines Beschwörers wurde gebissen und fiel nieder; der Lehrer brachte nit einer Nadel eine gewisse Quantität des Heilnittels in rerschiedene Körpertheile. Der Verwundete wưrde ganz schwarz und etwa eine Stunde lang stöhnte und zitterte er, dann erholte er sich nach und nach, obgleich er schon aufgegeben war.

Die Besclıwörer bebaupten zweierlei Medicamente zu haben, eiue. welche die Schlange anzieht, und eine, die sie absehreckt: mit der ersten tätowiren sie auf einer Hand und einem Schenkel die Gestalt einer Schlange, mit der zweiten auf der anderen Hand und dem anderen Schenkel die Gestalt eines Adlers.

Ob jene Angabe der Beschwörer wahr ist, konnte Forbes nicht entscheiden, doch sah er öfter, dass die Sehlange gehorsam den Bewegungen der mit ihrem A bbilde verzierten Hand fillgte, dagegen sofort zurückfuhr, wenn ihr die Hand mit dem Adler entgegengehalten wurde, und bewegungslos liegen hiliel, bis die Hand weggrenommen wurde.

Forbes bestätigt ebenfalls, dass die Beschwörer den ichlangen nicht vorher die Giftzähne ausgerissen haben, und dass sie eben so wenig denselben vorher ein wollenes Tuch oder irgend einen anderen Gegenstand vorwerfen, damit sie durch Hineinbeissen ihr Gift entleeren und bei den Productionen ihren Neistern selbst durch etwaige Bisse lieinen schaden mehr hringen können. Dass vielmehr die Schlangen im Vollhesitze ihres Giftes sind, geht daraus hervor, dass l'orbes innerhalb zehn Jahren drei \%uschaner bei den Productionen und zwei Beschwörer selhst an erlittenen Bissen sterben sah.

Fis scheint nicht unmögrlich, dass eine Kaste, welche, Jahrhunderte hindurch ihr ganzes Interesse einem solchen liegenstande widmete, schlirssslich ein greheimes Mittel ent- 
decken komnte, das auf Schlangen eine Wirkung in dem angegebenen Sinne ausïbt.

Es ist auch nicht unmöglich, ja, für uns sogar wahrscheinlich, dass manche Schlangenbeschwörer die Impfung: mit Schlangengift an sich vollziehen und dadurch immun werden. Es ist keinesfalls für den grösseren Theil dieser Individuen zutreffend, wenn man ihre Kumst darauf zurückführt, dass sie die Giftschlangen vorher so oft in Thiere oder Gegenstände beissen lassen, dass sich der Giftvorrath erschöpft. Unwahrscheinlich ist es auch, dass die Schlangenkünstler nur mit in der Verdauung begriffenen, und darum trägen, indolenten Schlangen operiren. Wohl ist es denkbar, dass auch eine Giftschlange sich an das häufige Berühren gewöhnen kann und nicht jedesmal zubeisst, also in gewissem Sinne gezähmt ist dies würde aber nicht ausreichen, um gerade mit Rücksicht auf den Charakter der meisten Giftschlangen, welche Berührung nicht gut vertragen und Freund und Feind beissen, eine Sicherung des mit denselben operirenden Menschen zu geben.

Manche Schlangenbeschwörer, wie die Aïssakais in Algier, lassen sich beissen, nachdem sie sich durch wildes Tanzen in einen Exaltationszustand versetzt haben. Minutoli erzählt, dass sich die afrikanischen Schlangenbeschwörer bei ihren Productionen wie Rasende gebärden, und ihnen der Schaum vor den Mund tritt; doch sollen sie gleichzeitig ein narkotisches Kraut kauen, das starke Vermehrung des Speichels erzeugt. Möglicherweise verfolgen diese Beschwörer dadurch, dass sie sich in einen solchen Erregungszustand versetzen, den Zweck, den depressorischen Wirkungen des Schlangengiftes auf das Nervensystem entgegenzuarbeiten und durch den dabei erzeugten Schweiss zugleich das etwa in den Körper hineing'elangte Gift wenigstens zum Theil wieder zur Ausscheidung zu bringen.

Wahrscheinlicher ist es jedoch, dass das gekaute Kraut eine prophylaktische Wirkung ausübt. Es fehlt auch nicht an solchen, welche die Kunst mancher Schlangenbeschwörer 
durch die bei den Productionen gemachte Musik erklären, wodurch die Schlange willenlos gemacht werden soll. Dass in der That die Musik, welche einige Autoren des Alterthums sogar als Heilmittel gegen Schlangenbiss rühmten, im Stande ist, die Bewegungen der Schlangen zu beeinflussen, ist nach sicheren Beobachtungen nicht zu bezweifeln.

Eine zufriedenstellende Erklärung für das sichere Hantiren mit diesen Thieren giebt aber auch diese Vermuthung nicht ab.

Welcher Art aber anch die Mittel sein mögen, durch welche sich die Schlangenbeschwörer gegen das Schlangengift zu sichern suchen, sei es Impfung mit Schlangengift selbst oder einem anderen Stoffe, sei es die innere oder äussere Anwendung von sonstigen Mitteln, besonders von pflanzlichen, so viel steht fest, dass auch sie nicht alle dauernd immun gegen Schlangengift sind. Es ist indessen wohl kaum zu be\%weifeln, dass wenigstens manche von ihnen im Besitz von Mitteln sind, welche ihnen, wenn auch keine absolute, so doch eine ziemlich grosse Immunität gegen dieses Gift verleihen.

\section{Operative und mechanische Mittel.}

Bei der Beurtheilung eines Gegenuittels gegen den Schlangenbiss ist man leicht Tüuschungen ausgesetzt. In vielen Fällen ist es dem Gebissenen gar nicht bekannt, ob die Schlange giftig war orler nicht, und, wenn es sich wirklich um eine Giftschlange handelt, wie viel Gift durch den Biss in die Wunde hineingelangt ist. Der letztere Umstand ist, wie bereits erwähnt wurde, bedeutungsvoll, da die Schlange kurz vorher durch Beissen eines Thieres ihren Giftvorrath grösstentheils erschöpft haben kann. Auch wird vielleicht nicht selten die Haut nur durch die nicht giftigen /äilue des Unterkiefers verlet»t. Es darf auch nicht umerwïhnt bleiben, dass die meisten febissenen, wenigstens in mseren Gegendron, ohure Iliilfr: genesess. Man darf also nicht immer 
behaupten, dass, wenn ein Gebissener nach Anwendung eines Mittels gesund wurde, das letztere die Ursache der Rettung war. Es ist ferner die Zeit zu berücksichtigen, die bis zum Beginn der Behandlung verstreicht, sowie die etwaige Mitwirkung eines zugleich angewandten anderen Mittels (z. B. Ligatur) bei Darreichung eines innerlichen Medicamentes oder eines Stimulans, in dem das Antidot enthalten ist.

Es folgt also hieraus, dass es nicht thunlich ist, allein aus der Thatsache, dass Dieser oder Jener nach einem Schlangenbiss unter Anwendung von Gegenmitteln am Leben blieb, den Werth der letzteren zu beurtheilen.

Versteht man unter einem Gegenmittel einen Stoff, welcher das Gift selbst chemisch bindet oder auf irgend eine andere Weise im Körper selbst unschädlich macht, so besitzen wir für das Schlangengift ein nach dieser Richtung hin wirkendes noch nicht. Da die activen Giftbestandtheile des Schlangengiftes Eiweisskörper sind, so müsste, wenn das Gift erst in den Blntkreislauf aufgenommen ist, das Gegengift electiv nur das Eiweiss des Schlangengiftes treffen, die diesem verwandten Eiweisskörper des Blutes und überhaupt des ganzen Körpers aber unberührt lassen - eine Präsumption, die möglich, bisher aber noch nicht erwiesen ist. Versteht man dagegen unter "Gegenmittel " eine Substanz, welche dem Gifte antagonistisch, d.h. symptomatisch entgegenwirkt, ohne nothwendiger Weise das Gift selbst zu verändern, so stehen uns gegen das Schlangengift eine ganze Anzahl von zum Theil sehr wirksamen Mitteln zur Verfügung.

Hierhin gehören zunächst eine Reihe von operativen und mechanischen Eingriffen. Dieselben sind noch heute im Wesentlichen dieselben geblieben, welche bereits von den Autoren des Alterthums erwähnt werden. So empfiehlt Dioscorides tiefe Excisionen zu machen, die Wunde mit dem Munde oder mit Hïlfe von Schröpfköpfen auszusaugen, und durch Eingiessen von scharfen, ätzenden Arzneien das Gift zu zerstören. Ausserdem empfahl man, zerschnittene junge Hühner aufzulegen, welche durch iḥre Wärme fähig sein 
sollten, allerlei schädliche Stoffe aus den vergifteten Körperstellen auszustossen und anfzusangen. Aehnliche Vorschriften ertheilen auch die übrigen Schriftsteller des Alterthums.

Celsus ${ }^{1}$ ) empfiehlt, sofort nach dem Biss oberhalb der Wunde eine Ligatur anzulegen, damit das Gift nicht zum Herzen dringen köme, aber nicht so stark, dass eine Schwellung eintritt. Sodann solle man Incisionen machen. damit mehr inficirtes Blut herauskommt, und das Gift mit einem Schröpfkopf oder mit dem ganz unverletzten Munde aussaugen. Darauf solle der Gebissene an einem warmen Orte so hingelegt werden, dass der gebissene Theil nach unten geneigt ist. Ist Niemand da, um die Wunde anszusaugen, so solle man ein zerschnittenes Hulın oder Lamm oder Böckchen noch warm auflegen, und zwar so, dass der innere Theil die Wunde berührt. Auch Pflaster, besonders das Ephesische (bestehend aus Terpentin, Galbanum, Mennige und anderen Stoffen), könne man auflegen. Plinius erwähnt bereits als einziges Rettungsmittel gegen die Bisse mancher Schlangen die Amputation. Von den Schriftstellern des Mittelalters empfiehlt Avicenna ausser den schon erwähnten und ihm ebenfalls bekannten Mitteln noch Ausbrennen der Wunde mit dem Glüheisen und besonders den Aderlass.

Hiermit wäre bereits im Wesentlichen die Zahl der mechanischen Mittel erschöpft. An Stelle des Aussaugens und der Schröpfköpfe trat eine Zeit lang das Festhinden von Vögeln, hesonders von Hühnern oder Tauben mit dem Anus auf die Wunde. Starb hierbei eines der Thiere, so sollte man ein anderes nehmen und damit so lange fortfahren, bis keines mehr stürbe. Gessner, der dieses Verfahren erwähnt. empfiehlt ansser den schon von Celsus angegebenen Mitteln noch die Wunde mit Essig und Wasser ausznwaschen oder sin Pflaster von Essig und Asche (hesonders von Feigenoder Lorbeerbaum oder vom Rebholz) aufzulegen, Blutegel anzusetzen und hei Blutreichen einen Aderlass vorzunehmen.

7 C'elsus, De medicina. V. C'up. 27. 
Ist das Gift schon tiefer gedrungen, so solle man das Glied rings um die Bisswunde mit einer Lanzette aufschneiden und zerhacken oder die Wunde mit glühendem Eisen ansbremen; denn das Feuer verzehre leicht das Gift und lasse die Wunde nicht zu schnell zuheilen. Auch mit gesalzenen Stoffen, mit gestossenem wilden Knoblauch, Zwiebeln oder Succus Cyrenaicus könne man die Wunde einige Zeit lang offen halten, damit das Gift herauskomme. Ausserdem solle man verhindern, dass der Gebissene schlafe. Derjenige, welcher die Wunde aussaugen will, solle zuvor zu seiner eigenen Sicherheit etwas essen, den Mund mit Wein ausspülen, sodann Rosen- oder Veilchenöl in den Mund nehmen und das Ausgesogene ausspeien. Den zum Ausziehen des Giftes und zur Linderung der Schmerzen aufgelegten zerschnittenen Thieren (Hühner, Tauben, Geisslein, Lämmlein, Ferkel) könue man noch einen Frosch ansetzen, der Blut und Gift aussaugen soll. Nach Gessner brennen die Aegrpter die Bisswunde mit glühendem Eisen oder siedendem Oele ans. Auch binden sie das Glied mit in Pech getauchten Binden fest $\mathrm{zu}$, schneiden die Wunde auf und tropfen Pech hinein; später lösen sie die Binde und bestreichen den Biss mit Zwiebeln und Knoblauch.

Von sonstigen früher angewandten mechanischen Mitteln sind noch zu erwähnen Erdbäder, Baden des gebissenen Theiles in heissem Wasser, heissem Oel, besonders Terpentinöl, in Milch, Kalkwasser oder in Wasser, in dem Kochsalz aufgelöst war; ferner Auflagen eines mit Grünspan überzogenen Stückes Kupfer, von ungelöschtem Kalk, von einsaugenden Erden, besonders englischer Pfeifenerde, von frischem Ziegenkäse, warmen Umschlägen, Kräutern und Fröschen, Annäherung eines glïhenden Messers an die Wunde, so lange es der Gebissene aushält, und in neuerer Zeit sogar die Elektricität.

Einer grossen Beliebtheit erfrente sich auch seit den ältesten Zeiten der sogen. "Schlaugenstein". Schon Plinius erzählt, dass die Scythen, wenn sie von einer Schlange 
erschreckt wurden, den Kopf derselben aufschnitten und den darin befindlichen Stein verschluckten. Der Glaube, dass sich in dem Gehirne der Schlangen ein Stein befinde, hat sich bis in die Neuzeit fortgepflanzt, und verschiedene Autoren, wie Redi, Charas und Mead, stellten sogar mit solchen ostindischen Schlangensteinen, die aus dem Kopfe der Cobra stammen sollten, Experimente an. Manche Steine sollten auch im Magen oder Darm von Thieren, besonders von der Bezoarziege (Capra Aegagrus), gebildete Kalkconcretionen darstellen. Es ist später gezeigt worden ${ }^{1}$ ), dass die noch jetzt in Indien unter dem Namen „zehr mohereh" verkauften Steine theils eine, wahrscheinlich aus Serpentin bestehende, mineralische Substanz darstellen, theils aus gebrannten Knochen oder Hirschhorn mit bisweilen dazu gemischter Kalkerde bereitet werden. Man legt einen solchen Schlangenstein auf die Wunde, wo er in Folge seiner Porosität festhaftet, um nach etwa einer halben Stunde abzufallen. In dieser Zeit soll er, wie man glaubt, das Gift aus dem Blute angezogen haben. Auch die Indianer von Paraguay legen, nachdem sie die Wunde ausgesangt haben, zuweilen noch einen Schlangenstein auf, der ebenfalls aus halbcalcinirten Knochen, aus Kreirle oder aus gebrannter Thonerde besteht ${ }^{2}$ ). Uebrigens beschränkte man sich nicht auf den Gebrauch dieser Steine gegen Schlangenbiss allein, sondern wandte sie auch schliesslich als ein Heilmittel gegen alle Krankheiten, als ein sogen. .Bezoar", an.

In ẗhnlicher Weise wie Schlangensteine gebrauchen noch jetzt die holliindischen Colonisten in Südafrika die sogen. "Herrenbohne", welche, zerschnitten aufgelegt, das Gift aussaugen und dann von selbst abfallen soll. Auch das Aufleggen von frisch zerschnittenen Hühnern soll daselbst noch jetzt in Gebrauch sein.

Die erwähnten mechanischen Mittel gegen Schlangenbiss,

1) Herbert, Asiatic Roscarches. Vol. XVI. 1828. p. 382 ff.

2) Ricngger 1. c. 
wie Incision, Excision, Aussaugung, Schröpfköpfe, Ausbrennen, Ligatur, Scarificationen und Amputationen, haben nur dann einen Nutzen, wenn sie so früh angewandt werden, dass das Gift noch nicht in den Blutkreislauf aufgenommen ist. Was die Amputation betrifft, so wird man sich heutzutage in Anbetracht des Umstandes, dass die meisten Fälle von Schlangenbiss nicht tödtlich verlaufen, wohl nur sehr selten noch entschliessen, eine so eingreifende Operation gleich von vornherein vorzunehmen. Wenn dagegen die nach dem Bisse auftretenden Folgezustände, wie Vereiterung oder Gangrän des Gliedes, dazu nöthigen, so wird man sie ausführen müissen. Es sind mehrfach Fälle beschrieben worden, wo die Gebissenen den Muth besassen, sich selbst sofort nach dem Bisse das verwundete Glied abzuschneiden oder abzuhamen, um so sicher einer Vergiftung vorzubeugen.

Die Scarificationen sollen nach Weir Mitchell den Zweck haben, die vasculären Verbindungen der Wunde mit den Centren zu zerstören und so ein Weiterdringen des Giftes zu verhindern.

Durch A ussangung kann das Gift wohl nur bei einer ungewöhnlich grossen Bisswunde oder nach vorher gemachten Incisionen wieder herausbefördert werden. Nach F a y rer ist Aussangung gefährlich, auch wenn sich im Munde des Aussaugenden keine Verletzungen befinden; sicherer ist es jedenfalls, sich, wenn möglich, eines Schröpfk opfes zu bedienen. Auch in Afrika soll in manchen Gegenden Jeder eine oben mit einem Loche versehene Hornspitze mit sich führen, um damit nöthigenfalls eine Bisswunde auszusaugen. Natürlich kann man auch durch $\mathrm{Abwaschen}$ und Ausdrücken der Wunde so viel Gift wie möglich zu entfernen suchen. Blutegel dürften jetzt wohl bei Schlangenbiss kaum noch angewandt werden. Schröpfköpfe und Aussaugung halten auch die Allgemeinvergiftung besonders durch Verlangsamung der örtlichen Circulation auf.

Die gleich nach dem Bisse oberhalb und möglichst nahe 
der Wunde umgelegte Ligatur ist auch heute noch einer der einfachsten und bewährtesten Eingriffe. Wenn es möglich ist, so sind Ligatur und Schröpfköpfe mit einander zu rerbinden, oder, wenn die Beschaffenheit des verletzten Theiles es rerlangt, letztere allein anzuwenden. Geht aber beides nicht, wie z. B. an der Nase, so bleibt Aussangung das einzige Mittel. Wenn durch Schwellung und unterbrochene Circulation Gangrän des gebissenen Gliedes einzutreten droht, so muss die Ligatur wieder gelöst werden.

Zweckmässig scheint die auch von Weir Mitchell empfohlene "intermittirende Ligatur" zu sein. Man giebt nach dem Anlegen der Binde alkoholische Getränke, bis eine genügende Excitation dadurch erreicht ist, und lockert danı die Binde ein wenig; sobald aber Zeichen einer Depression eintreten, zieht man sie wieder fest zu und giebt wieder Stimulantien. Auf diese Weise fährt man abwechselnd fort, damit das Gift nicht auf einmal, sondern portionenweise, also in geringerer Wirkungsstärke den Organismus durchsetzt. Später wird die Binde weiter oben angelegt, um zu grosse Constriction des afficirten Theiles zu vermeiden. Eine plötzliche Entfernung der Ligatur ist gefährlich. In einem Falle war das Gift 11; Stunden lang durch die Ligatur zurïckgehalten worden, während schon 2 Stunden nach dem Lösen derselben der Tod eintrat. Die erste Lockerung (nicht Beseitigung) der Ligatur soll nicht vor 6 Stunden erfolgen und dann alle 2 Stunden wiederholt werden. Als Material für die Ligatur kann man nehmen, was man gerade zur Hand hat, z. B. einen vom Kleille ahgerissenen Tuchstreifen, einen Lederriemen, eine Schnur oder dergl. Durch Unterstecken eines Stabes unter die Ligatur und Herumdrehen desselben kann man die Circulation in dem unterbundenen Gliede mit noch grösserer Sicherheit vollstïndig hemmen. Die Hauptsache bleibt immer, dass die Ijigatur möglichst sofort nach dem Bisse und möglichst fest angelegt wird. Ein einfaches Umfassen des Gliedes mit den Fingern orler Ḧ̈nden ist nicht ausreichend. Die Eingeborenen Indiens pflegen sogar mehrere Ligaturen umzu- 
legen, z. B. wenn sich die Bisswunde am Finger befindet, eine um den Finger, eine zweite um den Vorderarm und die dritte um den Oberarm, um so ganz sicher zu sein, dass nichts von dem Gifte in den allgemeinen Blutkreislauf hineingelangt. Diese mehrfachen Ligaturen sind empfehlenswerth.

Vereinzelt wurde auch geäussert ${ }^{1}$ ), dass die Ligatur schädlich wirke, und dass die Intoxicationserscheinungen ohne dieselbe allerdings schneller auftreten, aber auch leichter vorübergehen. Statt dessen empfiehlt man, gleich nach dem Biss durch die Bissstelle einen nur die Haut durchtrennenden Schnitt zu machen, Blut und Gift auszudrücken und in die Wunde Ammoniak zu träufeln.

Durch das Ausbrennen der Bisswunde sollen nicht nur die Gewebe zerstört und absorptionsunfähig gemacht werden, sondern auch das Gift selbst vernichtet werden. Am sichersten erreicht man dies mit dem Glüheisen oder Paquelinschen Thermocanter, wenn man diese Operation, um das Gift. sicher zu treffen, in sehr grossem Unjfange vornimmt. Jäger, die in der Wildniss gebissen worden sind, legen häufig Schiesspulver auf die Wunde und zünden dasselbe an.

Besser als das Ausbrennen ist das sofort nach dem Bisse vorgenommene Ausschneiden der ganzen Bissstelle, eine auch den Wilden wohlbekannte Operation. So erzählt Pöppig ${ }^{2}$ ), als er selbst einmal von einer Giftschlange gebissen war, habe ein "Calderon" ihm die Haut mit einer Nadel durchstossen, sie gewaltsam emporgehoben und bis auf die Muskeln kreisförmig weggeschnitten; sodann legte er ein glühendes Goldstück auf, da Silber oder Eisen nach dem in Peru verbreiteten Aberglauben schaden sollen.

Die in Deutschland zuerst gegen Schlangenbiss empfohlene Bluttransfusion ${ }^{3}$ ), von der man auch in anderen Ländern einige Male günstige Resultate sah, hat aus allgemein toxikologischen Gründen mit Recht wenig Verwendung gefunden.

1) Veth, Wiener med. Wochenschr. XXXVI. 1. S. 10. 1886.

$\left.{ }^{2}\right)$ Pöppig, Reise in Chile und Peru. II. 1836. S. 230.

3) Schiltz, De transfusione sanguinis. Bonn 1852. 
Dagegen scheinen Versuche an Hunden dafür zu sprechen, dass bei Vergiftung durch Schlangenbiss Ma ge nausspülungen besonders günstig wirken, da wie man es anch bei subcutanen Morphiuminjectionen beobachtet hat, ein Theil des Giftes auf der Magenschleimheit ausgeschieden werden soll ${ }^{1}$ ). Schon Fontana erwähnt, dass Hunde, die nach Vipernbiss viel erbrachen, eher genasen als andere. Auch die Wirkung starken Branntweins bei Schlangenbiss erklärt man sich zum Theil durch Fällung der in dem Magen ausgeschiedenen Toxalbumine; durch den nachfolgenden Brechact würden dieselben dann aus dem Organismus entfernt. Verwendet man also Alkohol als Ausspülungsflüssigkeit, so würde man erstens das Gift im Magen niederschlagen, zweitens dasselbe herausbefördern und drittens auch noch eine stimulirende Wirkung erzielen.

Alle Arten von Uuschlägen, Kräuteraufgüssen, Auflegen von rohem Fleisch, Bäder etc. können höchstens gegen die secundüre Gangrä̈n etwas nützen.

Auch das Auflegen eines Breies von animalischer Kolle wurde empfohlen ${ }^{2}$ ), und R. Schomburgk schreibt den voln einigen wilden Stämmen in Britisch-Guyana angewandten warmen erweichenden Umschlägen aus Cassada-Brot eine spezifische entgegenwirkende Kraft zu, aber wohl mit Unrecht.

Um den depressorischen Wirkungen des Schlangengiftes zu begegnen und zugleich die Ausscheidung desselben durch die Haut zu begünstigen, hat man empfohlen, den Körper in angestrengte Bewegung und in Transpiration zu versetzen. Das ebenfalls darauf hinzielende Verfahren der Schlangenbeschwörer habe ich bereits erwähnt. Auch die Eingeborenen von Indien halten den Gebissenen fortwährend in Bewegung. Ja, man construirte in England sogar eine mechanische Vorrichtung nach Art einer Tretmühle, un bei Gebissenen Hyperkinese und Transpiration zu erzeugen ${ }^{3}$ ).

1) A It 1. C.

2) Garrod, Jond. Giaz. Dec. 1813.

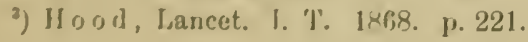


Als Beweis für den Nutzen solcher verstärkten körperliehen Leistung wird angeführt, dass ein von einer Cobra Gebissener dadurch gerettet worden sei, dass der Arzt ihn mit den Händen hinten an seinen Wagen band und ihn so zwang, eine englische Meile weit hinter demselben herzulaufen.

Zur Erzeugung von Schweiss kann man natürlich auch warme Bäder oder sonstige Mittel gebrauchen lassen. Auch das Einreiben von Baumöl, das ausserdem die Spannung der Hant des geschwollenen Gliedes vermindern soll, wurde zur Vermehrung der Hautansdünstung empfohlen.

Um die Wirkung des Giftes zu hemmen, übte man früher einen starken Druck auf die Wunde aus, indem man, gestützt auf Versuche von Bouillant, glaubte, dass während dessen kein Gift eingesogen würde ${ }^{1}$ ). Von diesem sehr zweifelhaften Mittel ist man aber schon lange abgekommen.

In Anbetracht des Umstandes, dass bei vielen Schlangengiften, namentlich bei dem der ostindischen Brillenschlange, Lähmung der Athmung die eigentliche Todesursache ist, hat man in neuerer Zeit versucht, die künstliche A thmung als lebensrettendes Mittel anzuwenden. Allein reicht dieselbe indessen auch nicht aus, um das Leben zu erhalten, da durch das Gift gleichzeitig anch die motorischen Herzganglien gelähmt werden. Immerhin verdient sie aber doch bei Schlangenbiss nöthigenfalls berücksichtigt zu werden, da sie nach den früher schon von verschiedenen Aerzten ${ }^{2}$ ) angestellten Versuchen im Stande ist, wenigstens einige Stunden das Leben zu erhalten, und man während dessen Zeit gewinnt, andere geeignete Mittel anzuwenden, welche die Elimination des Giftes befördern und eine erregende Wirkung entfalten.

1) I, enz, Schlangenkunde. 1832.

2) Weir Mitchell 1. c. - Vincent Richards, Indian Med. Gaz. May 1.1873. - F ayrer, Med. Times and Gaz. Sept. 6. 1873. p. 249. 


\section{Thierische Mittel.}

Inı Gegensatze zu den grösstentheils noch hente angewandten operaticen und mechanischen Mitteln gehören die thierischen Mittel gegen Schlangenbiss fast ausnahmslos der Vergangenheit an. Von den benutzten Thieren sind zunäehst die Schlangen selbst zu erwähnen. Schon Plinius empfiehlt den frisch abgerissenen Kopf einer Viper oder dessen Asche oder die Eingeweide ron Schlangen auf die Bisswunde zu legen und innerlich aus der Viper bereitete Theriakkügelchen, Brühe ron Schlangen oder gekochte Vipernleber zu nehmen, welche bewirken soll, dass man nie wieder gebissen wird. Auch könne man die Sehlange im Wasser zerstampfen und damit die Wunde bähen.

Nikander liess aus gekochtem Vipernfleisch eine Salbe bereiten, welche nicht nur gegen Schlangengift, sondern überhaupt gegen alle animalischen Gifte helfen sollte. Avicenna erwähnt Vipernpastillen, die aus zerstossenem Vipernfleisch mit geröstetem Brot bereitet wurden. Weder vor noch nach dem Trocknen dürfe die Sonne auf sie fallen, da dieselbe die Kraft des Vipernfleisches zerstöre. Sogar bis weit in die Neuzeit hinein wurden Kopf, Fleisch, Herz, Leber und andere ()rgane ron Schlangen nicht nur äusserlich angewandt, sondern auch als Antidote gegessen; die Bisswunde wusch man mit Vipernblut. Der Jesuit A thanasius Kircher ${ }^{1}$ ) behauptete, dass der innerliche Gebrauch von Schlangeneingeweiden nur den Biss gleicher Schlangen heile, und Aldrovandus, dass aufgelegte Vipern das Gift wie ein Magnet ansziehen. Ettmüller empfall eine Axungia serpentina gegen Schlangenbiss, und Gessner glaubte, ebenso wie Plinius, dass gegessene Schlangenleber immun gegen Schlangenbiss mache.

In neuester '/eit will man gegen Klapperselılangenbiss eine Lösung von Klapperschlangengalle in 10 Theilen Spiritus hei gebissenen Kaninuhen mit bestem Erfolge angewandt haben.

Eine grosse Rolle spielte auch das .Vipernsalz". Sehon

') A ti. Kircher, Mundus subtrraneus. Amstelod. 1678. lih, IX. 
die Alten kannten ein solches, das durch Verbrennen und Calcination der Schlangenknochen gewonnen and zum Theil mit Meer- and anderen Salzen gemischt wurde. Charas ${ }^{1}$ ) gab ein genanes Recept zur Bereitung eines guten Vipernsalzes an, das in der Hauptsache in einer Abkochung von Vipern und Zusatz von Seesalz besteht. Wirksamer soll dasselbe noch werden, wenn man statt des Seesalzes die Salze einiger theriakalischer Pflanzen zufügt, wie von den Wurzeln von Valeriana, Imperatorium, Angelica, Meum, von den Blättern von Scordium, Centaurea, Cardobenedicten u. a.

Für eins der besten Mittel in der Medicin überhaupt erklärt aber Charas das sogenannte, flüchtige Vipernsalz", bei dessen Bereitung es sich wesentlich um einen Destillationsprocess von Viperntheilen zu handeln scheint. Zahlreiche andere gegen Schlangenbiss gebrauchte zusammengesetzte Arzneimittel enthalten das Vipernsalz als Basis. Auch ein Vipernöl und Vipernfett wurden empfohlen.

Nach $\mathrm{Mead}^{2}$ ) soll das Aufstreichen des letzteren auf die Wunde verhindern, dass sich die flüchtigen Salze der giftigen Flüssigkeit in die spitzen Krystalle verwandeln (die Mead, wie oben erwähnt, im Viperngift gefunden haben wollte).

In manchen Gegenden Brasiliens verbindet man die Bisswunde mit dem öligen Decocte des Kopfes einer alten Schlange derselben Gattung ( el aceite de Cascavel“) oder reibt die Galle der aufgeschnittenen Schlange in die Bisswande ein.

Auch in Surinam werden die in Rauch getrockneten und dann in eisernen Töpfen verkohlten Köpfe giftiger Schlangen zusammen mit einigen getrockneten Pflanzen bei Schlangenbiss äusserlich und innerlich angewandt ${ }^{3}$ ).

Offenbar sind aber hierbei die betreffenden Pflanzen das

1) Charas, Nouvelles expériences sur la vipère. Paris 1694. p. $163 \mathrm{ff}$.

$\left.{ }^{2}\right)$ Mea d, De vipera. Opera medica. Vol. II. 1749.

$\left.{ }^{3}\right)$ K. Martin, Bericht über eine Reise nach Niederländisch-Westindien. I. S. $29 \mathrm{ff}$. 
Wesentliche. Ebenso wendet man auf Martinique liopf, Herz und Galle ron Giftschangen als Antidot gegen deren Biss an ${ }^{1}$ ). Nach Fontana essen die Mohamedaner, sobald sie gebissen sind, die Schlange roh mit viel Salmiak oder Kochsalz, und in Indien sollen Einige einen Balsam aus Leber und Herz der Schlange, mit etwas Salmiak und Zimmtessenz versetzt, einreiben und zugleich davon einen Löffel voll mit der doppelten Menge Oel innerlich nehmen.

Uebrigrens wurden anch gegen zahlreiche andere Krankheiten Viperntheile angewandt; so empfiehlt Dioscorides gekochtes Vipernfleisch gegen Augenkrankheiten, nervöse Leiden und Kröpfe; Vipernpastillen sollten bei Elephantiasis nützlich sein. Auch bei Aussatz und bösen Geschwüren wurden Vipern gebraucht, und in den verschiedenen Arten vou Theriak spielten Vipern gewöhnlich eine Hauptrolle. Noch jetzt wird Vipernbrïhe in Italien gegen chronische Krankheiten, wie Lähnungen, Hautkrankheiten, Marasmus senilis, Phthisis pulmonum angewandt, und das Oel ans den Eiern der Klapperschlange wird in Connecticut gegen Rheumatismus und Nemralgie gebrancht. Es soll starkes Brennen auf der Haut erregen. Axungia Viperarum stand noch in der Pharmacopoea Wirtembergica von 1760.

Anch zur Bereitung von Pfeilgiften wird Schlangengift, meist zusammen mit giftigen Pflanzenstoffen, noch heute von vielen wilden Völkerschaften benut\%.t. So besteht das Pfeilgift der Barineger aus dem Safte einer Baumwurzel und dem Decocte von Köpfen giftiger Schlangen. Die ConaquaHottentotten nehmen zu ihrem Pfieilgifte eine Milchsaft liefernde Pflanze und einige Schlangenarten, die Buschın̈nner Hornvipern. Auch die Muntschi in den Haussaländern, sowie verschiedene Volksstämıne auf der Malayenhalbinsel, den Sundainseln und noch in anderen Gegenden bedienen sich des Schlangengiftes zur Anfertigung ihrer Pfoilgifte ${ }^{2}$ ).

1) Ruf\% I. r. p. 1699.

2) L. I.c win, Die P'feilgifte. Virehow's Archiv. 13d. 136. 138. 1894. 
Von aus anderen Thieren bereiteten Mitteln gegen Schlangenbiss ist zunächst das Skorpionenöl zu erwähnen, womit das gebissene Glied eingerieben werden soll. Vom Hirsche, den man für immun gegen Schlangengift hielt, wurden verschiedene Organe, namentlich Magen und Leber, mit sehr verschiedenartigen anderen Substanzen, Wein etc. versetzt und auf mannigfaltige Weisen zubereitet, schon von Plinius als ein innerlich zu nehmendes Mittel empfohlen. Auch das aus dem Uterus einer jungen Hirschkuh geschnittene Coagulum soll gute Dienste leisten.

Gilbertus Anglicus empfahl, die Ligatur mit einem Hirschfelle zu machen. Charas gab in einem Falle von Schlangenbiss geraspeltes Hirschhorn innerlich, und ein Abt Tecmeyer rühmte gebranntes Hirschhorn als Gegenmittel. Auch Mead empfiehlt Hirschhorn mit warmem Wein. Von sonstigen Thieren, z. B. wilden Schweinen, Ziegen, Hasen, Flusspferden und vom Rhinozeros gebrauchte man verschiedene Organe, wie Gehirn, Leber, Magen, Hoden, ferner Blut, Galle, Magensaft und Talg. Verwendet wurden auch Bienen und spanische Fliegen innerlich und äusserlich.

Plinius behauptet, Hühner, die von Wanzen gebissen seien, sterben nicht an Schlangenbissen, eben so wenig Menschen, die solches Hühnerfleisch gegessen haben, und empfiehlt Auflegen von Wanzen mit Schildkrötenblut, sowie auch Galle vom Wiesel, oder aufgeschnittene Mäuse, frisch zerrissenes Tauben- oder Schwalbenfleisch, gebrannte Uhubeine mit Bleiwurz, das Blut von Fledermäusen mit Disteln gemischt, Auflegen von Hühnergehirn, Trinken von Hahngehirn mit Wein, Fleischbrühe von Hühnern, Asche von Ziegenhörnern, Milch, Harn, Käse, Talg und zahllose andere Mittel von der Ziege. Auch das Herz eines Raubvogels solle gegen Schlangen schützen. Avicenna empfiehlt, verbrannte und gepulverte Menschenzähne aufzustreuen.

Petrus de $\mathrm{Abano}{ }^{1}$ ) will zerriebene Krebse auflegen

1) Petrus de Abano, De venenis. 1473. 
lassen, und der schon erwähnte Abt Tecmeyer hält es sogar für. möglich, dass ein Zahn des Caiman, wenn man ihn nur in der Tasche trägt, den Vipernbiss heilen könne.

Ton Thierproducten spielte die Milch, wie noch heute bei vielen anderen Vergiftungen, von jeher eine grosse Rolle. Man bevorzugte Ziegenmilch, die innerlich und äusserlich, und geronnene Hasenmilch mit IVein, die innerlich verordnet wurde. Einige Indianerstïmme Guyanas glauben sogar in Frauenmilch ein wirksames Gegengift entdeckt zu haben, die sie zugleich mit Umschlägen aus Cassada-Brot anwenden. Auch die Neger sollen die Bisswunde von Coluber haje mit Frauenmilch auswaschen. Celsus empfiehlt das Trinken von Enten-, Schaf- oder Kalbsbrühe, andere Autoren Froschbrühe mit Salz und Oel. Auch rohes Eiweiss, sowie Käse wurde vielfach verwendet.

Sogar die Excrete von Thieren und Menschen wurden als Gegenmittel betrachtet. So erzählt Plinius, dass nach M. Varro der Gebissene durch Trinken des eigenen Urins geheilt werde. Das Gleiche behauptet auch Mercurialis ${ }^{1}$ ), und noch neuerdings empfahl ein französischer Arzt ${ }^{2}$ ) Answaschen der Wunde mit dem eigenen Harn. Auch die Darmexcrete ron Katzen, Hunden, Ziegen, Schafen, zum Theil mit Es-ig oder Wein gekocht oder geknetet, wurden theils immerlich, theils äusserlich angewandt, - bei den Indianern Perus und Brasiliens sogar der Menschenkoth ${ }^{3}$ ).

In Bolivia und Südafrika gebraucht man - falls die Eingeborenen nicht absichtlich in einem solchen Falle, un das wahre Mittel zu verheimlichen, die Unwahrheit sagten Kuren mit schweissgetrïnkten alten Mützen und anderen Giegenständen, wie es schien, mit wunderbarem Erfolge ${ }^{4}$ ).

1) Mercurialis, De venenis. 1584.

2) Jesmartis, far. hebd. V. 1858.

$\left.{ }^{2}\right)$ l'oppig l. c. Il. S.26\%. - Spix, Serp. Brasil. Spec. novae. [1. (6i).

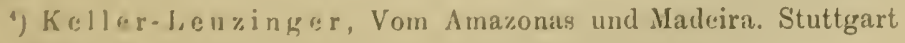
1F74. S. . il. 
Einem gebissenen Hunde wurde zunächst fein zerschnittener und in Wasser eingeweichter Minastabak eingegeben; später wusch ein alter Neger ein von Schmutz starrendes Täschchen, das er an einer Schnur um den Hals trug, und gab das Waschwasser dem Thiere ein, worauf der Hund alsbald wieder völlig gesund wurde, nachdem vorher sein Gang wankend gewesen war, sich Würgen eingestellt hatte, und an der Bissstelle eine beinahe sichtlich zunehmende Geschwulst entstanden war.

Die Indianer Louisianas legen auf die Bisswunde Smegma praeputii und unterbinden das gebissene Glied mit einem Baumwollfaden, den sie stets unter dem Präputium tragen ${ }^{1}$ ).

In der Provinz Sào Paulo wird nach Tschudi den verkohlten Federn und Knochen eines rebhuhnartigen Vogels, des Macuco (Tinamus brasiliensis), auch "Nabú-Assú oder "Tona" genannt, eine spezifische Heilwirkung bei Bissen giftiger Schlangen zugeschrieben. In anderen Theilen Brasiliens wird noch heute bei Schlangenbiss das Fett einer grossen Eidechse (Lacerta Teguixia L.) eingegeben. Auch legt man daselbst geglühte Knochenstücke (vielleicht von Hirschhorn), die mit der schleimigen, aus Krokodilshoden exprimirten Flüssigkeit getränkt sind, auf die Bisswunde.

Auf den Andamanen legt der Gebissene, falls er die Schlange getödtet hat, Nierenfett auf die Wunde; im anderen Falle wendet er die Unterbindung und Cauterisation an.

Auch der menschliche Speichel wurde mehrfach als Antidot gegen Schlangenbiss empfohlen. So rühmen Plinius, Galen u. A. den Speichel eines nüchternen Menschen als nützlich, und auch von den Negern wird derselbe bei Bissen von Coluber haje angewandt.

\section{Chemische Mittel.}

Von chemischen Mitteln waren vom Alterthume bis in die Neuzeit hinein in Folge der kleinen bekannten Zahl derselben nur wenige gegen Schlangengift in Gebrauch. Eigent-

1) Spix l. c. p. 66 . 
lich gab es deren früher nur drei, nämlich Essig, W ein und Kochsalz. Das Trinken von reinem Wein wird von Dioscorides, Celsus, Plinius, Avicenna und Anderen empfohlen. Celsus meint, statt reinen Weines mit Pfeffer könne man auch etwas Anderes trinken, „quod calori movendo est, nec humorem intus coire patitur"; denn die meisten Gifte gingen durch Kälte zu Grunde. Kochsalz soll nach Celsus trocken in die Wunde gestreut werden. Die genannten und auch spätere Autoren empfehlen ebenfalls Trinken von Essig und Auswaschen der Wunde mit demselben, indem man glaubte, er setze den sich eindickenden Saft im Menschen wieder in Bewegung. Nach Mercurialis liessen auch die Aegypter reichlich Essig trinken. Avicenna rühmt einen Oxymel aus Essig, Salz und Honig, und Gessuer die äussere Anwendung ron Essig, Salzwasser, Essig mit Salrbrühe vermischt und ein Pflaster aus Essig und Asche. Von Avicenna wird ausserdem noch ein Schwefelmittel von nicht näher angegebener $\mathrm{Zu}$ sammensetzung erwähnt. Auch Erdöl wurde, wenn auch selten, gebraucht.

Ton chemischen Mitteln der Neuzeit ist zunächst das auch heute äusserlich und innerlich noch häufig angewandte A mmoniakzu erwähnen. Es wurde zuerst im vorigen Jahrhundert von Jussieu, Chaussier, Sage und Anderen als eines der sichersten Mittel bei Schlangenbissen gerühmt. Wie es scheint, kam man deswegen auf ein Alkali, weil Mead das Viperngift für sauer erklärt hatte. Smith ${ }^{1}$ ) empfahl als bestes Mittel bei Schlangenbiss nach vorheriger Anlegung einer Ligatur um das verletzte Glied möglichst bald nach dem Bisse eine Dosis von $2 \mathrm{~g}$ Ammoniak auf einmal innerlich zu geben, und zwar nur in solcher Verdünnung mit Zuckerwasser, dass ein Hinunterschlucken eben noch möglich sei. Andere beschränken die Einzeldosis auf' 20 'Tropfen (gehörig nit '/uckerwasser verdüunt) und rathen, nicht über 4-12 g davon zu gehen. Auch subcutane Injectionen von mit 4 Theilen Wasser

') im ith, Brit. ined. Journ. Fel,r. 22. 1868. J. 164.

lstenniug, Jies Vergiftungen durch Schlangen. 
verdünntem Ammoniak zu 1/2-1 Spritze, oder intravenöse Injectionen von 10-40 Tropfen einer Lösung von Ammoniak in 2-3 Theilen Wasser sind empfohlen worden ${ }^{1}$ ). Selbst unverdünntes Ammoniak, zu $0,5 \mathrm{~g}$ subcutan injicirt, hatte bei Meerschweinchen stets nur günstige Wirkungen ${ }^{2}$ ). Die ebenfalls Ammoniak enthaltende und am Cap der guten Hoffnung unter dem Namen "Croft's drops" bekannte Flüssigkeit wird daselbst geradezu als ein Specificum gegen Schlangenbiss gerühmt.

Statt des Ammoniaks wurde früher vielfach auch der Liquor Ammonii succinici ("Eau de Luce") angewandt und soll auch jetzt noch in Ostindien in Gebrauch sein, ebenso das Ammonium carbonicum (Hirschhornsalz), das vor dem Ammoniak den Vorzug hat, innerlich genommen weniger zu ätzen.

Neueren Untersuchungen und Beobachtungen gegenüber hat jedoch das Ammoniak seinen Ruf als Antidot gegen Schlangengift nicht zu wahren vermocht. Schon Fontana fand dasselbe bei seinen Experimenten nutzlos gegen Viperngift, ebenso zahlreiche spätere Forscher auch gegen andere Schlangengifte. Sicher ist, dass das Ammoniak durchaus nicht auf das Gift selbst chemisch einwirkt und so etwa dasselbe zerstört und unwirksam macht. Höchstens kann man annehmen, dass es bei äusserer Anwendung, falls ihm in geeigneter Weise die Gelegenheit dazu geboten wird, durch Verätzung der Gewebe dieselben unfähig macht, das Gift zu absorbiren. Bei innerlicher Darreichung ist es indessen im Stande, durch Amregung der Herzthätigkeit unzweifelhaften Nutzen zu stiften, jedoch stehen uns zu diesem Zwecke, wir wir später sehen werden, andere Mittel zur Verfügung, die besser wirken als das Ammoniak. Immerhin gehört dieses $\mathrm{zu}$ denjenigen Stoffen, welche man nicht ohne Weiteres als unbrauchbar verwerfen darf.

1) Halford, Med. Times and Gaz. Dec. 27. 1873.

$\left.{ }^{2}\right)$ J. Schulz, Ueber Schlangengift. Inaug.-Diss. Berlin 1881. 
Da man auch, um das Schlangengift durch die Hautthätigkeit aus dem Körper zur Ausscheidung zu bringen, auf eine diaphoretische Wirkung des Ammoniaks Gewicht legte, so wandte man in neuester Zeit statt desselben ausser anderen schweisstreibenden Mitteln besonders subcutane Injectionen von Pilocarpin an. Indessen fehlen bis jetzt noch genügende $\mathrm{Be}-$ weise für die Wirksamkeit der Diaphoretica bei Schlangenbiss.

Aehnlich wie das Ammoniak verhalten sich auch die übrigen äusserlich als Aetzmittel gebrauchten Chemikalien, wie Kalilauge, Natronlauge, ungelöschter Kalk, Schwefelsäure, Salpetersäure, Essigsäure, Eisenchlorid, Butyrum Antimonii. Alle diese Mittel, die jetzt wohl nur noch selten angewandt werden, haben nur dann einen Zweck, wemn sie möglichst bald nach dem Biss applicirt werden, ehe noch eine grössere Quantität des Schlangengiftes in den Blutkreislauf gelangt ist, und wenn zuvor die Bisswunde hinreichend erweitert wurde, damit sie in gehöriger Weise auf die Gewebe resp. das in denselben enthaltene Gift selbst einwirken können. Denn, wie bereits an einer früheren Stelle erwähnt wurde, vermögen namentlich Kali- und Natronlauge in genügender Concentration und bei längerer Berührung mit Schlangengift dieses unwirksam zu machen, und verdienen deswegen in allen frischen Fällen wohl in Anwendung gezogen $\mathrm{zu}$ werden.

Was die Carbolsäure betrifft, so hat dieselbe zwar nur eine geringe Wirkung auf das Gift selbst, jedoch soll sie sich gut $\%$ Ueberschlägen auf den verletzten Theil eignen, weil sie die Circulation in den Blutgefässen und dadurch auch die Resorption des Giftes angeblich wesentlich verlangsamt ${ }^{1}$ ). Als innerlich zu nehmendes Mittel wurde die Carbolsïure gegen den Biss der australischen Tigerschlange empfohlen, hat aber wohl als solches ebenso wenig Nutzen wie das in Mittelasien gebräuchliche Bestreichen der Bisswunden von Trigonocephalus halys init Theer. 
Der Neuzeit gehört ferner als Mittel gegen Schlangenbiss das übermangansaure Kali an, über dessen Werth die Meinungen sehr getheilt sind. Schon vor ca. 25 Jahren behauptete man von demselben, dass es das Gift neutralisire und vollkommen wirkungslos mache ${ }^{1}$ ). Auch Lacerda ${ }^{2}$ ) empfahl dasselbe, da er es in mehr als 40 Versuchen wirksam gefunden hatte. Selbșt dann noch sollte es vorzügliche Dienste geleistet haben, wenn das Schlangengift direct ins Blut, also in eine Vene gespritzt wurde. Innerhalb 15-25 Minuten nach der Injection sollten sämmtliche Vergiftungssymptome verschwunden sein, so dass die Versuchsthiere keinerlei Abweichungen von ihrem normalen Verhalten zeigten. Lacerda schrieb dem Kalipermanganat allerdings keine specifische Wirkung gegen das Schlangengift zu, sondern war der Ansicht, dass das Schlangengift ähnlich den Verdauungssäften nach Art eines Fermentes wirke und durch das Mittel seiner fermentativen Eigenschaften beraubt werde, indem der active Sauerstoff, der sich durch Zersetzung des mit der organischen Materie in Contact gebrachten Kaliumpermanganats bilde, die chemischen Eigenschaften des Giftes ändere.

Von 30 Experimenten, bei denen Lacerda das Gift direct in die Venen spritzte, zeigte sich nur bei zweien das übermangansaure Kali wirkungslos, und zwar, wie er glaubte, deshalb, weil die betreffenden Thiere schlecht genährt, schwach und sehr jung waren, und ausserdem die Anwendung des Mittels zu lange hinausgeschoben war.

Während es bei sofortiger Injection des Kalipermanganats gleich nach dem Biss genügen soll, das Mittel nur, an der Bissstelle zu appliciren, rieth Lacerda, wenn das Mittel erst spät zur Anwendung gelange, auch im gesunden Gewebe mehrere Injectionen damit zu machen. p. 361 .

$\left.{ }^{1}\right)$ Shortt, Madras Monthly Journ. of Med. Sc. Vol. V. 1872.

$\left.{ }^{2}\right)$ Lacerda, O Permanganato de Potassa como antidoto de peçonha das Cobras. Rio de Janeiro 1881. - Leçons sur les venins des serpents du Brésil. Rio 1882. 
Im Gegensatze zu Lacerda, welcher sich bei seinen Versuchen der Gifte mehrerer zu der Familie der Crotalidae gehöriger Schlangen Südamerikas bediente, fanden aber andere Untersucher das Kaliumpermanganat entweder ganz nutzlos, selbst beim Crotalusgift, oder doch wenigstens lange nicht so wirksam wie jener.

Bei späteren Versuchen hat übrigens Lacerda selbst eingesehen, dass dieses Mittel durchaus nicht die Eigenschaften besitzt, welche er ihm früher zuschrieb. Die meisten Autoren der neuesten Zeit kommen darin überein, dass Kaliumpermanganat nur dann die Wirkung des Giftes mehr oder weniger zerstört, wenn es ausserhalb des Körpers längere Zeit mit demselben gemischt wurde, oder wenn es unmittelbar nach der Injection des Giftes oder nach dem Bisse an der Bissstelle selbst eingespritzt wird ${ }^{1}$ ). Bei dem Gifte der Brillenschlange ist aber auch dieses Verfahren unsicher und kann oft den Eintritt des Todes nur verzögern, aber nicht verhindern. Ganz zwecklos ist es jedoch, das Kaliumpermanganat erst dann anzuwenden, wenn bereits deutliche Erscheinungen der stattgefundenen Vergiftung aufgetreten sind.

Das Viperngift soll durch örtliche Behandlung mit Kaliumpermanganat allein die Localwirkungen verlieren, während die Allgemeinwirkungen nur abgeschwächt werden.

Da also dem Kalipermanganat gewisse neutralisirende Wirkungen gegen Schlangengift nicht abgesprochen werden können, so kann man immerhin versuchen, durch multiple Injectionen einer 3-50,0igen Lösung des Mittels tief in die ganz frische Bisswunde hinein das Gift zu zerstören oder wenigstens abzuschwächen. Uebrigens haben diese Injectionen den Nachtheil, dass sie caustische Wirkungen zurücklassen, und dass die Wunden danach, im Gegensatze zu denen, bei welchen die noch näher zu besprechende Chromsäure angewandt wurde, erst nach längerer \%eit zuheilen.

1) Itchards, Lancet. I. Jan. 1. 1882. 1. 35. - Calmette, Journ. de Pharin. et de Chimie. 1892. - Tricird, Arch. de mér. navale. IAXI. I). 3:57. 1894. 
Sehr geringe Erfahrungen liegen über das Natrium salicylicum vor. Dasselbe soll rings um die Wunde in einer Concentration von 1: 12 Wasser subcutan injicirt, und ausserdem alle 2 Stunden ein Esslöffel einer Lösung von $1 \mathrm{~g}$ Acidum salicylicum in $150 \mathrm{~g}$ Orangenblüthenwasser genommen werden ${ }^{1}$ ).

Eine grössere Beachtung als das zuletzt genannte Mittel verdient wohl die äusserliche Anwendung von Jod resp. der Lugol'schen Lösung gegen Schlangenbiss.

Ein französischer Forscher ${ }^{2}$ ) empfahl solche Injectionen von etwa $4-5 \mathrm{~g}$ einer Lösung von $0,6 \mathrm{~g}$ Jod und $1,8 \mathrm{~g}$ Jod$\mathrm{kali}$ in $30 \mathrm{~g}$ Wasser. Der gebissene Theil wird zuerst geschröpft, oder es wird eine Ligatur um das Glied gelegt, bis die Gewebe genügend durch Ansammlung von Serum geschwollen sind, so dass sich die injicirte Flüssigkeit durch die ausgedehnten areolären Räume verbreiten kann. Dann wird die Injection seitwärts in das Glied gemacht, unterhalb des noch 10 Minuten lang liegen bleibenden Schröpfkopfes. Ist bereits eine Schwellung eingetreten, so nimmt man weniger von den wirksamen Stoffen und mehr Wasser, damit diese grössere Flüssigkeitsmenge sich über die ganze geschwollene Partie verbreiten kann. Leider ist der nothwendige Apparat, namentlich Injectionsspritze und Schröpfköpfe, in den seltensten Fällen gleich zur Stelle.

Die günstige Wirkung dieser Jodinjectionen wurde dem, das Schlangengift selbst verändernden Einflusse des Jods zugeschrieben. Demgegenüber wurde jedoch später festgestellt, dass das Jod das Gift nicht verändert. Man erhielt bei Versuchen mit Gerbsäure dieselben Resultate wie mit Jod und schloss daraus, dass Jod und Gerbsäure mehr durch ihren Einfluss auf die Gewebe als auf das Gift selbst wirken. Indessen, wenn auch durch Jodinjectionen die Localsymptome geringer wurden oder ganz fehlten, und der Eintritt der allgemeinen

3) Bull. de l'Acad. de méd. 3. sér. XX. 1888. p. 603.

$\left.{ }^{2}\right)$ Brainard, Gaz. de Paris. 24. 25. 1854. 
Wirkungen des Giftes ron Crotalus verzögert wurde, so liess sich der Tod in den für diesen Zweck rorgenommenen Thierrersuchen schliesslich doch nicht vermeiden. Empfohlen wurde freilich das Mittel nicht gegen den Biss von Crotalus, sondern ron Crotalophorus tergeminus. In neuester Zeit wurde auch die Wirksamkeit der Brainard'schen Jodinjectionen gegen das Gift der Lanzenschlange auf Martinique untersucht ${ }^{1}$ ). Es zeigte sich hierbei, dass das Mittel, wenn es ausserhalb des Körpers mit dem Schlangengift gemischt wurde, das letztere allerdings unwirksam machte; wurde aber die Jodlösung selbst unmittelbar nach der Giftinoculation und an derselben Stelle wie das Schlangengift applicirt, so konnte dadurch auch nicht ein einziges der zu den Versuchen benutzten Thiere (T'auben, Hühner, Ratten, junge Hunde) gerettet werden. Es ist indessen wohl möglich, dass mit grösseren Thieren bessere Resultate erzielt worden wären. Beim Menschen ist das Brainard'sche Mittel nur einmal benutat worden, jedoch zugleich mit dem später zu besprechenden Bibron'schen Mittel.

Das ebenfalls von Brainard als Injection angewandte milchsaure Eisen $(0,5: 30,0$ Wasser $)$ steht an Wirksamkeit noch dem .Jod nach.

Günstigere Erfolge sind vielleicht von subcutanen Injectionen einer 1 \%oigen Chromsäurelösung zu erwarten ${ }^{2}$ ). Dieselbe scheint die Giftwirkungen zum Theil zu zerstören und die Ausbreitung der Localaffectionen zu hindern, und zwar sowohl wenn sie mit dem Gifte gemischt (2 Tropfen der Lösung zum Gifte zugefügt), als auch wenn sie einige Zeit nach demselben injicirt wurde. Sogar die bereits begonnenen Wirkungen des Schlangengiftes konnten dadurch bei Thieren völlig wieder aufgehoben werden, selbst wenn das Mittel erst 15 Minuten nach dem Bisse applicirt wurde. Auch gegen das Gift der Lanzenschlange erwies sich die Chromsäure wirksamer als Jod-

1) Tricard 1. c.

5) II. Ka ufmann, Du venin de la vipère. Paris 1889. - Compt. rend. de la Société de Biologie. 9. sér. T. VI. 10. Févr. 1894. p. 113. - Karlinski, Fortschritte der Medicin. VIII. 16. 1890. 
lösungen ${ }^{1}$ ). Die Heilung soll danach schnell eintreten, ohne dass caustische Wirkungen entstehen. Die Chromsäure muss aber genau da injicirt werden, wo das Gift ist, und zwar möglichst früh; später, wenn erst Schwellung eingetreten ist, sind mehrere Injectionen in dieselbe nöthig. Bei grösserer Ausbreitung der Schwellung soll man vorher Scarificationen machen. Die Allgemeinwirkungen des Schlangengiftes sollen jedoch durch die Chromsäure nicht aufgehoben, sondern nur abgeschwächt werden. Kaufmann nimmt deshalb zwei verschiedene im Gifte enthaltene Stoffe an, von denen nur der eine, welcher die Localwirkungen veranlasst, durch Chromsäure zerstört werden soll.

Die Schwierigkeit dieser, wie mancher anderer ähnlicher Therapie liegt darin, dass man das Gift nicht so leicht mit dem Mittel treffen kann.

Der Chromsäure ähnlich soll das ChJorwasser wirken. Lenz ${ }^{2}$ ) glaubte der nach Schlangenbiss vermeintlich eintretenden fäulnissartigen Zersetzung des Blutes durch äussere und besonders innerliche Anwendung des Chlorwassers, dessen fäulnisswidrige Eigenschaften bei brandigen Wunden er kennen gelernt hatte, entgegenwirken zu können. Strich er das Mittel nur auf die Wunde, so vermochte es nicht zu retten, wandte er es dagegen innerlich an, so rettete es selbst dann noch das Leben, wenn das Gift bereits resorbirt und im ganzen Körper verbreitet war. Er gab seinen gebissenen Hühnern täglich ca. $31 \mathrm{~g}$ Chlorwasser (=0,125 g Chlor), und kein einziges von ihnen starb an den Folgen des Bisses.

Auch in der neueren Zeit sah man vom Chlor günstige Resultate ${ }^{3}$ ). Man verwandte eine durch Glaswolle filtriirte Lösung von Chlorkalk und fand, dass dieses Mittel zuverlässiger wirkt als das übermangansaure Kali, und zwar sowohl wenn man eine Mischung von Chlorkalklösung und Schlangen-

1) Tricard l. c.

2) Lenz l. c.

${ }^{3}$ ) A ro n, Zeitschrift f. klin. Med. VI. 1883. S. 332 u. 385. 
gift, als auch wenn man erst das Schlangengift und darauf Chlorkalklösung injicirte. Noch in letzter Zeit hat man auch in Frankreich, nachdem bereits Roux und Vaillard günstige Wirkungen durch Anwendung unterchlorigsaurer Alkalien gegen Tetanustoxin gesehen hatten, mit Lösungen ron Chlorkalk und unterchlorigsaurem Natron bei verschiedenen Schlangengiften gute Erfolge erzielt ${ }^{1}$ ). Es zeigte sich hierbei, dass Thiere, welchen eine sonst in zwei Stunden zum Tode führende Giftdosis inoculirt war, mit dem Leben davonkamen, wenn ihnen innerhalb der ersten 20 Minuten nach der Giftinoculation eine Lösung von unterchlorigsauren Kalk oder Natron in einer Concentration von 1:36 rings un die Einimpfungsstelle und auch an verschiedenen anderen Körperstellen injicirt wurde. Sogar nach 20 bis zu 30 Minuten wirkten diese Mittel noch in dem Falle, wenn zugleich auch eine schwache Morphiumlösung eingespritzt wurde. Während sich subcutane Injectionen jener Salze stets wirksam erwiesen, war dies bei intravenösen Injectionen nicht immer der Fall. Uebrigens verdient Chlorkalk den Vorzug vor dem unterchlorigsauren Natron, weil die Einspritzungen von Lösungen des ersteren schmerzlos sein sollen, die des letzteren dagegen nicht.

Es würde sich also empfehlen, nach Anlegung einer elastischen Ligatur um das gebissene Glied möglichst bald $20-30 \mathrm{ccm}$ einer etwa $2 \%$ igen Lösung von Chlorkalk in die Wunde an mehreren Stellen rings um dieselbe und auch weiter centralwärts einzuspritzen, und zwar so tief, wie die Giftzälne eingedrungen sind; darauf kann man die Ligatur wieder abnehmen. Die Wunde selbst ist mit einer concentrirten Chlorkalklösung reichlich auszuwaschen. Die Chlorkalklösung muss wegen ihrer leichten Zersetzlichkeit fest verschlossen und im Dunkeln aufhewahrt werden.

Ob sich aber dieses Mittel auch bei seiner praktischen

2) A. Ca Imette, Compt. rend. de la Soc. rle Biologie. 9. sér. 'T. VI. 1894. ए. 120. - Annales de l'Institut Pasteur. 'T'. VIII. 1894. p. $27 \%$. 
Anwendung beim Menschen eben so wirksam zeigen wird wie bei den Versuchsthieren - das ist eine Frage, die bis jetzt noch nicht $z \mathfrak{u}$ entscheiden ist.

Auch dem Goldchlorid schrieb man die Fähigkeit zu, durch Bisse von Schlangen, insbesondere der Brillenschlange, vergiftete Thiere durch Neutralisation des absorbirten Giftes heilen zu können, vorausgesetzt, dass dieses Mittel noch vor Eintritt der Athmungslähmung in und um die Wunde, sowie auch an anderen Körperstellen in $1 \%$ iger sterilisirter Lösung eingespritzt würde ${ }^{1}$ ). Indessen hat sich das Goldchlorid nicht bewährt ${ }^{2}$ ). Es schlägt allerdings, wenn man es ausserhalb des Körpers mit dem Schlangengifte mischt, die toxisch wirkenden Albumosen desselben nieder, aber seine Heilwirkungen sind selbst bei sofortiger örtlicher Anwendung und selbst bei Inoculation 'mit dem Cobra-Gifte zugleich sehr zweifelhaft, und von den Kaninchen, welche wirklich von der Brillenschlange gebissen worden waren, wurde durch Goldchloridinjectionen kein einziges gerettet. Ganz ohne Wirkung bleibt auch die Einspritzung des Mittels in die Venen. Besser als gegen Cobra-Gift scheint das Goldchlorid gegen das Gift der Lanzenschlange zu wirken. Eine Mischung dieses Giftes mit $1 \%$ iger Goldchloridlösung zeigte sich nämlich bei Thieren stets unwirksam bei Injectionen, und wurde das Goldchlorid sofort nach dem Gifte injicirt, so wurden die Thiere in der Regel gerettet. Bei nicht directem Contacte des Mittels mit dem Gifte trat jedoch nur eine Verzögerung der Giftwirkung ein ${ }^{3}$ ).

Ausser Goldchlorid soll auch Platinchlorid, wenn vor der Einspritzung mit dem Gifte gemischt, die Giftigkeit des letzteren zerstören. Andere, zum Theil schon oben erwähnte Stoffe, wie Zinkchlorid, Jodtinktur, Sublimat, Silber-

1) A. Calmette, Annales de l'Institut Pasteur. 1892. p. 160. Journ. de Pharm. et de Chimie. 1892.

2) Kanthack, Lancet. I. 11. June 1892. p. 1296. - Vgl. auch Wall, Indian snake poisons, their nature and effects. London 1883.

3) Tricard l. c. 
nitrat. Carbolsäure, Eisenchlorid, schwächen nur die Wirkung des Giftes ab.

Ausser dem Sublimat wurden ron Quecksilberpräparaten früher Einreibungen mit grauer Salbe empfohlen.

In Brasilien sollen gegenwärtig vielfach Injectionen von doppelkohlensaurem Natron angewendet werden ${ }^{1}$ ).

Alle diese zuletzt genannten Stoffe haben aber nur eine untergeordnete Bedeutung.

In neuester Zeit hat man durch subcutane Injectionen von Strychnin günstige Erfolge bei Bissen der australischen Giftschlangen erzielt ${ }^{2}$ ). Die Veranlassung, mit demselben Versuche anzustellen, gab die Beobachtung, dass das Gift dieser Schlangen eine specifische lähmende Wirkung auf alle die Bewegung bewirkenden und regulirenden Centraltheile des Nervensystems hat, und zwar sollen gerade diejenigen Ganglienzellen von der Lähmung betroffen werden, welche vom Strychnin gereizt werden. Allen australischen Giftschlangen scheint allerdings diese dem Chloralhydrat ähnliche, und schon oben besprochene Wirkung zuzukommen, was man aber nicht auch ron den Giften anderer Schlangen in gleicher Weise behaupten kann, so dass also Strychnin keineswegs als Universalantidot für jeden Schlangenbiss angesehen werden kann. Das Verdienst, das sich Müller durch Einführung der Strychninbehandlung in Australien erworben hat, wird, vorausgesetzt, dass noch weitere günstige Erfolge mitgetheilt werden sollten, durch diese Einschränkung nicht geschmälert. Die Anwenrlungsweise besteht in subcutaner Injection von $10 \mathrm{mg}$ Strychnin, eine Dosis, die je nach Umständen noch ein- bis zweimal wiederholt werden kann.

Auch bei Bissen der in Ostindien vorkommenden Echis carinata und des Bungarus coeruleus haben sich Strychnin-

3) M. Schanz, Jas heutige Brasilien. Hamburg 1893. S. 112.

2) A. M ïller. Austral. med. Journ. May 15. 1888. - Austral. ned. Cia\%. VIJl. 1888/89. IX. 1890. - Virchow's Archiv. CXIJI. 1888. s. :393. 
injectionen als günstig bewährt ${ }^{1}$ ). Ebenso werden in Nordamerika jetzt vielfach Strychnininjectionen, verbunden mit innerlichem Gebrauche von Alkohol, mit gutem Erfolge angewandt.

Von den innerlich angewandten chemischen Mitteln wurde bereits das Ammoniak erwähnt. Aeltere Beobachter empfahlen auch bei Schlangenbiss ein starkes Brechmittel aus Brechweinstein, den man auch auf die Wunde streuen soll. Das letztere ist wohl insoweit werthlos, als die Zerstörung des lebenden Gewebes erst so spät beginnt, dass die Resorption des Giftes dann schon längst beendet sein kann.

Eine Zeit hindurch hatte der Arsenik eine grosse Berühmtheit als Gegengift. Sein Gebrauch stammt aus Ostindien, wo er als "Tanjore-Pillen" oder "tanschaurische Pillen" viel angewandt wurde ${ }^{2}$ ). Dieselben bestehen aus weissem Arsenik, von dem jede Pille $0,045 \mathrm{~g}$, also eine ziemlich starke Dosis, enthält, ferner aus zwei gepulverten Wurzeln, nämlich velli-navi und nervi-visham, den gepulverten Kernen einer abführend wirkenden Pflanze nervalam, aus Pfeffer und Quecksilber, und zwar alles zu gleichen Theilen. Man bereitet sie in der Weise, dass man zunächst Quecksilber mit dem Saft der wilden Baumwollpflanze (Asclepias gigantea) verreibt, bis die Kügelchen unsichtbar geworden sind, dann werden Arsenik und die übrigen Ingredienzien in gepulvertem Zustande hinzugefügt und das Ganze mit Baumwollsaft zur Pillenconsistenz verarbeitet. Nach dem Biss einer Brillenschlange giebt man eine gepulverte Pille mit etwas warmem Wasser gemischt; weml die Vergiftungssymptome zunehmen, nach einer Viertelstunde weitere zwei Pillen und eventuell nach einer Stunde noch eine Pille. Dies genügt im Allgemeinen. Ausserdem soll man die Wunde dilatiren und die warme Leber eines Vogels darauf legen. Beim Biss der

1) Banerjie, Lancet. I. 22. May 1892. p. 1183.

$\left.{ }^{2}\right)$ Russell, Account of Indian serpents. I. 1796. p. 74 ff. 
Vipern giebt man zwei Pillen, und wenn diese nicht wirken, nach einer halben Stunde noch zwei. Ist das Leben des Gebissenen augenscheinlich in grosser Gefahr, so verabfolgt man vier Pillen und macht auf dem Scheitel des Kopfes einen Einschnitt, reibt eine pulverisirte Pille in die Wunde ein und legt eine Vogelleber auf diese Stelle. Für den Biss weniger giftiger Schlangen ist eine Pille jeden Morgen für drei Tage genügend. Sechs Tage lang darf der Gebissene nur Reiswasser und Reis oder Milch und Reis geniessen; er muss Salz vermeiden, darf nur warmes Wasser trinken und in den ersten $2 f$ Stunden auch nicht schlafen. Die frisch bereiteten Pillen wirken stärker als alte.

Russell fand bei seinen Thierversuchen diese Arsenikpillen nur sehr unsicher wirkend, und es scheint auch, dass dieselben in neuerer Zeit selbst in Indien ihren guten Ruf verloren haben. Die Indier besitzen übrigens noch andere, unbekannte Mittel gegen Schlangengift.

Nach Pöppig wird auch in Peru und Columbien der Arsenik sehr gerühmt, ebenso Sublimat.

Ein neueres Mittel ist das Bibron'sche Antidot. Dasselbe besteht aus $18,75 \mathrm{~g}$ Brom, 0,24 g Jodkali und $0,12 \mathrm{~g}$ Sublimat. Daron werden 10 Tropfen mit 1-2 Esslöffel Wein orler Branntwein gegeben und nach Unständen stündlich wiederholt; auch soll man die Bissstelle damit einreiben. Der Erfinder dieser Zusammensetzung erprobte es an sich selbst und auch mehrere andere Untersucher ${ }^{1}$ ) empfahlen dasselbe. Ilunde sollen unter dem Linflusse des Mittels für einige Zeit gegen Klapperschlangengift geschützt sein. So soll in $17 \mathrm{Ex}-$ perimenten. leei denen drei Hunde zu verschiedenen Zeiten durch 17 verschiedene Schlangen gebissen waren, in keinem Falle das Mittel versagt haben. Es fehlen aber nühere Angaluen üterer den Zustand der Schlangen, die Zahl der Biss-

') Hammond, Americ Journ. XXXV. p. 94. 1858; ibid. p. 375. - IJ: Vesey, Ibid. April 1858. - Walker and Sabal, Jbid. Oct. leis - Henry, H,id. XXXVH. - Jones, Philad. med, and smrg. Rinport. July 20. 1\$89. p. 61. 
stellen und den Ort des Bisses. Ein Wolf wurde einmal durch das Brom augenscheinlich gerettet, starb jedoch, als er zu einer anderen Zeit dreimal gebissen war. Ja, in einem Falle wurden sogar bei einem gebissenen Menschen die Localsymptome durch den Gebrauch des Mittels schnell leichter, und in einem anderen, fast hoffnungslosen Falle liessen die schlimmsten Symptome nach dem Gebrauche zweier Dosen des Mittels schnell nach. Weir Mitchell vermisste jedoch bei seinen Versuchen die prophylactische Wirkung des Bibronschen Mittels und fand es auch sonst ziemlich unzuverlässig.

Weitere gegen Schlangenbiss empfohlene innerlich zu nehmende Mittel sind Calomel und Cyanquecksilber. Gegen den Biss von Coluber Ammodytes L. sollte die Plenck'sche Quecksilberlösung das beste Gegenmittel sein. $\mathrm{Croft}^{1}$ ) rühmt eine starke Lösung von Jod in Jodkalium. Auch Bromkali und Chinin wurden früher zuweilen gegen Schlangenbiss angewandt.

Alle diese Mittel stehen aber an Bedeutung weit zurück hinter einem anderen, welches gegenwärtig als das zweckmässigste von allen innerlich gegen Schlangengift zu nehmenden die allgemeine Anerkennung gefunden hat, nämlich hinter dem Alkohol, der hierbei als kräftiges, durch ähnliche Stoffe nicht genügend zu ersetzendes Stimulans wirkt. Ehe seine Anwendung gegen Schlangenbiss allgemein wurde, war derselbe schon lange in Dalmatien gegen Vipernbiss in Gebrauch. Er muss in grossen Quantitäten, bis zum Stadium des Rausches, resp. leichten Trunkenseins verabfolgt werden. Tiefe Trunkenheit ist jedoch $\mathrm{zu}$ vermeiden, da sie einen Zustand der Sedation, nicht der Excitation darstellt. Tief betrunkene Leute sind, wie die Erfahrung lehrte, wenn sie von Schlangen zufällig gebissen werden, nicht immun gegen das Gift. Der Einwand, der gegen die Anwendung von Alkokol erhoben wurde, dass nämlich das mit diesem gemischte Gift, wenn injicirt, schnell tödtlich sei, ist unberechtigt, da der Alkohol ja gar nicht als

3) Croft, Chem. News. XVIL. 1882. p. 165. 
chemisch auf das Gift wirkendes Antidot angesehen wird. Wenn häufiges Erbrechen das Verweilen des Alkohols im Magen vereitelt, so kann man vorsichtig Alkolıoldämpfe oder auch A ether inhaliren lassen oder Alkoholklystiere verabfolgen.

Auch die IVilden wissen die günstige Wirkung alkoholischer Mittel bei Schlangenbiss wohl zu schätzen. So gebrauchen die Indianer Mexikos einen Aloë-Branntwein (mescal), der durch Gährenlassen und nachherige Destillation des Saftes der Agave mexicana septentrionalis gewonnen wird und die Stärke eines $40 \%$ igen Spiritus hat ${ }^{1}$ ).

Statt des Alkohols kann man auch andere excitirende Mittel anwenden, namentlich Aether, starken Kaffee, starken heissen Thee, Campherinjectionen u. s. w. Paletta empfahl als diaphoretisch wirkendes Excitans besonders das Trinken ron Glüh we in.

Es hat übrigens auch nicht an Leuten gefehlt, welche die Anwendung von analeptischen Mitteln wenigstens bei allen schweren Fällen von Vergiftung durch Schlangenbiss gänzlich rerwarfen, weil sich bei Thierversuchen gezeigt hatte, dass jene Mittel durch Erhöhung des Blutdruckes eine ungeheure Steigerung der nach Schlangenbiss so häufig eintretenden hämorrhagischen Processe (Lungenblutung u. a.) hervorriefen ${ }^{2}$ ). Indessen stehen doch diese Resultate in einem solchen Widerspruche zu den Erfahrungen, welche man mit den Stimulantien bei von Giftschlangen gebissenen Menschen gemacht hat, dass es sichcrlich nicht gerechtfertigt ist, diese Mittel als schädlich bei Schlangenbiss zu erklären und deshalb ihre Anwendung zu unterlassen.

Zum Schlusse seien noch zwei Mittel, Atropin und Coffeïn, erwähnt, die in Thierversuchen zum Theil mit Erfolg benutzt wurden ${ }^{3}$ ). Das erstere wurde gewählt, weil es

1) Naphegyi, Philad. med. and. surg. Rec. XVIII. 12. p. 249. March 1868.

2) F'eoktistow, Mém. de l'Acad. des scienc. de St. Pétershourg. T. XXXV1. 188\%. No. 4.

") A ron, \%eitschr. f, klin. Med. VI. 188:3. S. 382 u. 385 5. 
gegen das ähnlich wie Schlangengift auf Herz und Athmung wirkende Morphium als Gegenmittel gegeben wird; es erregt heftig das Gehirn, wirkt indirect erregend auf die Herzaction durch vorübergehende Lähmung der hemmenden Vagusendigungen, steigert dadurch gleichzeitig den Blutdruck, und beschleunigt endlich auch die Athmung durch directe Erregung des Respirationscentrums in der Medulla oblongata. Alle diese Wirkungen entsprechen allerdings denen, welche ein ideales Gegenmittel gegen Schlangengift besitzen müsste. Indessen erreichte man mit dem Atropin nur, dass zwar die Herzaction der damit behandelten Thiere eine regere zu sein schien, der Tod aber nur in einem Falle dadurch hinausgeschoben wurde.

Das ähnlich wie Atropin wirkende $\mathrm{C}$ of fe ïn liefert leider auch keine besseren Resultate.

Als neuestes innerliches Antidot gegen Schlangengift wird auf Grund nur eines Falles das Cocaïn bezeichnet ${ }^{1}$ ). Bei einem von einer Kreuzotter Gebissenen wurde, nachdem bereits schwere Erscheinungen eingetreten waren, 1/4 Spritze einer 5\% $\%$ igen Cocaïnlösung subcutan eingespritzt, und der Kranke gerettet. Da ausser dem Cocaïn keine anderen Medicamente angewandt waren, so meinte man, dasselbe müsste in diesem Falle als Antidot gegen Schlangengift gewirkt haben, bedenkt aber dabei nicht, dass Kreuzotterbisse selbst nach Eintritt schwerer Symptome in der Regel doch noch von selbst in Heilung übergehen, und dass ausserdem in dem betreffenden Falle dem Gebissenen zugleich Wein, schwarzer Kaffee etc. verabreicht worden waren. Das Vorstehende ist selbstverständlich keineswegs geeignet, dem Cocaïn den Charakter eines Antidotes zu geben.

\section{Pflanzliche Mittel.}

Von allen Heilmitteln gegen Schlangenbiss haben von dem frühesten Alterthum an bis in die neueste Zeit die Pflanzen ohne Zweifel die grösste Bedeutung gehabt und haben sie in den Tropen zum Theil auch heute noch. Zahllos ist in allen

1) Harlander, Wiener med. Presse. XXXVII. 1893. S. 1455. 
Länderu. in denen überhaupt Giftschlangen vorkommen, und zwar besonders in Ostindien und Südamerika, die Menge derjenigen Pflanzen, welche als specifische Gegenmittel gegen den Schlangenbiss empfohlen worden sind, und manche von ihnen, bei denen häufig schon die Namen, wie Schlangenwurzel, Schlangenholz. Serpentina, Dracontium, Dracunculus ete., aut' den Zweck ihres Gebrauches hinweisen, hatten als unfehlbar eine allgemeine Berühmtheit erlangt. Nachdem aber unbefangene Beobachtungen und wissensehaftliche Untersuchungelı ergeben haben, dass von den bekanntesten und am häufigsten angewandten Pflanzen keine einzige als sicheres Heilmittel gegen Schlangenbiss zu betrachten ist, und dass auch die viel gerühmte Mikania Guaco kein Specificum ist, so hat sich gegrenwärtig ärztlicherseits die Anwendung von Pflanzen in der Therapie des Sehlangenbisses vermindert, und man überlässt es selbst in den Tropenländern meistens nur noch den Eingeborenen, die Gebissenen mit Pflanzenpräparaten zu behandeln. Fast überall sind die letzteren durch die chemischen Mittel verdrängt worden.

Diese Missachtung der Pflanzen ist aber durchaus nicht gereehtfertigt, denn wenn auch viele von ihnen, namentlich im Alterthum und Mittelalter, nur aus reinem Aberglauben angewandt wurden, z. B. weil sie die "Signaturen" von Schlangen trügen, $d . h$. weil ihre Wurzeln sehlingenförmig gekrümmt wären, oder ihre Dornen Vipernzïhnen glichen, oder ihre Blüten in der Zeichnung Vipernköpfen oder -zungen ähnlich sähen u. dgl,, so sind doch, wie wir später seleu werden, viele Pflanzen darunter, welche durch ihre Wirkung als I Diuretica. Diaphoretica, Purgantia und Emetica die Ausscheidung des Schlangengiftes aus dem Körper befördern oder durch ihre stimulirende Wirkung die Herzthätigkeit und dire Athmung aufrecht erhalten können, bis durch die Elimination des Gijtes jerle Gefahr vorüber ist. Jedenfalls ist nicht \%u bezweifeh. dass derartig wirkende Pflanzen als physiologische Giegenmittel hei Vergiftung durch Sehlangenlisiss ausge\%ciehnete Dicnste Jeisten kömnen. Freilich angeblich sperifisch 
wirkende Pflanzen sind bisher in Europa noch nie in rationellen Versuchen als solche erkannt worden. Es ist aber auch hervorzuheben, dass derartige Experimente bisher nur ganz vereinzelt angestellt wurden, und dass es ein Postulat ist, diejenigen Pflanzen, die von Reisenden als Antidota gerühmt und von den Eingeborenen tropischer Länder gebrancht werden, dem Laboratoriumsversuche zu unterwerfen. Erst nach solchen Prüfungen wird sich beurtheilen lassen, in welchem Umfange Wahrheit oder Aberglaube bei der Beurtheilung solcher tropischer Pflanzen eine Rolle spielen.

Ich habe mich im Folgenden bemüht, möglichst alle Pflanzen aufzuzählen, welche jemals als Mittel gegen Schlangenbiss gebraucht worden sind und noch jetzt gebraucht werden. Von den im Alterthum angewandten Pflanzen habe ich alle diejenigen berücksichtigt, welche sich überhaupt nit einiger Sicherheit bestimmen lassen. Auch von den in der Neuzeit gebrauchten Pflanzen hoffe ich keine irgendwie wichtigere übergangen zu haben, obwohl es sehr wohl möglich ist, dass in dieser oder jener Reisebeschreibung noch Pflanzen erwähnt werden, deren Anwendung gegen Schlangenbiss in den von mir benutzten Werken mit Schweigen übergangen ist.

\section{Ramunculacece.}

Die Pflanzen dieser Familie spielen in der Therapie des Schlangenbisses nur eine untergeordnete Rolle; auch im Alterthum gebrauchte man nur wenige von ihnen.

Nigella sativa L., Schwarzkümmel, von Plinius ${ }^{1}$ ) als Gith, Melanthion, Melaspermon angeführt, legte man mit Essig und Honig zusammen auf die Bisswunde. Die Samen der Pflanze, früher als Semen Nigellae s. Melanthii officinell, enthalten ein ätherisches Oel, einen glycosidähnlichen Körper, zwei Alkaloide und ein Glycosid Melanthin. Die Wirkung ist vorzugsweise eine diuretische. Das Hauptalkaloid, Nigellin genannt, bewirkt bei intravenöser Injection grösserer

$\left.{ }^{1}\right)$ Plinius, Hist. nat. XX. 71. 
Mengen eine Curare-artige Lähmung: hohe Dosen lähmen den Herzmuskel. erregen ähnlich dem Pilocarpin Speichel- und Thränenfluss und rufen Anfälle von Athemnot hervor. Das zweite Alkaloid, Conigellin, bewirkt ebenfalls Herzlähmung ${ }^{1}$ ).

N. aristata Sm. ist die von den Alten ${ }^{2}$ ) als Cuminum oder Cuminum silvestre bezeichnete Pflanze, welche wohl ähnlich wie die vorige wirkt.

Paeonia officinalis L. (P. peregrina Mill.). die Glrkyside. Paeonia. Pentorobos des Plinius ${ }^{3}$ ). Man gab die schwarzen Samen der Pflanze in Wein. Dieselben enthalten ausser anderen Bestandtheilen auch ein Alkaloid.

P. corallina Retz. wurde ebenso gebraucht und ebenso bezeichnet wie die vorige Art.

Delphinium Staphisagria L., die Staphis oder Astaphis der Alten. Die zerriebenen Blüthen sollen nach Plinius ${ }^{4}$ ) mit Wein innerlich und äusserlich angewandt werden.

Von auch in neuerer '/eit angewandten Pflanzen sind zu nennen:

Helleborus antiquorum Braun, der Helleborus melas des Hippokrates und

H. niger L.. die schwarze Nieswurz, deren Wurzel früher officinell war $^{5}$ ).

Die Wurzeln und Wurzelblätter der Gattung Helleborus eathalten neben fetten () elen, scharfen Harzen und anderen Stoffen als wesentliche Bestandtheile die beiden Glycoside Helleboreïn und Helleborin. Das Helleboreïn ist ein Herzgift (2-4 dg tödten Kat\%en in 2-5 Stunden) und wirkt wie Digitaliı. Ausserdem wirkt es auf den Darm als Drasticum, auf die Respiration, die Secretionsorgane, besonders Speicheldrüsen und Nieren, und auf das Nervensystem in der

1) Pellaciani, Arch. f. Experim. P'athol. 11. Pharmakol. XVl. $188 \%$.). S. $44 \%$.

2) Plinius, Hikt. nat. $\mathrm{XX} .57$.

3) Ihisl. XXVII, 60 .

4) It,id. XXIII. 1:?.

7) liamette d. Santr. 5. Nov. 182.2. 
Art, dass sich lähmungsartige Schwäche und Convulsionen einstellen. Die örtliche Wirkung ist eine irritirende. Das Helleborin dagegen hat narkotische Eigenschaften und tödtet durch Lähmung der Nervencentra. Auch auf den Darm wirkt es ein, doch schwächer als Helleboreïn.

In Nordamerika ${ }^{1}$ ) gebrauchte man früher und vielleicht auch noch jetzt bei Schlangenbiss:

Actaea racemosa L, welche die dort officinelle, sehr bittere Radix Cimicifugae Serpentariae liefert, sowie einige Arten der Gattung Thalictrum. Das in einigen derselben enthaltene Thalictrin wirkt dem Aconitin ähnlich, jedoch weit schwächer und mehr lähmend, aber weniger brechenerregend und Athemstörung herrorrufend. Die Diurese wird angeregt.

Ranunculus repens L. und andere Arten der Gattung Ranunculus. In derselben scheint bei vielen Arten das Anemonin vertreten zu sein, welches eine lähmende Wirkung auf Gehirn und Medulla oblongata ausübt.

Aconitum ferox Wall., Mahoor (Hind.), Vashanari (Tam.) gilt in Indien als Mittel gegen Schlangenbiss ${ }^{2}$ ). Die Pflanze enthält ebenso wie Aconitum Napellus und andere Aconitum-Arten giftige Basen. Das Extract bewirkt Athemnoth, Schwäche, Lähmung, die bei den Hinterextremitäten beginnt, Schwindel, Convulsionen, Pupillenerweiterung und Tod durch Asphyxie.

\section{Magnoliaceae.}

Drimys granatensis L. ist in Südamerika, besonders in Columbien, unter den Namen Malambo, Bejuco de Guayaquil, Canelo de la costa als Mittel gegen Schlangenbiss bekannt ${ }^{3}$ ).

$\left.{ }^{1}\right)$ Schöpf, Reisen durch einige der mittleren und südlichen Vereinigten nordamerikanischen Staaten nach Ostflorida und den Bahamainseln. Erlangen 1788. Bd. I. S. 191.

$\left.{ }^{2}\right)$ D rury, The useful Plants of India. 2. ed. London 1873. p. 12.

${ }^{3}$ ) Saffray, Voyage à la Nourelle Grenade (in le Tour du monde, t. XXIV. p. 98). 


\section{Menispermacere.}

Aus dieser Familie werlen in Südamerika und in Ostindien folgende Pflanzen gregen Schlangenbiss angewandt:

Cissampelos glaberrima St. Hil., „Erva de Nossa Senhora", "Sipo de cobras", in Brasilien ${ }^{1}$ ).

C. ebracteata St. Hil. (C. ovalifolia D. C.) in Brasilien

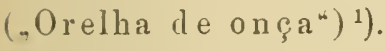

C. Caepeba L. in Südamerika.

C. convolvulacea Willd. (C. Pareira L.) in Südamerika und Ostindien ${ }^{2}$ ).

Die gegen Schlangenbiss benutzten Wurzeln der Cissampelos-Arten wirken diaphoretisch und diuretisch.

Cocculus Filipendula Mart., "Abuta miuda", in Brasilien $\left.{ }^{1}\right)$.

C. acuminatus D. C. (hindustanischer Name: bag a mushadee) in Ostindien (Stengel) $²$ ).

Abuta rufescens Aubl. (Cocculus Pahni Mart.) in Guyana (Wurzel und Stengel) ${ }^{3}$ ).

Die angeführten Arten der Familie scheinen bisher nicht genauer chemisch untersucht zu sein. Vielleicht enthalten die Cocculus-Arten. wie die bekannte Colombo-Wurzel (Jateorrhiza palmata Viers., Cocculus palmatus Wallich.), in ihren Wurzeln den Bitterstroff Columbin und die Columbosïure, oder in ihren Fruchtlemen, wie die Kokkelskörner (Anamirta Cocculus IVight u. Arnod, Cocculus suberosus Dec.), das als Hirnkrampfgift wirkende Pikrotoxin.

T'iliacora acuminata (Miers.), Bagaluta (Hind.), 'Tilia-kora (Beng.), Vullycaniram (Mal.), wird in Indien zwischen zwei Steinen \%erriehen und mit Wasser gemischt bei Schlangenbiss angewandt').

1) v. Martius, Syst, mat. med, veget. Brasil. 184:3. 1, 42.

2) Waring, Madras Quart. Journ. of Med. Se. IV. p.5.

") Lanessan, las plantes utiles des colonies françases. Paris $18 \times 6$. [5. 394.

4) Drury 1. (2. [1. 427. 


\section{Berberidaceae.}

Von Leontice Leontopetalum L. gebrauchte man im Alterthum die Wurzel gegen Schlangenbiss.

\section{Papaveraceae.}

Paparer somniferum L. Mohnsaft resp. Opium wurde von Avicenna, Mercurialis, Grevinus und selbst noch in der ersten Hälfte dieses Jahrhunderts als Mittel gegen Schlangenbiss empfohlen, obwohl der wesentlichste seiner Bestandtheile, das Morphium, anstatt der entgegengesetzten fast die nämlichen Wirkungen wie das Schlangengift hervorruft. Auch die rerschiedenen Arten von Theriak enthielten als Hauptbestandtheil fast immer Opium, das Meconium der Alten.

P. Argemone L. wird als Argemonia ron Celsus ${ }^{1}$ ) und Apulejus Platonicus ${ }^{2}$ ) gegen Schlangenbiss gerühmt.

Chelidonium majus L. wird von Plinius ${ }^{3}$ ) als Mittel gegen Schlangenbiss erwähnt. Wurzel und Kraut waren früher officinell und wurden namentlich bei Stockungen im Pfortadersystem gebraucht. Die Pflanze enthält ausser anderen Stoffen in ihrer Wurzel die Alkaloide Chelidonin, $\alpha$-Homochelidonin, $\beta$-Homochelidonin, Chelerythrin und Protopin.

Sanguinaria canadensis L. Ein Decoct der Wurzel dieser Pflanze wird in den Vereinigten Staaten gegen Schlangenbiss und auch sonst als Emeticum, Expectorans, Diaphoreticum, Purgans und Stimulans angewandt. Die Wurzel ist dort als blood-root oder Puccoon bekannt ${ }^{4}$ ). Sie enthält die

1) Celsus, De medicina. V. cap. 27.

$\left.{ }^{2}\right)$ Apulejus Platonicus, De viribus herbarum.

$\left.{ }^{3}\right)$ Plinius, Hist. nat. XXV. 56.

4) Schöpf, Materia medica americana. 1787. 
Alkaloide Sanguinarin. $\beta$-Homochelidonin, Chelerythrin und Protopin ${ }^{1}$ ).

Argemone mexicana L. wird auf Martinique gegen den Biss der Lanzenschlange gebraucht und hat eine diaphoretische Wirkung ${ }^{2}$ ).

Die Papareraceenalkaloide sind neuerdings ron H. Meyer.3) untersucht worden. Danach scheint es, als ob das Protopin, das sich auch im Opium und wahrscheinlich auch in Macleya cordata findet, von allgemeiner Bedeutung für die ganze Familie ist. Es erregt die psychische Sphäre und führt in grösseren Dosen Krämpfe und Tod durch Erstickung oder Erschöpfung herbei. Herz und Gefässnervencentrum werden gelähmt, die Athmung aber wird nicht beeinflusst.

Das Chelidonin liefert bei Oxydation mit Kaliumpermanganat dieselben Producte wie Morphium, so dass man auf eine gewisse Verwandtschaft dieser beiden Alkaloide schliessen kann. Auch seine Wirkung ist eine dem Morphiun ähnliche narkotische. Es lähmt das centrale und einen Theil des peripherischen Nervensystems. Die Pulsfrequenz wird herabgesetzt. der Blutdruck fällt zuerst, steigt dann wieder zur Norm an; bei grossen Dosen sinkt er stetig. Die Herzthätigkeit wird durch Narkose der motorischen Ganglien und durch Erregung der Vagus-Endigungen im Herzen gelähmt.

Das g. - Ho mochclidonin wirkt fast wie Chelidonin. Es ruft morphiumartige Narkose und Analgesie, absteigende Paralyse, Läihmung der sensiblen Nervenendigungen und der motorischen Herzganglien hervor.

Beim ק-Homochelidonin sind, ähnlich wie beim Protopin, die narkotischen Wirkungen schwäicher, die krampferregenlen stäirker. Es wirkt örtlich stark anästhesirend.

1) Ceber die Alkalojde der Wurzel von Sanguinaria s. Koenig, Inaug.-Diss. Marburg 1890 und 'T'ietz, Inaug.-Diss. Narburg 1891.

2) Riuf\%, linquîte. p. 131 .

3) H. Wey॰r, Archiv fur experim. Pathologie und Pharmakologie. XXIX. 1892. S. 397. Vgl. auch E. Sch inidt, Archiv der Pharmacie. ('CXXVII. 1890. S.96. CCXXXI. 1893. S. 136. 
Das Sanguinarin ist ein heftiges Gift, besonders für die nervösen Centralorgane. Es erhöht stark die Reflexerregbarkeit, verursacht in grossen Dosen Krämpfe mit schnellem Uebergang in Lähmung und Speichelfluss. Die Athemfrequenz ist anfangs erhöht und sistirt plötzlich bei letalem Ausgange. Der Blutdruck ist ohne wesentliche Aenderung der Pulsfrequenz erhöht, bei starken Dosen aber herabgesetzt durch Lähmung des Gefässnervencentrums.

Das Chelerythrin endlich bewirkt absteigende motorische Paralyse und Tod durch Athemlähmung. Grosse Dosen lähmen auch die Herzaction und die vasomotorischen Centren. Dem Chelerythrin wird meistens die Schuld an der Giftigkeit des Chelidonium majus zugeschrieben, indessen ist es darin in nur ganz minimalen Mengen enthalten. Die Schärfe der Pflanze beruht vielmehr auf in ihrem gelben Milchsafte befindlichen, vermuthlich harzartigen Stoffen. Das trockene Kraut. ist unwirksam und unschädlich.

\section{Cruciferae.}

Die wenigen gegen Schlangenbiss angewandten Pflanzen dieser Familie sind im Wesentlichen folgende:

Sin a p is alba L. Der Senf wurde, mit Essig abgerieben, auf die Bisswunde gelegt ${ }^{1}$ ). Die Samen enthalten ausser anderen Stoffen das Alkaloid Sinapin und das Glycosid Sinalbin.

Brasica Rapa L. (Rapo der Alten). Die Samen wurden aufgelegt und in Wein getrunken ${ }^{2}$ ).

Lepidium sativum L.

Isatis tinctoria L. (Isatis sativa, Angion, Arufion, Gluta, Glastum) ${ }^{3}$ ). Die Pflanze enthält Indican.

Raphanus sativus L. ${ }^{4}$ ).

1) Plinius, Hist. nat. XX. 87.

2) Ibid. XX. 9.

$\left.{ }^{3}\right)$ A pulejus Platonicus l.c.

4) Petrus de Abano, De venenis. 1473. 
Alyssum spinosum L. ${ }^{1}$ ) (s. Echium vulgare).

Ausser diesen Arten werden von alten Autoren noch einige nicht genauer zu bestimmende Cruciferen erwähnt, wie Nasturtium, Lepidium, Iberis, Thlaspi, Eruca.

\section{Cappuridaceue.}

Capparis spinosa L. wurde nur aus dem Grunde angewandt, weil die Dornen den Vipernzähnen ähnlich wären ${ }^{2}$ ).

\section{Violacere.}

Viola ovata Nutt. Ein Infus der Pflanze wurde von Williams empfohlen ${ }^{3}$ ).

\section{Bixineae.}

Von Flacourtia sepiaria Roxb., Courou moelli (Mal.), Sottacla (Tam.), giebt man in Indien innerlich ein Infus der Blätter und Wurzel ${ }^{4}$ ).

\section{Polyyalaceae.}

Polygala Senega L. ("rattle-snake root"). Die Senegawurzel führen die Seneka-Indianer in Nordamerika überall, wo sie von einer Schlange gebissen zu werden fürchten, bei sich, streuen, sobald sie gebissen sind, etwas von der gepulverten Wurzel in die Wunde und nehmen auch eine geringe Menge davon ein 5). Der Gebrauch der Pflanze gegen Schlangenbiss wurde im Jahre 1735 durch John Tennant bekannt, der das Geheimniss von den Indianern erfahren hatte $\left.{ }^{6}\right)$. Die Wurzel enthält als wirksamen Bestandtheil ein Saponin, welches exprectorirende Eigenschaften hat, in grösseren Dosen

1) Schöpf, Reisen.

2) Kedi, Observationes do vipera. 1729.

3) Williams, Journ. de chim. méd. Nov. 1834.

4) Uheede, Hort. Malabar. V. 77.

s) Sschöp f. c.

") Harton, Vegetable Mat. man, of the L'nited States, 1817/18. Vol. II. 
aber das Herz, das vasomotorische und das Athmungscentrum lähmt. Die darin enthaltene Quillajasäure ist ein Protoplasmagift, indem sie lebendes Protoplasma in todtes verwandelt und die rothen Blutkörperchen auflöst. Diese Wirkung zeigt sich aber nur bei subcutaner Injection der Säure, innerlich genommen ist sie unwirksam ${ }^{1}$ ). Von geringerer Bedeutung sind:

Polygala purpurea Nutt.,

P. sanguinea L., welche in Nordamerika gegen Schlangenbiss gebraucht werden, und

P. crotalarioides Roxb., die in Vorderindien zu demselben Zwecke angewandt wird ${ }^{2}$ ).

\section{Caryophyllaceae.}

Plinius ${ }^{3}$ ) empfiehlt den Samen der feuerrothen Lychnis in Wein abgerieben zu trinken, womit er vielleicht die südeuropäische Agrostemma coronaria L. meint.

Auch in neuerer Zeit scheinen die Pflanzen dieser Familie nur sehr selten gegen Schlangenbiss angewandt worden zu sein. Die einzige $\mathrm{zu}$ ermittelnde Art ist

Polycarpaea spadacea Lam. in Vorderindien ${ }^{1}$ ).

\section{Portulaceae.}

Portulaca oleracea L. (Porcillaca, Peplis) wurde in Alterthum gegen die Bisse des Haemorrhus und Prester gegessen und aufgelegt ${ }^{5}$ ).

\section{Hypericineae.}

Das von älteren Autoren empfohlene Hyperikon oder Hyperion ist vielleicht identisch mit Hypericum Coris L. S. 232.

${ }^{1}$ ) Kobert, Archir f. experim. Pathol. u. Pharm. XXIII. 1887.

2) Madras Quart. Journ. IV. p. 7.

$\left.{ }^{3}\right)$ Plinius, Hist. nat. XXI. 98.

4) Rheede, Hort. Malabar. X. I3I.

5) Plinius, Hist. nat. XX. 81. 
In Brasilien benutzt man ron Hypericum laxiusculum St. Hil. (Alecrim bravo") und H. connatum Lam. (. Orelha de Gato") ein Decoct der adstringirend wirkenden Blätter ${ }^{1}$ ).

\section{Guttiferae.}

Mesua ferrea L.. hindostanisch Nagasur. Blüthen, Blätter und Rinde werden in Indien innerlich und äusserlich als Pulver angewandt. Die Wirkung ist eine diaphoretische ${ }^{2}$ ).

\section{Halvaceae.}

Malven wurden bereits im Alterthum zuweilen bei schlangenbiss gebraucht. In der Neuzeit wendet man vou Malraceen an:

Hibiscus Abelmoschus L., Kala-kastoree (Hind.), Katta-kasturi (Mal.). Kathe-kasturi, Kasturi-venday. Vettlei-kustorei (Tam.) in Indien") und

Gossypium brasiliense Macf. auf Martinique "), und zwar hiervon ein Infus der Wurzel, von Hibiscus dagegen die an Pflanzenschleim reichen Samen innerlich und äusserlich.

\section{Lineae.}

Linum usitatissimum L. Leinsamen werden von Avicenna gegen Schlangenbiss empfohlen.

Erythroxylon anguifugum Mart. ( ${ }_{n}$ Fruta de $P\left(\mathrm{mba}^{\circ}\right)$. Man benutzt hiervon in Brasilien die Rinde der (Wurzel ${ }^{5}$ ).

Von Hugonia Mystax L., Modera canni (Mal.), I goore (T'am.). gebraucht man in hndien die zerquetschte Wurzel äusserlich und die Wurzelrinde innerlich $\left.{ }^{6}\right)$. Die

') v. Martius, Syst. mat. merl. Brasil. p. 116.

2) Madras Quart. Journ. IV. 1) 12.

3) Ibicl. 1). 11.

4) $\mathrm{K}$ u $\mathrm{z}$, knquites. p. 138.

5) v. If a rtius 1. c. 1. 73 .

') Khe hed r:, Hort. Malabir. 11. :3). 
Pflanze wirkt diuretisch, diaphoretisch, tonisch und stimulirend.

\section{Malpighiaceae.}

Von Byrsonima crassifolia H. B. Kth. (B. Moureila Loud.) wird in Guyana ein Infus der Rinde gegen Schlangenbiss angewandt ${ }^{1}$ ).

\section{Zygophylleae.}

Tribulus terrestris L. wird von Dioscorides als Mittel gegen Schlangenbiss erwähnt.

\section{Geraniaceae.}

Eine Oxalis war im Alterthum in Gebrauch 2).

Averrhoa Carambola L. wird in Indien ${ }^{3}$ ), und

Impatiens in mehreren Arten in Nordamerika benutzt ${ }^{4}$ ).

\section{Rutaceae.}

Ruta graveolens L. (Ruta, Peganum) wurde im Alterthum als Mittel gegen Schlangenbiss sehr hoch geschätzt und als solches von Dioscorides, Plinius, Celsus und Anderen empfohlen. Die Raute enthält ausser einem ätherischen Oele in ihren Blättern das Glycosid Rutin.

Der Gebrauch des

Dictamnus albus L. gehörte mehr dem Mittelalter als dem Alterthum an.

Citrus Limonum Risso. Schon Rhazes empfiehlt Citronensamen gegen Schlangenbiss, und noch gegenwärtig scheint der Citronensaft in den verschiedensten Ländern zu demselben Zwecke angewandt zu werden, so auf Martinique innerlich und äusserlich, ebenso wie die Wurzel

1) Rich. Schomburgk, Reisen in Britisch-Guyana, und Lanessan 1. c. S. 371 .

2) Scribon. Largus in Matthioli Commentarii.

3) Burman, Thesaur. Zeylanicus. p. 148.

$\left.{ }^{4}\right)$ Germer, Wöchentlicher Leuchtthurm von Erie. 23. Juli 1869. 
des Baumes gegen den Biss der Lanzenschlauge ${ }^{1}$ ), und auch in Paraguar ${ }^{2}$ ). Die Citronen enthalten Citronenöl, Citronensäure und in den Kernen das Glycosid Limonin.

Pilocarpus pinnatus Lam. Die Blätter dieser Pflanze, die Folia Jaborandi ${ }^{3}$ ), in Südamerika und zwar besonders in Brasilien schon lange als Mittel gegen Schlangenbiss bekannt und geschätzt, wurden erst 1874 näher bekannt. Sie enthalten als wirksame Bestandtheile neben einem ätherischen Oele zwei Alkaloide, Pilocarpin und Pilocarpidint). Beide bewirken hauptsächlich Vermehrung der Speichel- und Schweisssecretion, jedoch das Pilocarpin in weit stärkerem Grade als Pilocarpidin. Auch die Diurese wird gesteigert. Vielleicht ist die Beschleunigung der Giftausscheidung durch die Anregung der Drüsenthätigkeit als Ursache des Gebrauchs heranzuziehen.

Bergera Königii L. (Murraya Königii Spr.), Karibepon. Karreya-pela (Mal.), Carroova-pillay (Tam.), Karay-paak (Hind.). Rinde und Wurzel werden in Indien gegen Schlangenbiss gebraucht ${ }^{5}$ ). Vielleicht findet sich darin ebenso wie in den Blüthen von Murraya exotica das Glycosid Murrayin. Die Wirkung ist eine stimulirende und laxirende. Auch legt man die in Milch gekochten Blätter der Pflanze zerquetscht als Umschlag auf die Bissstelle ${ }^{6}$ ).

Von Aegle Marmelos Corr., Madja (Mal.), Môdjôh (Jav.). werden auf Java die Blätter, deren Saft laxirend wirkt, als Antidot bei Schlagenbiss angewandt ${ }^{7}$ ).

1) liufz, Enquête. p. 147, 193.

$\left.{ }^{2}\right)$ Rengger. Meckol's Arch. f. An. u. Whys. 1829. S. 271.

) Auch diıs ähnlich wirkende Pjper reticulatum I. führt in südamerika den Namen ${ }_{\pi} J a l$, or a $\mathrm{ndi}^{*}$.

4) F. Harnack, Arch. f. exprerin. Pathol. u. Tharm. XX. 1886. - 4.9 .4$.

8) Roxburgh, Flor. Inil. II. 374.

6) Drn ry l. c. p. 78 .

7) B івясhор, (irevelink, Planten van Nerlerlandsch-Indie. Aunsterliam 188:i. p. 481 . 


\section{Simarubaceae.}

Von Samadera indica Gaert. gelten in Indien die Blätter als Antidot gegen Schlangenbiss ${ }^{1}$ ). Die Pflanze enthält wahrscheinlich Quassiin.

Simaba Cedron J. F. Planch. Die Samenkörner der Pflanze sollen im Jahre 1828 von Indianern auf den Markt von Carthagena in Columbien gebracht, und ihre Wirksamkeit an Thieren, die man von Schlangen beissen liess, erprobt worden sein. Dieses Mittel fand in Folge dessen bald ein solches Ansehen in jener Gegend, dass der Preis für ein einziges Korn auf 83 Franken stieg. Herran, der das Mittel prüfte, sah ebenfalls nach innerlicher Anwendung von fünf bis sechs Körnern als Pulver günstige Erfolge. Nach Dumont dagegen sind die Körner nur, wenn einige Stunden vor dem Bisse genommen, im Stande die Wirkung des Giftes abzuschwächen, so dass nur Localerscheinungen auftreten, der Tod aber vermieden wird. Nach dem Bisse genommen sollen sie jedoch erfolglos sein ${ }^{2}$ ). Die Samen enthalten den intensiv bitteren Stoff Cedrin, der viele Analogieen mit Strychnin zeigt und ein starkes Gift ist. Die Früchte enthalten ebenso wie die Samen von Picrolemma Valdivia G. Planch. den Bitterstoff Valdivin, der noch giftiger ist als Cedrin, Hunde in Dosen von $0,006 \mathrm{~g}$ in $5-6$ Stunden tödtet und beim Menschen zu 0,004 $\mathrm{g}$ in einer Viertelstunde emetisch wirkt. Restrepo, der mit beiden Stoffen Versuche anstellte, fand dieselben erfolglos bei Hunden und Kaninchen ${ }^{3}$ ).

\section{Burseraceae.}

A m y ris Gilia densis L. wird in Aegypten bei Schlangenbiss gebraucht ${ }^{4}$ ).

1) Rheede, Hort. Malabar. VI. 32.

2) Rufz, Enquête. p. 297.

$\left.{ }^{3}\right)$ Restrepo, Etudes du Cédron, du Valdivia et de leurs principes actifs, la cédrine et la valdivine. Thèse, Paris 1881.

4) A inslie, Mat. med. ind. I. 27. 
Balsamodendron africanum Arn. in Senegambien und

B. Mukal Hook. in Indien liefern ein früher zur Bereitung ron Pflastern benutztes Gummiharz. Bdellium, das rom Alterthum bis in die neueste Zeit eine ausgedehnte Verbreitung in der Behandlung des Schlangenbisses gefunden hat.

B. Myrrha Nees liefert das Myrrhenharz, und mehrere Arten ron

Boswellia das Olibanum (Weihrauch), welche beide ebenfalls zur Heilung des Schlangenbisses gebraucht wurden.

\section{Celastrineae.}

Von Elaeodendron Roxburghii W. et A. gilt die Wurzel in Indien als ausgezeichnetes Mittel gegen Schlangenbiss. Die mit Wasser geriebene Wurzelrinde soll äusserlich angewandt fast jede Schwellung beseitigen. Die Wirkung ist eine sehr stark adstringirende ${ }^{1}$ ).

\section{Rhamneae.}

Paliurus australis Gaertn. (Kizyphus Paliurus Willd.) wurde nur selten benutzt.

Ampelidiceate.

Vitis vin ifera L. Der Genuss von Weintrauben wurde in Alterthum auch für heilsam gegen den Schlangenbiss erachtet.

\section{Sapindaceue.}

Sapindus trifoliatus L., Ritha (Hind.), Pounitukottai ('Tam.) in Südindieu. Man benutat die Pulpa der Frucht. in der $z u 11, \pi n_{n}$ Saponin enthalten ist. Die reifen Fruchte enthalten üher $10{ }^{\circ}$ G Glucose und etwas Pectin. Der Destillation unterworfen zeigt die Drogue eine Substanz, die der Buttersïure gleicht ${ }^{2}$ ).

') Jury l. r. p. 190.

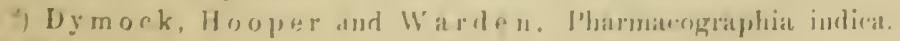
II 1. 3.t; 8 


\section{Aceracear.}

A c e r N e g u n d o L. wird in Nordamerika gegen Schlangenbiss angewandt. Der Saft ist wie auch bei anderen Ahornarten stark zuckerhaltig.

\section{Anacardiacene.}

Pistacia vera L. Die von Plinius ${ }^{1}$ ) empfohlenen Fruchtkerne, die sogenannten Pistacien, enthalten ein süsses, fettes Oel.

\section{Leguminosae.}

Von in früheren Zeiten benutzten Leguminosen sind $\mathrm{zu}$ nennen:

Psoralea bituminosa L. (Triphyllon, Trifolium bituminosum).

Lupinus hirsutus L. und

L. angustifolius L. (Lupini silvestres). Die Lupinen enthaiten Alkaloide (Lupinin u. a.).

Cicer arietinum L. (Cicer silvestre).

Glycyrrhiza glabra L. (Liquiritia) enthält in ihrer Wurzel das Glycosid Glycyrrhizin, das purgirend wirkt.

Ferner Arten von Astragalus, Orobus, Medicago, Trifolium.

In der Neuzeit werden folgende Arten gegen Schlangenbiss gebraucht:

Pongamia glabra Vent. in Indien (Saft der Blätter) ${ }^{2}$ ).

Erythrina Corallodendron L. auf Martinique ${ }^{3}$ ). Der Baum enthält ein narkotisches Alkaloid.

Mucuna mutisiana D.C. in Neu-Granada ( ojo de venado", Hirschauge) und Brasilien ("Mucuna Guaca“) ${ }^{4}$ ). Trifolium lupinella ${ }^{5}$ ).

1) Plinius, Hist. nat. XXIII. 78.

$\left.{ }^{2}\right)$ Rheede, Hort. Malabar. VI. 6.

$\left.{ }^{3}\right) \mathrm{Rufz}$, Enquête. p. 117.

4) Saffray l. c.

5) De Rose, Gaz. Méd. 1846. p. 562. 
Cassia occidentalis L., Kasondi, Gajarság, Sarikasondi (Hind.). Ponna-virai, Pera-virai (Tam.),

C. ala ta L., Veleytie Aghatia (Hind.), Wandukolli, Seemee Aghatie (Tam.) und

C. Sophera L. in Indien. Die Blätter und Wurzeln dieser Pflanzen werden mit schwarzem Pfeffer gegen Schlangenbisse gebraucht. Die von C. Sophera enthalten in den wässrigen Lösungen des alkoholischen Extractes eine harzige Substanz und ein bitteres Princip, das nicht alkaloider Natur ist ${ }^{1}$ ).

Indigofera tinctoria L.,

I. Anil L. und andere Indigoarten werden ebenfalls in Indien bei Schlangenbissen angewandt.

Guilandina Bonducella L., Caesalpinia Bonduc Roxb., A rachis hypogaea L. und A cacia Farnesiana Willd. auf Martinique ${ }^{2}$ ).

A. Seeressa Roxb. (Albizzia Lebbek Benth.), Siris (Hind.), Katturagai (Tam.) in Indien (Rinde) ${ }^{3}$ ).

Uraria picta Desv., Dábrá (Hind.), Sankar-jata (Beng.) soll ein Antidot gegen die Phoorsa-Schlange (Echis carinata) in Indien $\left.\operatorname{sein}^{4}\right)$.

Von Butea frondosa Roxb., Palás, Dhak (Hind.), Purashu, Murukkan-maram (Tam.), gebraucht man in Indien die Rinde zusammen mit Ingwer bei Schlangenbiss. Durch Aether lïsst sich aus Butea-Gummi eine geringe Menge Pyrocatechin entfernen ${ }^{5}$ ).

Von B. superba Roxb., Palís-lata (Hind.), Kodimurukkan (Tam.), benutzt man in Indien die Wurzel mit gleichen Nengen der Wurzeln von Nyctantlies und Woodfordia floribunda, den Samen von Cassia T'ora und Vernonia anthelminthica, und dem Stengelsaft von 'T'ri-

1) Pharmacographia indica. II. p. 520. - Drury I. e. p. 119.

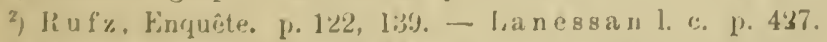

3) Madras Quart. Journ. of Med. Sc. IV. [1. 14.

4) by mock, Veg. Vat. med. of Western Indial. p. 181.

s) Pharnacregraphis indira. II. 1. 454.

lirenning, the Vergifungen durch Sohlang"th. 
chosanthes palmata mit Kuhurin zu einer Paste verarbeitet äusserlich, und zugleich Aristolochia indica innerlich ${ }^{1}$ ).

Euchresta Horsfieldii Bennet, Prono Djiwa (Jav.) gilt auf Java als Heilmittel gegen Schlangenbiss ${ }^{2}$ ).

\section{Rosaceae.}

Im Alterthum werden von den Rosaceen angehörigen Pflanzen folgende erwähnt: Agrimonium, Pentaphyllum oder Quinquefolium (eine Art der Gattung Potentilla), Rosa, Rubus oder Eruscus (vielleicht Rubus fruticosus L.).

In der neueren Zeit scheint nur eine Rosacee gegen Schlangenbiss Anwendung gefunden zu haben, nämlich:

Spiraea trifoliata L. in Nordamerika.

\section{Saxifragaceae.}

Ribes nigrum L., die schwarze Johannisbeere, soll in Nordamerika als Mittel gegen Schlangenbiss gelten.

\section{Combretaceae.}

Calycopteris floribunda Lam. in Indien, Assam etc., hindustanischer Name Kokoranj. Man gebraucht die Wurzel mit der von Croton oblongifolium als Paste gegen den Biss der Phoorsaschlange (Echis carinata) ${ }^{3}$ ).

\section{Myrtaceae.}

Punica Granatum L. Die Wurzeln werden von Avicenna als Mittel gegen Schlangenbiss erwähnt.

\section{Lythrarieae.}

Lythrum Salicaria L. wird von den Alten als Lysimachia ${ }^{4}$ ) bei Schlangenbiss empfohlen.

1) Pharmacographia indica. II. p. 458.

2) Bisschop Grevelink l. c. p. 70 .

3) Pharmacographia indica. III. p. 15.

4) Plinius, Hist. nat. XXV. 55. 


\section{Cucurbitaceae.}

Im Alterthum bediente man sich ron Pflanzen dieser Familie, wie es scheint, nur der Gurke, Cucumis sativus L., und einer Bryonia, wahrscheinlich der Bryonia cretica L., in der Therapie des Schlangenbisses.

Bryonia umbellata Rottl. wird in Indien benutzt ${ }^{1}$ ). $\mathrm{Ob}$ die Wurzel dieser Pflanze ebenfalls das in derjenigen von B. alba L. entdeckte Glycosid Bryonin enthält, ist zweifelhaft.

Luffa echinata Roxb.; hindustanische Namen: Kukarlata, Bindál, Ghagar-bel, Deodáil. Der Inhalt der Frucht wird in Indien als Infus gegen Schlangengift gebraucht. In der Frucht ist ein Stoff, der dem Colocynthid in verwandt ist. Er verursachte, einer Katze eingegeben, Erbrechen. blutigen Stuhl, Pupillenerweiterung, Contractionen der Bauchmuskeln, Lähmung der hinteren Extremitäten, darauf Convulsionen derselben, spasmodisches Athmen, und führte schliesslich den Tod des Thieres herbei. Ferner findet sich darin noch ein anderer Stoff "Luffe ïn" ${ }^{2}$ ).

Cucumis Colocynthis L. Hiervon werden ebenfalls die Früchte, die Coloquinthen, welche das drastisch wirkende Glcyosid Colocynthin, sowie noch einen anderen Stoff, das Colocynthidin, enthalten, in Indien angewandt ${ }^{3}$ ).

Fevillea cordifolia L. Die Früchte gelten auf Martinique als Antidot gegen Schlangenbiss ${ }^{4}$ ).

Corallocarpus epigaeus Hook, Akasgadda, Chhilihinda, Garaj-phal (Hind.), Akásha-garudan, Gollankovaik-kizhangu (Tam.). Die Wurzel der Pflanze wird in Indien innerlich und äusserlich gebraucht; sie enthält ein dem Bryonin gleichendes bitteres Prinzip ${ }^{5}$ ).

Cayaponia Cabocla Mart. ( "Purga do Gentio",

1) Lanessan I. c. p. 596 .

3) Pharmacographia indicas. III. 1.81 fl.

s) Sonnerat, Voyages. II. 54. (Madras Quart. Journ. IV. p. 14.)

4) I. an cessan I. c. 1. 480 .

") Pharmacograplitia indice. III. p.90 ff. 
"Purga do Caboculo"). Man benutzt in Brasilien ein drastisch wirkendes Infus der Wurzel oder Frucht ${ }^{1}$ ). Der wirksame Bestandtheil soll das Cayaponin sein.

Cucurbita Lagenaria L. wird auf Martinique mit anderen Pflanzen zusammen gegen Schlangenbiss angewandt ${ }^{2}$ ). Die Früchte sind zuckerhaltig.

\section{Umbelliferae.}

Die Familie der Umbelliferen gehört zu denjenigen, von denen im Alterthum und Mittelalter eine grosse Zahl von Pflanzen gegen Schlangenbiss im Gebrauch waren, welche jetzt dagegen für diesen Zweck fast ausnahmslos obsolet sind. Die Früchte vieler Pflanzen dieser Familie zeichnen sich durch einen reichen Gehalt an ätherischen Oelen aus, manche enthalten Glycoside und campherähnliche Körper. Die Wurzeln vieler Gattungen sind reich an Gummiharzen, Säuren, Bitterstoffen und Farbstoffen. Einzelne Pflanzen enthalten auch Alkaloide.

Die am neisten benutzten Pflanzen sind folgende:

Eryngium campestre L.,

E. marmitimum L. und

E. planum L. Von diesen 3 Arten nahm man die viel Schleim enthaltenden und purgirend wirkenden Wurzeln in Wein. Der alte Name ist Erynge oder Eryngion.

E. campestre wird noch jetzt in Venezuela gebraucht (s. Echium vulgare), ebenso Eryngium aquaticun L. und Sanicula canadensis L. in Nordamerika.

Petroselinum sativum Hoffm. wird von Apulejus Platonicus ${ }^{3}$ ) erwähnt. Die Petersilie, deren diuretische Wirkung lange und allgemein bekannt ist, enthält einen Campher und das Glycosid Apiin.

Pimpinella Anisum L. (Anisum creticum) entlält ein diuretisch und als Carminativum wirkendes ätherisches Oel.

1) v. Martius, Syst. mat. med. Brasil. p. 81 .

2) Rufz, Enquête. p. 143.

$\left.{ }^{3}\right)$ A pulejus Platonicus, De viribus herbarum. 
Sium Sisarum L. (Elaphoboscon :).

Ammi majus L. und

A. Visnaya L. sollen nach Plinius ${ }^{1}$ ) mit gleichen Theilen M $\mathrm{yr}$ ha gegen Bisse der Hornschlangen gegeben rerden.

Thapsia Silphium Viv. (Silphion, Laser).

Bupleurum protractum L. (die Samen); die BupleurumArten wurden auch als Perfoliatum bezeichnet.

Foeniculum officinale All.

Seseli Hippomarathrum L. soll nach Petrichus und Micton das beste Mittel gegen Schlangenbiss sein.

Meum athamanticum Jacq.

Athamanta cretensis L. (Daucus). Die Wurzel wurde in Wein genommen.

Levisticum officinale Koch. (Ligusticum).

Selinum Carrifolia L.

Archangelica officinalis Hofim. (Angelica). Wurzel und Samen sind reich an ätherischem Oele.

Peucedanum officinale L. Plinius empfiehlt den Saft gegen Schlangenbiss zu trinken.

Imperatoria Ostruthium L.

Anethum graveolens L.

Pastinaca sativa L. (Elaphoboscon?).

Daucus Carota L. (Staphylinus, Pastinaca erratica). Wer die Pflanze bei sich trägt, soll von Schlangen nicht gebissen werden, und wer davon gegessen hat, soll unverletzlich $\operatorname{sein}^{2}$ ).

Caucalis orientalis $\mathbf{L}$.

Myrris odorata Scop.

Coriandrum sativum L.

Smyrnium perfoliatum L.

Ferula communis L. Die Wurzel wurde mit Wein genommen.

3) Plinius, Hist. nat. XX. 58.

2) Hid. XX. 15. 
Von Ferula galbaniflua Boiss., F. Opoponax Spr., F. rubricaulis Boiss., F. Schaïr Borszcz. wurden theils die Wurzeln gebraucht, theils der eingetrocknete Milchsaft (Galbanum). Wahrscheinlich gehören auch viele von den im Alterthum als Panaces aufgeführten Pflanzen dieser Gattung an. Petrus de Abano ${ }^{1}$ ) empfiehlt gegen Schlangengift eine Arznei aus Asa foetida (die ebenfalls von FerulaArten stammt), alter Butter, Allium und reinem Wein.

Mehrere andere im Alterthum angewandte Pflanzen, wie Heracleum, Bupleuros, Buselinon und andere lassen sich nicht mit Sicherheit bestimmen.

\section{Cornaceae.}

Alangium decapetalum Lam., Akola, Akarkanta (Hind.), Alingie-marum (Tam.), Angolam (Mal.). Die gepulverte Wurzel gilt in Indien als Antidot bei Schlangenbissen. Sie wirkt diuretisch und purgirend ${ }^{2}$ ).

\section{Caprifoliaceae.}

Aus dieser Familie wurden in früheren Zeiten nur angewandt:

Sambucus Ebulus L., deren Wurzel z. B. Matthiolus empfiehlt, und

Lonicera Caprifolium L. (Kissanthemos der (Alten) ${ }^{3}$ ).

\section{Rubiaceae.}

Galium Aparine L. Die Samen werden von Plinius ${ }^{4}$ ) empfohlen.

Rubia tinctorum L. (Erythrodanus der Alten). Die Blätter wurden auf die Bisswunde gelegt ${ }^{5}$ ). Matthiolus

1) Petrus de Abano l. c.

$\left.{ }^{2}\right)$ Drury l. c. p. 24.

$\left.{ }^{3}\right)$ Plinius, Hist. nat. XXV. 68.

4) Ibic. XXVII. 15.

$\left.{ }^{5}\right)$ Ibid. XXIV. 56. 
empfiehlt den Saft der Wurzel. Dieselbe enthält ausser Farbstoffen und anderen Substanzen auch ein Glycosid, die Ruberythrinsäure.

Pentas lanceolata (Forsk.) K. Sch. (P. carnea Bth.) gilt in Arabien als Mittel gegen Schlangenbiss.

Chiococca anguifuga Mart. (Ch. densifolia Mart.), in Brasilien unter dem Namen "raiz preta" oder "raiz de cobra" bekannt. Sie hat in ihrem scharfen, widerlichen Geruche viel Aehnlichkeit mit Senega und Valeriana. Der Kranke muss grosse Mengen des Absudes trinken, und die Umschläge von den frisch zerquetschten Blättern und Wurzeln werden abwechselnd mit denen von mehreren anderen Pflanzen, z. B. der "Lóco" (Plumbago scandens L.), die Blasen zieht, dem "Picáo" (Bidens graveolens und leucantha W.), der "Erva de Sa. Anna" (Kuhnia arguta H.) und dem Spilanthes brasiliensis häufig erneuert. Wenn der Gebrauch der "raiz preta" starke Ausleerungen auf allen Wegen zur Folge hat, so schöpft man Hoffnung auf Genesung; besonders sollen starke Schweisse und Stuhlentleerungen günstige Zeichen sein. Man fährt dann mit demselben Mittel ohne Unterlass mehrere Tage lang fort, bis der Kranke seine normalen Gesichtszüge wieder erhält ${ }^{1}$ ). Der Negern inoculirte Saft der Pflanze soll dieselben ein ganzes Jahr lang gegen Schlangengift schützen, und reibt man seine Hände damit, so soll man, ohne gebissen zu werden, die Schlangen ergreifen können ${ }^{2}$ ).

Chiococca racemosa L. (Raiz preta“, "Cainca", "Cainana", „Puaia“, „Cruzereinha") wirkt wie die vorige diuretisch, diaphoretisch, cathartisch und emetisch. Man gebraucht auch hiervon Extracte, Decocte und das Pulver der Wurzel ${ }^{3}$ ). Das diuretische Prinzip ist die in der Wurzelrinde enthaltene Caincas ïure.

Ophiorrhiza mungos L. (singalesisch Mendi, Nagah-

1) Spix u. v. Martius, Meise in Grasilien. I. S. $305 \mathrm{f}$.

$\left.{ }^{2}\right)$ Spix, Serpent. Brasil. Species novae. p 67.

$\left.{ }^{3}\right)$ v. Martius, Syst. inat, morl. Jiasil. 1). 93. 
walhi, javanisch Ellar) soll nach Kaempfer ${ }^{1}$ ) u. A. sehr wirksam bei Schlangenbiss sein. Ausser auf Ceylon und Java bedient man sich ihrer auch auf Martinique ${ }^{2}$ ). Man benutzt Decocte von der Rinde, den Blättern und der sehr bitteren Wurzel.

Cephälis Ipecacuanha Rich. ist eine schon in älteren Zeiten häufig bei Schlangenbiss empfohlene Pflanze. Nach $\mathrm{Mead}^{3}$ ) soll sie durch ihre emetische Wirkung die oft nach dem Bisse eintretenden Krämpfe verhüten. Der wesentliche Bestandtheil der Wurzel ist das Alkaloid Emetin.

Macrocnemum corymbosum R.P. Die sehr adstringirende Rinde wird in Peru zur Heilung des nach dem Bisse zurückbleibenden Geschwüres gebraucht ${ }^{4}$ ).

Die von $\mathrm{C}$ inchona-Arten stammende Chinarinde, welche, nachdem ihre Bedeutung als Fiebermittel um die Mitte des 17. Jahrhunderts bekannt geworden war, auch bei Schlangenbiss empfohlen wurde, erkannte schon Fontana als nutzlos gegen Schlangengift.

\section{Valerianaceae.}

Valeriana celtica L. ist die von Plinius ${ }^{5}$ ) als Nardum gallicum gegen Schlangenbiss empfohlene Baldrian-Art.

V. officinalis L. wurde unter dem Namen $\mathrm{Phu}$ noch häufiger benutzt als die vorige. Sie enthält in ilhrer Wurzel Valerianöl, Valeriansäure und zwei Gerbsäuren.

\section{Compositae.}

Diese weit verbreitete Familie lieferte zu allen Zeiten zahlreiche Pflanzen gegen Schlangenbiss, und zwar im Alterthum und Mittelalter besonders folgende:

1) Ka empfer, Amoenitatum exotic. politico-physico-med. fasciculi V. Lemgo 1712. $4^{\circ}$.

2) Ruf z, Enquête. p. 163.

3) Mead, De vipera. 1749.

4) Pöppig, Reisen in Chile und Peru.

5) Plinius, Hist. nat. XXI. 79. 
Inula Helenium L. (Helenium, Inula, Enula). Das Pulver der im Schatten getrockneten Wurzel wurde mit Tein getrunken ${ }^{1}$ ). Dieselbe enthält den sog. A lautcampher (Helenin) und war früher als Expectorans und Diureticum officinell.

I. Britannica L. (Herba Britannica) ${ }^{2}$ ).

Artemisia Abrotanum L. (Abrotonum). Die Blätter der Pflanze enthalten ein ätherisches Oel, einen bitteren Extractivstoff und Gerbstoff. Man gebrauchte sie inmerlich mit Wein und auch äusserlich ${ }^{3}$ ).

A. Absinthium L. enthält das Wermuthöl und den Bitterstoff Absynthiin.

Anthemis nobilis L.

A. tinctoria L.

Matricaria Chamomilla L. Diese und vielleicht noch andere Kamillenarten wurden in der Weise angewandt, dass man Blätter, Blüthen und Wurzeln zu einer Paste mischte ${ }^{4}$ ). Die Kamillen enthalten ein ätherisches Oel und sind noch heute ein allgemein bekanntes Diaphoreticum.

Tragopogon picroides L. (Hieracion). Man nahm die in Essig abgeriebenen Blätter und Stengel ein.

Gnaphalium sanguineum L. (Baccharis).

G. Stoechas L. (Helichrysum, Chrysanthemum).

Carthamus tinctorius L. (Sideritis).

C. lanatus L. (Cnicus, Atractylis).

Cnicus benedictus Gaertn., das Cardobenedictenkraut, wurde besonders im Mittelalter viel bei Bronchialkatarrhen, Hydrops, chronischer Dyspepsie und auch bei Schlangenbiss gebraucht. Es enthïlt den Bitterstoff Cnicin.

Arctium Iappa L. (Persolata, Personata, Arlios, Prosopis).

Santolina Chamaecyparissus L.

1) Pliniug, Hist. nat. XX. 19; XXI. 91.

3) Itbid. XXV. 55.

$\left.{ }^{3}\right)$ Ithid XXI. 92.

4) Itid. XXII. 2fj. 
Cichorium Intybus L. Die Blüthen enthalten ein Gloycosid.

\section{Endivia L.}

Auch eine Lactuca wird verschiedentlich erwähnt, jedoch ist die Art nicht sicher zu ermitteln; ebenso verhält es sich mit den alten Namen Lactucella, Sonchus, Condrilla, Carlina, Carduus und anderen.

Scorzonera hispanica L. soll ihren Namen von einer in Catalonien lebenden Schlange "escorçu" haben, gegen deren Biss Wurzel und Kraut der Pflanze angewandt wurde ${ }^{1}$ ).

Doronicum Pardalianches L. (Scorpio, Aconiton, Thelyphonon). Von der Pflanze gebraucht man noch jetzt in Indien die Wurzel gegen Schlangenbiss ${ }^{2}$ ).

Mikania Guaco H. B. Kth., in Brasilien unter dem Namen "vejuco de huaco" bekannt, ist diejenige Pflanze, welche von allen die grösste Berühmtheit als Mittel gegen Schlangengift erlangt hat. Was den Namen der Pflanze betrifft, so soll "Guaco" oder "Huaco" den Schrei eines falkenartigen Vogels bezeichnen, welcher von Schlangen leben und sich durch Gebrauch dieser Pflanze von den Bissen, die er im Kampfe mit den Schlangen erhalten hat, heilen soll. Uebrigens führen ausser dieser noch verschiedene andere Arten der Gattung Mikania und sogar auch anderer Gattungen, wie Aristolochia, wie wir weiter unten sehen werden, den Namen "Guaco". Mikania Guaco nennt man auch zum Unterschiede voll anderen Guaco-Arten "Guaco de Guatemala". Sie wurde zuerst durch Mutis bekannt, dem im Jahre 1788 ein Indianer das Geheimniss entdeckt hatte ${ }^{3}$ ). Man gebraucht sie in fast ganz Südamerika, besonders in Chile und Peru. Ihre Anwendung daselbst ist sehr einfach: man tropft den ausgepressten Saft in die etwas erweiterte Wunde, bedeckt die umliegenden Theile wiederholt mit den zerquetschten

1) Monardes, De lapide Bezaar et herba Scorzonera. p. 7. (In Carolus Clusius, Fxoticorum libri X. 1605.)

$\left.{ }^{2}\right)$ Pharmacographia indica. III. p. 292.

3) Otto, Casper's Wochenschr. 1835. Nr. 11. 
Blättern und lässt den Saft auch innerlich nehmen. Man rühmt auch die aus dem Guaco mit Zuckerbranntwein bereitete Tinctur als ein sicheres und von den Reisenden leicht mitzuführendes Arzneimittel. In Guayaquil formt man aus der frisch zerquetschten Pflanze kleine Kuchen, die, an der Sonne getrocknet, lange ihre Wirksamkeit behalten.

Die Wirkungen des Guaco treten zwar nicht bei Allen gleich schnell und entscheidend ein, indessen soll in den meisten Fällen schon nach 24stündigem Gebrauche des Mittels, abgesehen ron einem zurückbleibenden kleinen Geschwüre, Heilung eintreten. In manchen Orten sind seit Menschengedenken durch Gebrauch des Guaco nur einige Kinder an Schlangenbiss gestorben. Nur gegen eine Schlangenart, den Urrucu-Machacayu, dessen Biss in einer Stunde töltet, soll der Guaco unwirksam sein. Auch in ganz Columbien schätzt man denselben als untrügliches Heilmittel. In einem Orte sollen, wie Pöppig berichtet, innerhalb elf Jahren von 220) gebissenen Einwohnern ausser 8 alle durch Behandlung mit Guaco, Limonensaft und Salz geheilt worden sein. In einem anderen Orte wurden in 14 Jahren mehr als 200 Personen mit Ausnahme eines Mädchens, dem man keine Mittel gegeben hatte, durch Guaco gerettet. Eine giftige Schlange, der man den Saft eingoss, soll in Betäubung verfallen und später trotz mancher Bisse nicht mehr im Stande gewesen sein, einen kleinen Hund zu tödten, da ihr Gift unwirksam geworden war. In Columbien soll ein Bischof von Sa. Martha sogar alle Indianer einer Schutzimpfung mit Guacosaft unterworfen haben, und zwar mit solehem Erfolge, dass dieselben jede Furcht vor Schlangen verloren. Wenn auch in diesen Berichten ohne //weifel viele Uebertreibungen sind, so scheint doch nach den Beobachtungen Pöppig's die Wirksamkeit des Guaco eine recht grosse $z u$ sein. Nach Otto nchmen auch die Indianer selbst an sich die Impfung vor, indem sie sechs kleine Einschnitte in dic Haut machen, nämlich zwei in die llïnde, zwei in die Fusse und einen in jerle Seite der Brust, und in allo diese. Wunden den Guaco-Saft bringen; zuvor 
trinken sie jedoch zwei Löffel davon und wiederholen diese Dosis nachher alle Monate 5-6 Tage nach einander, weil sonst die Impfung ihre Schutzkraft verlieren soll.

Auch in Mexiko ist der Guaco seit uralten Zeiten als Mittel gegen Schlangenbiss bekannt und wird daselbst als Decoct oder als Tinctura Huaco alkoholica oder Tinctura Huaco aetherea angewandt; die letztere ist von sehr starker Wirkung und wird nur zu 5-6 Tropfen gegeben ${ }^{1}$ ). Man stellte auch Untersuchungen über die Wirkung des Guacoextractes auf Thiere an und fand, dass dasselbe besonders auf das Nervensystem wirkt ${ }^{2}$ ). Die Versuchsthiere zeigten nach Absorption der Substanz zunächst eine Periode der Erregung, begleitet von gastrointestinalen Störungen (Nausea, Erbrechen, Diarrhöe), sodann fallen sie in Somnolenz; bei starker Dosis folgt darauf vollständige motorische Lähmung und Tod. Die Respiration ist beschleunigt, die Inspirationen sind weniger tief, die Herzschläge erfolgen langsamer, die Arterienspannung sinkt. Im Urin findet sich oft Eiweiss. Die Temperatur steigt zuerst etwas und sinkt darauf um $3-4^{\circ}$. Man kann das Guacoextract äusserlich als Analgeticum, sowie ein 2\%-Decoct der Pflanze bei Ekzem und auch als Emetico-catharticum benutzen. Es gelang bisher noch nicht, ein Alkaloid oder ein Glycosid aus der Pflanze darzustellen. Fauré ${ }^{3}$ ) erhielt durch Extraction der Blätter mit Aether das Guacin, das aber kein reiner Körper sein soll ${ }^{4}$ ) und in Dosen ron 0,06 $\mathrm{g}$ Erbrechen, Pulsbeschleunigung, Schweiss und Absonderung stark harnsäurehaltigen Urins bewirkt. Neuere Autoren ${ }^{5}$ ) sprechen übrigens dem Guaco jeden Nutzen bei Schlangenbiss ab.

Andere gegen Schlangenbiss empfohlene Mikania-Arten sind noch:

1) Chabert, Du Huaco et ses virtus médicinales. Paris 1853.

2) Butte, Sémaine médicale. 1889. p. 328.

3) Fauré, Journ. de Pharm. (2) XXII. 291.

4) v. Pettenkofer, Ueber Mikania Guaco. München 1844.

5) Guibourt, Journ. de Pharm, et de Chimie. 1867. 
Mikania opifera Mart., "Erra di cobra“. Man legt in Brasilien auf die scarificirte Wunde zerquetschte Blätter und giebt innerlich von Zeit zn Zeit einige Löffel des ausgepressten Saftes ${ }^{1}$ ). Sie soll die Krisis besonders durch Urinabsonderung herbeiführen.

M. Huttoni Willd. wird in Mexiko gebraucht ( G u aco de Veracruz").

M. saturejaefolia Willd. (Nathites saturejaefolia D.C.), um Montevideo einheimisch, soll die gleichen Heilkräfte besitzen wie Mikania Guaco.

Von Eupatorium Ayapana Vent., Ayapána (Hind.), Ayapáni (Tam.), Daon Prasman, Daon Panahaw (Mal., Jav.) wird in Indien und auf den Sundainseln der frische Saft innerlich und äusserlich bei Schlangenbiss angewandt ${ }^{2}$ ). Ebenso legt man in Brasilien auf die scarificirte Wunde eine öfter zu wechselnde Menge zerquetschter Blätter und lässt zugleich so lange, bis man den Kranken frei von allen Symptomen, besonders der schrecklichen Angst, sieht, von Zeit zu Zeit einige Löffel des ausgrepressten Saftes einnehmen ${ }^{3}$ ). Die Pflanze enthält Fett, ätherisches Oel, einen Bitterstoff und Spuren von Zucker ${ }^{4}$ ). Sie wirkt stimulirend, tonisch und diaphoretisch ${ }^{5}$ ).

E. macrophyllum L wird in Südamerika ${ }^{6}$ ) und

E. perfoliatum L. in Nordamerika ${ }^{7}$ ) gegen Schlangenbiss benutzt.

Von weniger wichtigen, den Compositen angehörigen Pflanzen sind in Amerika, besonders in den Vereinigten Staat. $n$ und in Brasilien, folgende in Gebrauch:

Aster montanus Nutt.

1) Spix u. v. II artius, lieise in Brasilien. I. S. 279. Note 2.

2) Pharmographia indica. III. p. 24.5 und Madras Quart. Journ. IV. 1 -62. p 7 .

s) Spix u. v. Martius l. c. 1. S. 279 . Note 1.

क) W il flart, Joum. de I'harm. Jan. 1829.

c) I) rury l. c. 1. 203.

6) fiuilourt 1. c. 186;7. 11. 83.3.

") Geriner. l. 
Erigeron canadensis L. und andere Arten dieser Gattung ${ }^{1}$ ).

Solidago canadensis L. ("Klapperschlangenkraut") ${ }^{1}$ ).

Liatris spicata Willd. ("Gay feather", "Button snake root").

L. dubia (?) ("rattle-snake root"),

L. squarrosa Willd. ( „Pinetta di prairia",

L. scariosa Willd. Jrattle snake's master").

Von diesen vier Pflanzen legt man in den Vereinigten Staaten die zerquetschten Knollen auf die Bisswunde, während man innerlich eine Abkochung davon in Milch nimmt ${ }^{2}$ ). Die Wirkung ist eine diuretische. Brainard sah bei seinen Thierversuchen keinen Erfolg von der Anwendung dieser Pflanzen.

Prenanthes alba L. ${ }^{1}$ ) in Nordamerika.

P. Serpentaria Pursh. ${ }^{2}$ ).

Lactuca virosa L. ${ }^{3}$ ). Der Milchsaft der Pflanze, das Lactucarium, enthält einen Bitterstoff, Lactucin, und wirkt ähnlich dem Opium narkotisch.

Bidens graveolens Mart. und

B. leucantha W. sind in Brasilien als "Picáo" bekannt. Man macht von den frisch zerquetschten Blättern und Wurzeln Umschläge ${ }^{4}$ ).

Hieracium venosum L. ${ }^{5}$ ) in Nordamerika.

Echinacia purpurea Moench.

(E. serotina D.C.)

E. angustifolia D.C.

Milleria Contrayerba L. in Nordamerika.

Spilanthes brasiliensis Spr. $\left.{ }^{4}\right)$ in Bra-

S. ciliata H. B. Kth. ("Guaco de Santa Fé") silien. Kuhnia arguta H.B. ${ }^{4}$ )

1) Schöpf l.c.

2) Barton, Vegetable materia medica of the United States. 1817/18. Vol. II. p. 225. - Germer 1. c.

3) Spix, Serpentum Brasil. Species novae. 1824. p. 64.

$\left.{ }^{4}\right)$ Spix u. v. Martius l. c. I. S. 286 . Note 49.

5) Schöpf l. c. 
Eclipta alba Hassk. ("Louise Beberie") in Surinam ${ }^{1}$ ). (Siehe Solanum mamosum.)

In Indien gebraucht man:

Artemisia rulgaris L., Nagdoun, Mastáru (Hind.), Máchipattiri (Tam.), Tiru-nitripachcha (Mal.), und zwar das Kraut der Pflanze ${ }^{2}$ ); ferner

A. maritima L., Kirmálá (Hind.). Die Blüthenköpfe enthalten das bekannte Santonin und werden mehr als Wurmmittel als gegen Schlangenbiss angewandt ${ }^{2}$ ). Das Oel der Samen wirkt auch diuretisch und purgirend.

Serratula amara L., Girmot der Javaner, ist auf Ceylon und an der Westküste von Ostindien in Gebrauch ${ }^{3}$ ).

Inula squarrosa $\mathrm{L}$. wird von $0 \mathrm{modei}^{4}$ ) erwähnt.

Vernonia anthelmintica Willd., Caatsiragum (Tam.), Catta-seragam (Mal.), Buckche (Hind.). Die Samen bilden einen Bestandtheil eines gegen Schlangenbiss gebrauchten Pulvers in Indien und wirken wurmtreibend und diuretisch ${ }^{5}$ ).

\section{Ericaceae.}

Erica arborea $L$. wurde nur selten angewandt.

Pirola maculata L. und P. rotundifolia $L^{6}{ }^{6}$ ) werden in Nordamerika benutzt.

\section{Plumbaginaceae.}

Plumbago scandens L., in Brasilien unter dem Namen "Loco" bekannt. Die frisch zerquetschten Blätter und Wurzeln werden daselbst als Umschläge äusserlich angewandt. Die Pflanze hat die Eigenschaft, Blasen zu ziehen ${ }^{7}$ ).

1) Martin, Bericht über eine Reise nach Niederländisch-Westindien. 1. S. $29 \mathrm{ff}$.

2) Pharmacoyraphit indica. III. p. 284 u. 288.

3) Horsfield, Account of the Medical Plants of Java. 1816.

") Cmodei, Annali universali di medicina. Vol. IXXXII. April 18.97. 1. 5.

s) J) rury l. c. p. 441.

") IS a rton, Transact. Am. Phil. Soc. Vol. III. p. 103.

3) Spix u. v. Martius l. c. I. p. $305 \mathrm{f}$. 
Statice Limonium L. (Leimonion, Limonium) wird u. a. von Plinius ${ }^{1}$ ) empfohlen.

\section{Primulaceae.}

Anagallis arvensis L., in Europa, Westasien und Indien. Hindustanische Namen: Jonkmari, Jainghani. Die Pflanze wurde schon im Alterthum unter dem Namen Corchorus ${ }^{2}$ ) und wird noch jetzt in Indien ${ }^{3}$ ) bei Schlangenbiss gegeben. Nach Malapert (1857) enthält die Pflanze einen dem Saponin sehr ähnlichen Stoff. Aus dem trockenen Kraute stellte man eine geringe Menge eines flüchtigen, eigenthümlich und stark riechenden und sauer schmeckenden Oeles dar. Ein paar Tropfen davon verursachten Kopfschmerzen und mehrere Stunden andauernde Uebelkeit.

Cyclamen persicum Mill., in Griechenland, Persien etc., wird ebenfalls schon von Plinius ${ }^{4}$ ) empfohlen. Die Pflanze enthält ebenfalls einen dem Saponin ähnlichen Stoff, das Cyclamin. Es hat einen bitteren, scharfen Geschmack, bildet mit Wasser eine seifige Mischung und wird, wenn mit Säuren gekocht, in Glucose und in eine harzige Substanz verwandelt, die man Cyclamiretin nannte. Vergiftete Fische sterben asphyktisch. Das Cyclamin erregt im Magen Brennen, Uebelkeit, Erbrechen, sowie Speichelfluss, wenn es in die Gefässe gelangt.

\section{Ebenaceae.}

Von Diospyros Kaki L. f. wird im nördlichen Japan der stark gerbsäurehaltige Saft der unreifen Früchte bei Schlangenbiss äusserlich angewandt ${ }^{5}$ ).

1) Plini us, Hist. nat. XXV. 61.

$\left.{ }^{2}\right)$ Ibid. XXI. 106.

3) Pharmacographia indica. IV. 345.

$\left.{ }^{4}\right)$ Plinius, Hist. nat. XXV. 67.

5) Mittheilungen der deutschen Gesellschaft für.Natur- u. Völkerkunde Ostasiens. I. Heft 9. S. 6. 1876. 


\section{$-129-$}

\section{Oleaceae.}

Olea europaea L. Das aus dem Fruchtfleische des Olirenbaumes gewonnene Olivenöl wurde zuerst im Jahre 1707 ron einem englischen Bauer als Mittel gegen Schlangenbiss empfohlen und erlangte als solches bald einen solchen Ruf, dass die Pariser Akademie Hunauld und Ge offroy mit der Prüfung des Mittels beauftragte. Diese führte zu dem Resultate, dass das Olivenöl kein Specificum gegen Schlangenbiss sei; aber, obgleich Männer wie Mead und Fontana auf Grund ihrer Versuche dasselbe ebenfalls für nutzlos erklärten, so hat es doch bis in die neueste Zeit hinein eine ausgedehnte innere und äusssere Anwendung gefunden, und noch 1850 behauptete $\mathrm{D}$ u s o u r d ${ }^{1}$ ), dass das lauwarme Olivenöl das beste Mittel gegen Vipernbiss sei. Einreibungen des Oeles um die Wunde bewirken allerdings häufig ein schnelles Erweichen der Geschwulst; dagegen wirkt dasselbe bei innerlichem Gebrauch, bei dem es esslöffelweise gereicht werden soll, in sehr hohen Dosen höchstens als Brechmittel und Catharticum, aber sicher nicht specifisch. Auch Weir Mitchell sah keinen Erfolg von der Anwendung des Olivenöles bei seinen Versuchsthieren.

Fraxinus excelsior L. Der Saft vom Eschenlaub wurde gegen den Kreuzotterbiss von Mercurialis und Montin empfohlen. Man stellte aus Eschenblättern einen purgirend wirkenden Stoff Fraxinit dar, der aber vielleicht nichts weiter als Mannit war.

Von Nyctanthes Sambac L. (Jasminum Sambac Ait.) und Jasminum pubescens Willd. benutzt man in Indien die Wurzel gegen Schlangenbiss ${ }^{2}$ ).

\section{Sulvadoracene.}

Salvadora oleoides bone., Pilu, Jhál (Hind.), Kalarva, Kárkol, Ughai-puttai ('Tam.). Die Samen wur-

1) J иво о rd, liull. de: 'Thérap. Mni 1450.

3) liheede, Hort. Malabar. VI. 8\%. 95.

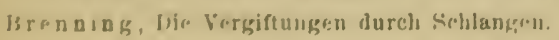


den in mehreren Fällen von Schlangenbiss in Indien mit gutem Erfolge gegeben ${ }^{1}$ ). Sie enthalten ein weisses Fett und ein in Aether und Amylalkohol lösliches Alkaloid.

Von S. persica L., Piloo-kurjal (Hind.), Ooghaimarum (Tam.) werden ebenfalls die purgirend wirkenden Samen innerlich angewandt ${ }^{2}$ ).

\section{Apocynaceae.}

Von Apocyneen werden als Mittel gegen Schlangenbiss von den alten Autoren empfohlen:

Vinca major L. (ägyptische Clematis, Daphnoides, Polygonoides) ${ }^{3}$ ).

Nerium Oleander L. (Rhododendros der Alten) ${ }^{4}$ ). Die frischen Oleanderblätter enthalten neben Oleandrin und Pseudocurarin ein Glycosid Neriin, das alle Eigenschaften des Digitale ïns zeigt und wahrscheinlich mit diesem identisch ist. In trockenen Blättern fand man ausserdem die dem Digitaliresin entsprechenden Derivate des Oleandrins und Neriins, ferner einen stickstofffreien Stoff Nerianthin, der Digitalinreaction giebt und beim Kochen mit verdünnten Säuren Glycose und ein krystallinisches, dieselbe Reaction gebendes Spaltungsproduct Nerianthogenin liefert ${ }^{5}$ ). Das Oleandrin ist ein Herzgift, das zu $0,25 \mathrm{mg}$ systolischen Herzstillstand beim Frosche bedingt. Neriin wirkt wie Digitaleïn, dagegen bringt Nerianthin keinen systolischen Herzstillstand hervor.

N. odorum Ait., Kaner (Hind.), Alari (Tam., Mal.) wird in Indien gegen Schlangenbiss angewandt. Aus der Rinde lassen sich zwei ebenfalls als Herzgifte wirkende Bitterstoffe, Neriodorin und Neriodoreïn extrahiren ${ }^{6}$ ). Vielleicht sind dieselben identisch mit Oleandrin und Neriin.

$\left.{ }^{1}\right)$ Bomb. Med. and Phys. Trans., New Ser. III. p. 80 .

2) Madras Quart. Journ. IV. 13.

3) Plinius, Hist. nat. XXIV. 90.

4) Ibid. XXIV. 53.

5) Schmiedeberg, Archiv für experimentelle Pathologie und Pharmokologie. XVI. 1882. S. 151.

6) Greenisch, Pharm. Journ. Transact. (3) XI. p. 873. 
N. tomentosum Roxb. (IVrightia tomentosa R. et S.), Velam-pala (Mal.). Die Rinde der Wurzel wird in Indien innerlich gegen Schlangengift gegeben.

Ophioxylon serpentinum L. (Kauwolfia serpentina Benth.) wird in Indien und auf Java gegen Schlangenbiss benutzt. Die einheimischen Namen sind: Chandraka, Chandrapushpa (Sanskr.), Chota-chand, Moonlet (Hind.), ('livan-amelpodi (Mal.), Puli-pandak (Jav.). Den Gebrauch der Pflanze gegen Schlangenbiss soll man angeblich, wie auch den des Guaco, von Thieren kennen gelernt haben, und noch 1831 erzählt Duncan ${ }^{1}$ ), der in Ostindien eineu Kampf eines Ichneumons mit einer Brillenschlange mit angesehen haben will, dass jenes, als es von der Schlange gebissen war, zuerst in heftiger Aufregung herumlief, in verschiedene Büsche und Blätter biss, endlich aber Ophioxylon serpentinum fand und, nachdem es einige Blätter davon verzehrt hatte, wieder auf die Schlange zulief, sie tödtete und gesund blieb. Man giebt den Gebissenen innerlich eine Abkochung besonders der jungen, intensiv bitter schmeckenden Wurzeln und applicirt ausserdem dieselben gepulvert auf die Wunde und auf die Augen ${ }^{2}$ ). Ebenso träufelt man den ausgepressten Saft in die Augen. Der wirksame Bestandtheil der Wurzel ist ein Alkaloid"). Das beste Erkennungsmittel für die OphioxylonWurzel ist die mikrochemische Reaction mit Salpetersäure. Befeuchtet man ein Wurzelscheibchen mit dieser Sïure, dann färbt sich der lindentheil dunkel kirschroth. Bei älteren Wurzeln fürbt sich der Holztheil und die Korkschicht gar nicht; bei jungen Wurzeln ist auch noch stellenweise im Holztheile ein wenig Alkaloid abgesetzt. Man kann durch diese Reaction nicht nur die Localisation des Alkaloides in der OphioxylonWurzel erkennen, sondern auch die Wurzel selbst von anderen

1) Archiv der ['harmacie. XXXVIJ. 18:31. S. 369.

2) I'harmacographia indica. IV. 414.

$\left.{ }^{3}\right)$ M. G roshoff, Mededeelingen uit s'Iands I'lantentuin. VII. l) Sl Patavia 1890 . 
ähnlichen, oft zur Verfälschung der ersteren angewandten Wurzeln unterscheiden, so von Calotropis gigantea, Cocculus umbellatus und von der falschen Pandak-Wurzel, die von Plumbago rosea L. abstammt.

Uebrigens liefern ausser Ophioxylon serpentinum L. auch andere Arten, nämlich 0 . trifoliatum Gaertn., O. majus und $\mathrm{O}$. obversum das berühmte javanische Heilmittel PuliPandak. Die Wurzel gehört zu den ersten Heilmitteln, die von Indien nach Europa kamen. Man findet sie in älteren Werken ausser als Ophioxylon auch als Radix Mungos (Radix Serpentum) aufgeführt, unter welchem Namen auch die Wurzeln der Rubiacee Ophiorrhiza Mungos L. verkauft wurden.

Theretia Ahovai L. und

Th. neriifolia Juss. (Cerbera Thevetia L.) werden in Brasilien in der Weise angewandt, dass man den Milchsaft oder die zerquetschten Blätter und Samen auf die Bisswunde applicirt ${ }^{1}$ ). Letztere enthalten das Glycosid Thevetin, das sehr stark toxisch wirkt und bei Hunden Speichelfluss, Erbrechen, flüssige Stühle, Zittern u. a. Symptome hervorruft; die Thiere sterben nach $0,5 \mathrm{~g}$ in $5^{1} / 2$ Stunden. Auf Kaninchen und Frösche wirkt es als Herzgift; der Herzstillstand erfolgt in der Systole. Die örtliche Wirkung ist eine reizende. Beim Kochen mit verdünnten Säuren spaltet sich das Thevetin in Glycose und Theveresin, welches letztere ebenfalls stark giftig ist und Steifigkeit der Glieder, Insensibilität sowie Herzstillstand verursacht.

\section{Asclepiadaceae.}

Vincetoxicum officinale L., die Schwalbenwurz, wird nur selten als Mittel gegen Schlangenbiss erwähnt. Sie enthält einen glycosidischen Stoff, Asclepiadin, der emetisch, diaphoretisch und purgirend wirkt. 
Asclepias Dioscoridis Fraas. (Asklepias, Dracontium der Alten). Nan gebrauchte die Wurzeln offenbar nur ihrer Gestalt wegen, denn Apulejus Platonicus sagt ron der Pflanze: radix ima caput dracontis habet.

A. gigantea Ait. (Calotropis gigantea R. Br.), A k. M a d a r (Hind.), Y e r k m (Tam.), Yerica (Mal.), Traduri (Jar.) bildet mit ihrem Safte einen Bestandtheil der schon früher genannten Tanjore-Pillen. Auch wendet man die purgirend wirkende Wurzel der wilden Baumwolle äusserlich an ${ }^{1}$ ).

Daemia extensa R. Br., Utrum (Hind.), Vela paruti (Tam.). Velli navi, ist ebenfalls in den Tanjore-Pillen enthalten ${ }^{2}$ ).

Ferner benutzt man noch folgende Asclepiadeen in Indien gegen Schlangenbiss ${ }^{3}$ ):

Tylophora asthnatica Wight., Unta-mool (Hincl.), Kurinja (Tam.).

Hoya pendula Wight. (Nansjira-patsja).

Ceropegia Candelabrum L. (Watta-kaka codi).

Gymnema silvestre R. Br., Mera-singi (Hind.), Sirukurinja (Tam.). Die Hindus legen die gepulverte Wurzel auf den gebissenen Theil und geben eine Abkochung derselben innerlich ${ }^{4}$ ). In Tunis gebraucht man die Blätter der Pflanze äusserlich gegen Schlangenbiss. Wurzel und Blätter haben die Eigenthümlichkeit, dass sie, wenn man sie kaut, für längere Zeit den süssen Geschmack, in geringem Maasse auch den bitteren, aufheben. Das wirksame Prinzip ist die Grymnesinsäure. Die Blätter enthalten ausserdem Weinsiiure, Glycose und einen Alkaloidreaction gebenden bitteren Stoff $\left.{ }^{5}\right)$.

1) Vadras Quart. Journ. IV. p. :3.

2) It,id. JV. p. 1.

3) [bill. IV. 1. ? -4 .

1) Pharmacogr. indica. IV. 450. - Madras Quart. Journ. IV. p. 2.

i) Suchannik, 'Therap. Monatshefte. VIJl. 1894. S. 403. 


\section{Loganiaceue.}

Die Gattung Strychnos ${ }^{1}$ ) liefert den grössten Theil des früher so berühmten Lignum colubrinum, welches einen hohen Rang unter den Alexipharmacis einnahm. Es wird zuerst von Garcia ab Horto erwähnt ${ }^{2}$ ). Derselbe führt drei Arten von Ceylon an; die eine war wohl die Wurze] von Ophioxylum serpentinum L., die beiden anderen Producte von Strychnos colubrina L. und Strychnos ligustrina Blume.

Strychnos colubrina L. wird von den Eingeborenen Indiens von allen Schlangenhölzern am meisten geschätzt. Die einheimischen Namen sind : K oochila-luta (Beng.), Mahapenala (Sing.), Widoroo-pait, Vidoo-pait (Jav.). Es ist das "Pào de Cobra" der Portugiesen. Man giebt das Holz der Wurzel äusserlich und innerlich. Die Pflanze enthält ebenso wie alle folgenden Arten von Strychnos die beiden Alkaloide Strychnin und Brucin.

S. ligustrina Blume, auf dem Malayischen Archipel, ist das alte Lignum colubrinum von Timor. Einheimische Namen: Caju-ular, Caju-nassi, Caju-bidara-lant.

S. potatorum L. Einheimische indische Namen: Nirmulee, Nir-mal-i (Beng. u. Hind.), Téttan-kotei (Tam.). Die Samen sollen ein gutes Antidot bilden.

S. Ignatii Bergius (Ignatia amara L.) auf den Philippinen und in Cochinchina. Es werden hiervon ebenfalls die Samen, die bekannten Ignatius bohnen, gegen Schlangenbiss gebraucht. Der hindustanische Namen der Pflanze ist Pepeitha. Die Samen enthalten die Alkaloide Strychnin und Brucin.

Als Schlangenholz werden auch folgende Arten in Indien verkauft $\left.{ }^{3}\right)$ :

1) E. J. Waring, Antidotes to Snake-Bites. Madras Quart. Journ. of med. sc. III. 1861. p. $336 \mathrm{ff}$.

2) Garcia ab Horto, Historia Aromatum etc. 1579. p. 161. J. A. Darellius, Lignum colubrinum. Dissertatio sub praes. Caroli Limé. Upsalae 1749.

3) Pharmacographia indica. IV. 503. 
S. Rheedii Clarke. Modira-caniram (Mal.), Kuchilalata (Hind.).

S. B eddomei Clarke.

S. Iaurina Wall.

S. cinnamomifolia Thwaites.

S. Gautheriana Pierr. (S. Malakkensis Benth.), "Hoang nan" oder "Huang nan", wird in Tonkin gegen Schlangenbiss gebraucht ${ }^{1}$ ).

Die grösste Bedeutung aber von allen Strychnosarten hat als Antidot gegen Schlangenbiss

S. nux vomica L., die bekannte Brechnuss. Sie wird besonders in Indien, Birma und auf Ceylon unter folgenden Namen gebraucht: Koochla, Kagphill (Hind.), Koochila (Beng.), Yetti (Tam.). Auch die Araber sollen sie als Antidot kennen. Nach Rheede sollen 1-2 Samen täglich, zwei Jahre lang genommen, den Körper gegen Cobra-Gift schützen. Wie schon oben erwähnt, ist das aus den Samen dieser Pflanze bereitete Strychnin in neuester Zeit von A. Müller in Australien mit grossem Erfolge gegen die dortigen Giftschlangen angewandt worden.

\section{Gentianaceae.}

Gentiana lutea L. Vom gelben Enzian wurden die Blätter und besonders die Wurzel zu allen Zeiten als wirksam gegen Schlangengift gerühmt. Dieselbe enthält ausser anderen Stoffen Gentiansäure und einen glycosidischen Bitterstoft' Gentiopikrin.

Erythraea Centaurium Pers. wird ebenfalls häufig von älteren Autoren erwähnt.

Menyanthes indica Thunb. wird in Indien angewandt ${ }^{2}$ ).

\section{I'olemoniacerae.}

Polemoniun coeruleum L. (Polemonia, Philetaeris ler Alten) wird von Plinius ${ }^{3}$ ) empfohlen.

1) Kobert, Jalıresh. d. Pharmakoth. f. 1884. S. 36).

$\left.{ }^{2}\right)$ Kheerle, Hort. Malabar. XI. 56.

$\left.{ }^{2}\right)$ Plinius, Hist. nat. XXV. 55. 


\section{$-136$}

Hydrophyllaceae.

Hydrophyllum canadense L. wird in Nordamerika bei Schlangenbiss benutzt ${ }^{1}$ ).

\section{Boragineae.}

Heliotropium villosum Desf. (Heliotropium, Helionscorpion, Solago major) ${ }^{2}$ ). Die Pflanze enthält ein Alkaloid, das Heliotropin, das zu $0,025 \mathrm{~g}$ subcutan applicirt Katzen unter Somnolenz, der zuweilen Zittern, Unruhe und Erbrechen voraufgeht, tödtet.

Cynoglossum officinale L. und

C. pictum Ait. (Cynoglossa, Lingua canina ${ }^{3}$ ). Aus ersterem ist ebenfalls ein $\mathrm{zu} 0,1 \mathrm{~g}$ auf Frösche paralysirend wirkendes Alkaloid dargestellt worden.

C. virginicum L. in den Vereinigten Staaten.

Echium rubrum L. (Anchusa, Onochiles, Rhexia, Arcebium). Man gebrauchte Wurzel und Blätter innerlich ${ }^{4}$ ).

E. vulgare L. (Pseudoanchusa, Echis, Echion, Doris). Man nahm gegen Schlangenbiss einen Trank von den Blättern oder Samen ${ }^{5}$ ). Die Bewohner von Valencia in Venezuela nehmen, wenn sie von einer Giftschlange gebissen sind, neun Tage lang Morgens und Abends etwa 1,25 $\mathrm{g}$ von einem Pulver ein, das aus gleichen Theilen von Echium vulgare, Eryngium campestre, Nepeta marifolia und Alyssum spinosum besteht ${ }^{6}$ ).

Das frische Kraut von Echium vulgare enthält ein Alkaloid, das bei Fröschen zu 0,025 g Irregularität der Athmung und Muskelrigidität, zu 0,1 g tetanischen Krampf und mehrtägigen Rigor der Muskeln erzeugt.

1) Schöpf l. c.

${ }^{2}$ ) Plinius, Hist. nat. XXII. 29. - Apulejus Platonicus, De viribus herbarum.

3) Plinius, Hist. nat. XXV. 41.

4) Ibid. XXII. 25.

$\left.{ }^{5}\right)$ Ibid. XXII. 24; XXV. 58.

6) Gmelin l. c. 


\section{- $137-$}

Anchusa tinctoria L. (Alkibiadion, Alkibidion). Blätter und Wurzeln wurden innerlich und äusserlich angewaudt ${ }^{1}$ ). Ausser den Alkannaroth soll die Wurzel noch eine giftige Base enthalten.

Trichodesma indicum Lehm., Chota-kulpee (Beng.), Jhingi, Jhingino (Hind.), ist in Vorderindien berühmt als Mittel gegen Schlangenbiss $\left.{ }^{2}\right)$. Die Wirkung ist eine diuretische.

Tiaridium indicum Lehm., Hatee-shooro (Beng.), Tayl-kodukhoo (Tam.), Benapatsja (Mal.), wird auf Jamaica, mit Kicinusöl gekocht, äusserlich gebraucht. Die Pflanze wirkt adstringirend und soll nach Martius mit sicherem Erfolge Entzündungen mildern ${ }^{3}$ ).

\section{Convolvulaceae.}

Convolvulus Cantabrica L. wurde im Alterthum häufig bei Schlangenbiss gebraucht ${ }^{4}$ ).

C. purpureus L. (I pomoea purpurea Rotli.) in Nordamerika ${ }^{5}$ ).

Ipomoea bona nox L. ${ }^{6}$ ).

I. campanulata L. ${ }^{7}$ ).

I. grandiflora Roxb. (Calonyction grandiflorum Choisy) ${ }^{8}$ ) in Ostindien.

\section{Solanaceae.}

Mandragora officinalis Mill. (M. officinarum L.), der bekannte Alraun, wurde im Alterthum auch gegen Schlangenbiss angewandt.

') Plinius, Hist. nat. XXVII. 22.

$\left.{ }^{2}\right)$ Madras Quart. Journ. IV. p. 10. - Pharmacographia indica. IV. 52\%. - Spry's Modern India. Vol. I.

$\left.{ }^{3}\right)$ Drury 1. c. p. 426 . $\mathrm{XXV}, 55$

+) Celsus, De medicina. V. cap. 27. - Plinius, Hist. nat.

s) Sch ijpf l. c.

") I'harmacographia indic: IV. 540.

7) Rlierde, Hort. Malabar. XI. 115.

\%) A inslie, Mat. inerl. ind. 11. 3355.5. 
Von Physalis somnifera L. (Halicacabum, Callium) legte man die mit Oel abgeriebene Wurzel auf. Wenn man die Wurzel den Schlangen nähert, so schlafen sie, wie man glaubte, ein und verlieren ihre giftigen Eigenschaften ${ }^{1}$ ). Die Pflanze, welche den Bitterstoff Physalin enthält, hat eine diuretische Wirkung.

Von Hyoscyamus niger L., H. albus L. u. a. nahm man die zerstossenen Blätter mit Wein innerlich ${ }^{2}$ ). Die Pflanzen enthalten die sehr giftigen Alkaloide Hyoscyamin und Hyoscin.

Nicotiana Tabacum L. und andere Nicotianaarten werden noch in der neuesten Zeit in den verschiedensten Ländern als ein gutes Mittel gegen Schlangenbiss gerühmt. Man gebraucht vom Tabak zu diesem Zwecke theils die frische Pflanze, besonders den Saft, innerlich und äusserlich, theils Decocte, Infuse, Tincturen etc. In Japan rieb man früher die Bisswunde mit Tabakssaft ein, den auch die Neger auf Martinique in derselben Weise verwenden; er wirkt vermöge seines hohen Nicotingehaltes reizend, vielleicht sogar caustisch.

Von anderen Nicotianaarten gebraucht man

N. Langsdorffii Weinm. in Brasilien ${ }^{2}$ ).

Solanum incanum R. Pav. Aus den Blättern macht man in Peru zusammen mit denen des Tabaks einen warmen Brei und verbindet damit die Bisswunde ${ }^{4}$ ).

S. mammosum L. ("matrozendruif"). Die Wurzeln und Blätter dieser Pflanze werden in Niederländisch-Westindien zusammen mit denen von Eclipta alba ("Louise Beberie ") und der Prairiebohne gegen Schlangenbiss gebraucht; dazu fügt man noch die verkohlten Köpfe giftiger Schlangen. Man erhält so eine an Roggenbrot erinnernde Masse, welche die Leute stets bei sich führen und gegen hohe Preise verkaufen. Dieselbe wird aber weder eingeimpft noch als Präservativ-

1) Plinius, Hist. nat. XXI. 105.

2) Ibid. XXV. 58.

3) v. Martius 1. c. p. 120.

4) Pöppig, Reise in Chile und Peru. II. S. 268 ff. 
mittel genommen, sondern nur dem bereits Gebissenen eingegeben. Zu diesem Zwecke muss sie in Schnaps („dram“) oder dergleichen gelöst sein, ebenso wird sie in aufgelöstem Zustande auf die Wunde gelegt. Indessen kann auch das trockene Präparat einfach gekaut und dann auf die Bissstelle gebracht werden; der Schnaps ist also unwesentlich ${ }^{1}$ ).

S. mammosum enthält ebenso wie die Kartoffel und andere Solanumarten das Glykosidalkaloid Solanin, welches besonders central wirkt und in erster Linie die motorischen und das Athmungscentrum lähmt, also durch Erstickung tödtet. Ausserdem wirkt die Pflanze diuretisch.

Franciscea uniflora Pohl (Brunfelsia Hopeana Benth.) ist in Brasilien unter dem Namen "Manacá" als Mittel gegen Schlangenbiss bekannt. Die ganze Pflanze, besonders die Wurzel, wirkt diaphoretisch, diuretisch und purgirend ${ }^{2}$ ). Wurzel und Blätter enthalten ein Alkaloid.

Capsicum baccatum L. und C. frutescens L., Mollaghai (Tam.), Capoo mologoo (Mal.), Lunka mirch (Hind.), werden in Nordamerika und in Indien angewandt. In Indien nimmt man den Saft der Blätter innerlich oder reibt denselben in eine auf dem Scheitel des Kopfes gemachte Incision ein ${ }^{3}$ ). Das wirksame Princip des spanischen Pfeffers, die flüchtige Base Capsaicin, scheint nur eine local irritirende Wirkung zu haben.

\section{Scrophuluriacecep.}

Verbascum Blattaria L. (Blattaria),

V. Thapsus L.

V. sinuatum L.

V. plicatum Sibth.

(Verbascum, Phlomos,

V. limnense Fraas (Phlomis, Lychnitis) sind die in Alterthum gebrauchten Pflanzen dieser Familie ').

1) K. Martin, Bericht über eine leice nach Nisderländisch-Westindion. I, 1888. S. 29 ff.

3) v. Martius I i. p. 1;7.

3) Madras Quart. Journ. IV. 1. 1\%.

-) Plinius. Hlist. nat. XXV. 60.73. 74. 


\section{$-140$}

Digitalis Sesanum (?) wird auf Martinique gegen Schlangenbiss benutzt ${ }^{1}$ ).

Herpestes colubrina H. B. Kth., in Chile und Peru, soll noch wirksamer bei Schlangenbiss sein als der berühmte Guaco ${ }^{2}$ ).

Scrophularia marilandica L. in Nordamerika.

\section{Bignoniaceae.}

Von Bignonia chelonoides L. gilt in Indien die Rinde, von B. unguis cati L. gelten auf Martinique die Wurzel und Blätter als Mittel gegen Schlangenbiss ${ }^{3}$ ).

\section{Acanthaceae.}

Acanthus ilicifolius L. (Dilivaria ilicifolia Juss.), Kolee-molee-cheddie (Tam.), Hurkut, Hárkúchkánta (Hind.), Paina-schulli (Mal.) wird in Indien äusserlich angewandt. Die Blätter enthalten ein Alkaloid ${ }^{4}$ ).

Rhinacanthus communis Nees., Palak-juhi (Hind.), Nága-malli (Tam.), Puzhuk-kolli, Pushpa-kedal (Mal.). Die Wurzel wird in Indien gegen Schlangenbiss gebraucht ${ }^{5}$ ). Sie enthält Rhinocanthin, eine harzige, chinonähnliche Substanz.

Barleria cristata L. (Surp-jeeba). Man benutzt in Indien die Samen ${ }^{6}$ ).

Peristrophe bicalyculata Nees., Nhasa-bhaga (Beng.). Die junge Pflanze wird in Indien innerlich und äusserlich angewandt ${ }^{7}$ ).

1) Rufz, Enquête. p. 161.

2) Pöppig, Reise in Chile und Peru.

3) Rheede, Hort. Malabar. VI. 48. - Lanessan l. c. p. 471.

$\left.{ }^{4}\right)$ Pharmacographia indica. V. 42.

$\left.{ }^{5}\right)$ Roxburgh, Flor. ind. I. 121.

$\left.{ }^{6}\right)$ Madras Quart. Journ. IV. p. 4.

7) Ibid. IV. p. 5. 


\section{Verbenaceae.}

Verbena officinalis L., (Verbenaca, Hierabotane, Verminacia) ist eine im Alterthum häufig gegen Schlangenbiss empfohlene Pflanze ${ }^{1}$ ).

Von $Y$. virgata R. P. gebraucht man in Brasilien innerlich und äusserlich ein Infus ${ }^{2}$ ).

Von Vitex agnus castus L. (Vitex, Lygos, Agnos) gab man im Alterthum die Samen und Blätter mit Wein ein ${ }^{3}$ ). Die Samen sollen einen alkaloidischen Stoff Viticin enthalten.

Von V. altissima Roxb, gebraucht man in Indien die Blätter $\left.{ }^{4}\right)$.

Ton Aegiphila salutaris Kth. ( Contracolevra") benutzt man in Südamerika ein Decoct der Blätter ${ }^{5}$ ).

Clerodendron infortunatum L. Die Blätter sind aut Java gegen Schlangenbiss in Gebrauch ${ }^{6}$ ).

Zapania nodiflora L., Blookokra (Hind.), Baleya eetheecannee (Mal.). Der Saft wird in Indien benutzt ${ }^{7}$ ).

\section{Labiatae.}

Die an Arzneipflanzen und Küchengewächsen so reiche Familie der Labiaten lieferte im Alterthume eine grosse Menge von gegen Schlangenbiss gebrauchten Pflanzen, vielleicht sogar die meisten ron allen Familien. Offenbar spielte das Vorkommen von ätherischen Oelen in derselben bei ihrer Anwendung eine bedeutende liolle.

Abgesshen von einigen Gewäclssen, deren Gattung und Art sich jetzt nirht mehr mit Sicherheit bestimmen lassen,

1) Plinius, Hist. nat. XXV. n9. - Apulejus Platonicus, De viribus herbarum.

3) I, enz. Schlangenkunde.

") J'linius, Hist. nat. XXIV. :38.

") Rherede, Hort Malabar. V. "3.

") Saffray 1. c.

c) Bisachop, Grevelink 1. c. p. 689.

7) theorde. Hort. Malalar. X. 9?. 
werden von den alten Autoren besonders folgende Arten gegen Schlangenbiss empfohlen:

Mentha piperita L. (Mentha sativa).

M. silvestris L. (Mentastrum).

M. Pulegium L. (Pulegium).

Salvia officinalis L. (Salvia, Sphakos, Elelisphakos; mit letzteren beiden Namen sind vielleicht auch Salvia pomifera L., Salvia calycina L. u. a. gemeint).

S. Horminum L. (Orminon, Corruda). Von dieser Pflanze wurde der gekochte Saft benutzt.

Origanum vulgare L. (Origanum viride).

O. heracleoticum L. (Cunila gallinacea).

O. smyrnaeum L. (Dictamnus). Auch die oft erwähnte Cunila bubila ist eine, jedoch nicht genau $\mathrm{zu}$ bestimmende Origanum-Art.

Thymus Serpyllum L.

T. Tragoriganum L. ist vielleicht das alte Tragoriganon.

Satureja hortensis L.

S. Juliana L. ist zum Theil ebenfalls das alte Tragoriganum.

Calamintha Clinopodium Benth.

Hyssopus officinalis L.

Nepeta Cataria L.

N. italica Willd.

Dracocephalum Moldaricum L. (Melissa).

Betonica Alopecurus L. (Herba Vettonicae, Syderitis, Serratula); vielleicht ist auch Sideritis syriaca $L$. gemeint.

Marrubium vulgare L. (Prasion).

Ajuga Ira L. (Abiga, Chamaepitys).

Teucrium Scorodonia L. (Scordotis).

T. Scordium L. (Scordion).

T. Chamaedrys L., auch T. lucidum L., T. flavum L. (Chamaedrys, Chamaedrops, Teucria, Teucrion, Trixago). 
T. Polium L.

Ocimum basilicum L. (Basilica, Ocymum).

Rosmarinus officinalis L. (Rosmarinum, Ros maris, Libanotis).

In neuerer Zeit werden von den Labiaten folgende Arten gegen Schlangenbiss angewandt:

Collinsonia canadensis L. und

Cunila Mariana L. in Nordamerika. Von letzterer Pflanze gebraucht man den ausgepressten Saft mit Milch äusserlich; sie wurde zuerst von Schöpf ${ }^{1}$ ) empfolılen.

Ocimum basilicum L. in Nordamerika und Cochinchina ${ }^{2}$ ).

(). gratissimum L. und

O. minimum L. ebenfalls in Cochinchina, und zwar die Samenkörner.

Mikromeria marifolia Benth. (Nepeta marifolia Car.) in Venezuela (s. Echium vulgare).

Pogostemon parviflorus Benth. Die Wurzel wird in Indien innerlich und äusserlich, besonders beim Biss der Phorsa-Schlange (Echis carinata), angewandt ${ }^{3}$ ). Die Pflanze enthält ein Alkaloid Pogostem on in, ferner Trimethylamin. harzige Stoffe und einen flüchtigen Körper.

L eucas cephalotes Spr., Goma, Madha-pati (Hind.), Tumba (Mal.),

L. aspera Spr. (Phlomis aspera Willd.), Halkusa, Chota halkusa (Hind.),

I. linifolia Spr. und

L. zeylanica R. Br. werden in Indien meistens in der Weise benutzt, dass man den Saft der zerquetschten Blïtter in die Nase einzieht "). Die zuletzt genannte Art enthält ein flüchtiges Alkaloid.

1) Siblonpt, Mat. med. americana. 1787.

4) L, an ceвsan 1. c. p. 7ris.

3) Pharmaengraphia indica. V. 95.

4) Ilirl. V. 122 ff: 


\section{Plantagineae.}

Plantago maritima L. (Herba Plantago) wird von Apulejus Platonicus und

P. Serpentina Lam. von Matthiolus empfohlen.

\section{Amarantaceae.}

Achyranthes aspera L., Chirchirà, Chikrà (Hind.), Na-yurioi (Tam.), Kataláti (Mal.). Die Samen der adstringirende und diuretische Eigenschaften besitzenden Pflanze gelten in Indien als Heilmittel gegen Schlangenbiss ${ }^{1}$ ).

\section{Chenopodiaceae.}

Beta vulgaris L. Die Runkelrübe oder Mangoltwurzel wurde im Alterthum und Mittelalter häufig angewandt; sie enthält Betaïn.

\section{Phytolaccaceae.}

Phytolacca decandra L. wird in Nordamerika gebraucht; die Samen enthalten Phytolaccin, die Beeren Phytolaccinsäure.

\section{Polygonaceae.}

Rheum Rhaponticum L., Rh. Rhabarbarum L. u. a. Rhabarberarten wurden in früheren Zeiten auch gegen Schlangenbiss empfohlen.

Polygonum Bistorta L. wurde wegen der schlangenförmigen Gestalt der Wurzel gebraucht.

\section{Aristolochiaceae.}

Die Arten dieser Familie ${ }^{2}$ ) haben von allen gegen Schlangenbiss angewandten Pflanzen neben Micania Guaco den grössten Ruhm erlangt. Namentlich sind es einzelne Arten der Gattung

1) Drury l. c. p. 11 .

$\left.{ }^{2}\right)$ L. Planchon, Les Aristoloches. Montp. 1891. - E. J. Waring 1 . c. 
A ristolochia, welche in allen Zeitaltern und in alleu Ländern als die besten Mittel gegen Schlangengift empfohlen wurden, so schon ron Theophrastus, Dioscorides, Plinius, Apulejus Platonicus. Avicenna, später von Petrus de Abano, Grevinus, Charas und vielen Anderen. Manche glaubten sogar, es genüge schon, sich die Hände mit einer Aristolochia zu reiben, um Vipern einzuschläfern und unschädlich zu machen oder sie zu verscheuchen. Im Alterthum und Mittelalter gebrauchte man folgende Arten:

Aristolochia rotunda L.; diese galt für die wirksamste und bildete einen wichtigen Bestandtheil mancher Sorten Theriak, von Skorpionen-Oelen und anderen Medicamenten.

A. longa L.

A. Clematitis $\mathrm{L}$.

A. Pistolochia L. wurde zuerst von Plinius unterschieden, während die anderen Arten bereits lange vor ihm bekannt waren. Man gebrauchte die Wurzel unter dem Namen radix Aristolochiae tenuis oder radix Polyrrhizae s. Pistolochiae.

Die Neuzeit ersetzte die erwähnten 4 Arten, welche jetzt als Mittel gegen Schlangenbiss nirgends mehr im Gebrauch zu sein scheinen, durch folgende:

Aristolochia Serpentaria L. (Serpentaria virginiana). Dicse Pflanze ist die ehemals so berühmte Virginische Schlangenwurzel, welche als Virginian snake-root oder snake-weed zuerst um die Mitte des 17. Jahrhunderts ron Thomas Johnson crwähnt wurde. Sie findet sich besonders in den südliclien Vereinigten Staaten, wo man sie in der Weise gebraucht, dass man den Saft der frischen Wurzel oder der gekauten Pflanze cinnimmt und die zerquetschten Blitter auf die Wunde legt. Die Pflanze soll cin ausgezeichnetes Diaphoreticum sein und anch stimulirend, antiseptisch, diuretisch und purgirend wirken.

A. reticulata Nutt., die Scruentaria von Texas oder fitsche Virginische Schlangenwurzel, wird in den Vereinigten Staaten ebenso wie die vorige $\Lambda$ rt angewandt.

litenning, Dis Vergiftungen durch Schlangrin, 
A. macroura Gomez, in Brasilien, der Heimat der Pflanze, Jarrinha genannt. Man benutzt Wurzel und Stengel.

A. trilobata L. (Raiz de Milhomens, Urubu-ca) wird in Brasilien, Guyana und auf den Antillen, besonders auf Martinique, sehr geschätzt. Sie ist ein gutes Diaphoreticum und vielleicht die wirksamste von allen Aristolochien ${ }^{1}$ ). Man gebraucht die Wurzel als Pulver oder Infus innerlich oder äusserlich.

A. glandulosa Kickx soll nach d'Almeida in Brasilien unter dem Namen "Angelico" gegen Schlangenbiss angewandt werden.

A. ovalifolia Duch. (Flor de Guaco) in Mexiko.

A. maxima L. (Guaco, Vejuco-Carare, Capitan) in Centralamerika und Columbien.

A. fragrantissima Ruiz (Bejugo de la Estrella, Contrayerba de Bejugo, Pehuamo, Guaco, Guaco de terra caliente) in Peru, Ecuador, Centralamerika. Man legt die frische Rinde auf die Bisswunde.

A. cynanchifolia Mart. in Peru.

A. anguicida L. (Guaco von Columbien, Mort aux serpents, Manarou, Yabacani, Contra capitan, Snake poison) auf den Antillen und der benachbarten amerikanischen Küste von Mexiko bis Brasilien, besonders in Columbien. Diese Pflanze, auf deren Bedeutung in der Therapie des Schlangenbisses schon ihre Namen hinweisen, ist eine der am meisten gerühmten Arten. Wenn man einige Tropfen ihres Saftes einer Schlange in den Mund bringt, so soll sie betäubt werden. Dieser Thatsache sollen sich die Gaukler bei ihren Productionen mit Giftschlangen bedienen, um letztere auf diese Weise unschädlich zu machen. Einige behaupten, die Schlange sterbe sogar unter Zuckungen, wenn man die Wurzel der Pflanze kaut und ihr einige Tropfen des Speichels beibringt; ebenso soll sie sterben, wenn sie in die ihr vor-

1) Th. Peckolt, Ueber brasilianische Volksheilmittel. Arch. der Pharm. LXXXII. 93. 
gehaltene Trurzel beisst. Auch soll es schon genügen, sich Hände und Füsse mit der Pflanze zu reiben, um die Schlange ohne Gefahr ergreifen zu können. Ist man gebissen, so legt man die Pflanze auf die frische Wunde und nimmt ein Decoct daron innerlich.

A. tenera Pohl (Matos) in Columbien. Nach der Sage soll sich ein kleines Säugethier, genannt "Matos", durch Essen der Wurzel rom Schlangenbisse heilen.

A. c jmbifera Mart. (Jarra, Papo de Perù) in Brasilien. Man gebraucht das Pulver, den Saft oder ein Infus oder Decoct von den Blättern. Bei Thieren treten folgende Intoxicationserscheinungen nach Eingeben der Pflanze auf: zuerst Erregung, Erbrechen und Diarrhöe, dann Somnolenz, Schwäche und absolute motorische Paralyse, schliesslich Stillstand der Respiration vor dem des Herzens ${ }^{1}$ ).

A. brasiliensis Mart. (Vejugo, Mil-homens) in Brasilien (der Name "Vejugo " bedeutet weiter nichts als "Liane").

A. ringens Tahl. (Vejugo carare, Mil-homens, Racine du Soleil) auf den Antillen, in Columbien, Venezuela und Brasilien. Man benutzt die Stengel und Wurzel als Pulver oder Decoct und auch den frischen Saft. Die Wurzel hat einen äusserst penetranten, widerlichen, rauteähnlichen Geruch und einen stark bitteren, aromatischen Geschmack; sie soll in ihren Wirkungen fast ganz der Aristolochia Serpentaria L. gleichen.

A. cordifolia Mutis (Contracapitana de Monpox, Flor de Alcatras de Monpox) in Columbien (Wurzel).

A. odoratissima I. (Tacopatle, T'acopaste, Tlacopatli, Raiz para el flato, Contrayerva, Birthwort) auf den Antillen, in Moxiko, Central- und Südamerika (Wurzel und Samen).

A. sempervirens L. liat in Arabien einen grossen Ruf.

1) Hutte, Recherches experimentales sur l'action physiologique -t therapentirne de l'rextrait aquewx du (iuaco (Aristol. cymbifera). Journ. des nouveaux remiolen. 1889. 1. 460. 
Eine 40 Tage lang gebrauchte Abkochung der Wurzel soll gegen die schädlichen Zufälle des Schlangeubisses schützen ${ }^{1}$ ). Man legt auch die gekauten Blätter als Kataplasma auf dieWunde.

A. Turbacensis Bonpl. (Capitana de Corazon) in Mexiko (Decoct der Wurzel).

A. galeata Mart.,

A. rumicifolia Mart.,

A. theriaca Mart. und

A. antihysterica Mart. in Brasilien ${ }^{2}$ ).

A. indica L. in Ostindien, Arabien, Australien, auf Java, Timor, den Philippinen etc. Sie ist bekannt unter den Namen Ishar mul, Isar mel, Ishar a moula, Isarmul - jora bel (Hind. und Bengal.), Perumarundoo, Peroum-Aroundou, Ischuramuli, Ichura-muliver (Tam.), Akarmulia, Ishwari, Sunanda (Sanskr.), Wallas (Jav.), A karpoe-loeron (Mal.).

Die ehemaligen portugiesischen Ausiedler an der Westküste scheinen zuerst ihren Gebrauch von den Eingeborenen gelernt zu haben und nannten sie "raiz de cobra". Einige Forscher ${ }^{3}$ ) rühmen ihre Wirksamkeit bei Schlangenbiss, andere fanden sie dagegen unwirksam ${ }^{4}$ ). Nach einem Hindustanischen Sprichworte soll die Pflanze sogar die Schlangen fernhalten (dasselbe behauptet Plinius von der A. pistolochia). Low ther ${ }^{5}$ ) berichtet zwei Fälle, wo eine schon fast für todt gehaltene junge Frau und ein bereits comatöses Kind durch innere und äussere Anwendung der Blätter dieser Pflanze gerettet wurden. Aeusserlich gebraucht man letztere in der Weise, dass man Stirn und Glieder mit den Blättern reibt und dieselben zugleich in die Nase steckt. Auch bedient man sich der getrockneten Wurzel, oder einer Abkochung der ganzen Pflanze, oder der in Wasser zerstossenen Wurzel.

1) Forskah l, Flora aegyptiaco-arabica. p. 156.

$\left.{ }^{2}\right)$ v. Martius l. c. p. 107.

$\left.{ }^{3}\right)$ Rhe ede, Hort. Malabar. VIII. p. 18-25. - Burman, Thes. Zeylan. p. 33.

4) Russell, Indian serpents. I. p. 86 .

5) Madras Quart. Journ. V. p. 138, 742. 
A. bracteata Retz., Cattrabungla (Sanskr.), Keeramár (Hind.), Addin-náppále (Tam.) in Ostindien, Persien, Arabien etc. Sie wird in Mysore zusammen mit Nux vomicaRinde gegeben. Auch in Abessynien wird sie als Mittel gegen rergiftete Wunden gebraucht.

Es ist sehr wahrscheinlich, dass ausser diesen angeführten Arten noch andere, besonders in Südamerika, gegen Schlangenbiss angewandt werden.

Die Wirkung der Aristolochien ist, wie schon bei einzelnen Arten angegeben wurde, im Allgemeinen eine stinulirende, diuretische, diaphoretische und antiseptische. Es ist möglich, dass der scharfe frische Saft. wenn örtlich angewandt, auch auf das Gift selbst eine im gewissen Grade caustische oder sonst irgend eine Wirkung ausübt.

Orfila ${ }^{1}$ ) fand, dass Thiere durch grössere Mengen der Wurzel ron Aristolochia Clematitis oder deren wässrigem Extracte nach einigen Tagen unter allgemeinen Lälımungserscheinungen zu Grunde gingen. Die Section ergab leichte Entzündungserscheinungen der Magenwand. Bei Pferden sah man nach Eingaben grösserer Mengen eine Art Trunkenheit, unsicheren Gang, allgemeine Trägheit, Somnolenz, Coma, Krämpf, Mydriasis auftreten; nach Besserung dieser Symptome blieb noch längere Zeit Verstopfung und starke Diurese zurück.

Frühere Untersucher fanden in den Aristolochien einen Bitterstoff, gelben Farbstoff, Oele und Harze. Pohl ${ }^{2}$ ), der die Samen von Aristolochia Clenatitis und die Wurzeln von A. longa und rotunda verarbeitete, fand als giftigen Bestandtheil das Aristolochin. Kaninchen starben daran in wenigen Tagen infolge einer sehr heftigen acuten Nephritis an Urämie; die Jiurese war anfangs vermelırt, wahrscheinlich durch leizung der secernirenden Nierenelemente, später wurde der Harn spärlicher und bluthaltig. Fs traten ferner l'arese der hinteren Extremitäten, Pendelbewegungen des Kopfes, selten

1) Orfilat, 'l'oxicologie. II. S. 471. 1854.

2) l'ohl, Ueber Aristolorhin. Arch. f. exprriun. I'athol. u. Pharmacol. XXIX. :3. 4. 1891. S. 282. 
Trismus ein. Die Athmung wurde beschwerlich, der Herzschlag aussetzend, die Cornealreflexe schwanden. Dosen von $0,02 \mathrm{~g}$ pro Kilo erwiesen sich als tödtlich. Ein Kaninchen abortirte. Bei der Section zeigte sich eine ausgebreitete Nekrose der epithelialen Nierenelemente. Die Glomeruli waren intact.

Bei Hunden traten nach subcutaner Application des Aristolochins Würgbewegungen, Erbrechen, dünnflüssige Stuhlentleerungen, Schwäche, stockende Respiration und Tod unter Coma und Respirationslähmung auf. Albuminurie fehlte; dagegen zeigte sich eine deutliche Herabsetzung des Blutdruckes. Die Herzaction war nicht nennenswert verändert. Bei den Sectionen ergaben sich Hyperämien, Blutungen und hämorrhagische Infiltrationen besonders im Darme.

Wahrscheinlich bewirkt das Aristolochin eine Gefässdilatation im Darmgebiete, welche die allmählich bis zum tödtlichen Grade fortschreitende Blutdrucksenkung, sowie die starke hämorrhagische Infarcirung der Darmschleimhaut zur Folge hat. Das Aristolochin ist nach Pohl eins der heftigsten bisher bekannten Nierengifte. Aehnlich dem Aristolochin, doch weit schwächer, wirkt das Aloin ${ }^{1}$ ).

Man benutzte übrigens die Aristolochien besonders wegen ihrer diaphoretischen und diuretischen Eigenschaften ausser gegen Schlangenbiss auch gegen zahllose andere Krankheiten.

Von sonstigen zur Familie der Aristolochiaceen gehörigen Pflanzen werden noch folgende gegen Schlangenbiss empfohlen:

Bragantia Wallichii R. Br. (Apamia siliquosa Lamarck, malaiisch Alpam, Alpama und Pahiora). Der Saft der Blätter wird mit Acorus calamus in Indien als Antidot gegen Schlangengift äusserlich gebraucht, ebenso die zerriebene Wurzel mit Limonensaft als Schnupfmittel gegen Cobra-Biss. Die Wurzel wird auch innerlich in Milch gegeben und als Kataplasma aufgelegt. Nach einem malabarischen Sprichwort verlässt das Gift den Körper, sobald „alpam" in ihn eintritt.

1) Murset, Arch. f. experim. Pathol. u. Pharmacol. XIX. S. 310. 
In Nordamerika benutzt man

Asarum virginicum L. und

A. canadense L., auch canadische Serpentaria genannt und mit Aristolochia Serpentaria zusammen gegeben. Die Wurzel dieser Pflanze wirkt brechenerregend und purgirend und regt vielleicht, wie die von Asarum e u ropa e m L., die Gefässthätigkeit an. (Asarum europaeum enthält den Haselwurzcampher Asarin.)

\section{Piperaceae.}

Piper nigrum L.,

P. reticulatum L. (Jaborandi in Brasilien),

P. procumbens Desc. (?),

P. nodulosum Link,

P. unguiculatum R. P. (Nhandi, Nhandu, Pimenta dos Indios) werden in Amerika, besonders in Brasilien, viel bei Schlangenbiss angervandt. Der schwarze Pfeffer wurde auch in Europa früher häufig zu demselben Zwecke empfohlen, so schon von Celsus ${ }^{1}$ ). Man gebraucht den Pfeffer in Amerika theils innerlich, theils legt man die zerquetschten Wurzeln auf die Bisswunde. Die Wurzel von P. reticulatum soll ein hräftiges Sialagogum sein ${ }^{2}$ ), P. nodulosum und P. unguiculatum dagegen diuretisch wirken ${ }^{3}$ ). Von P. procumbens gilt der Stengel auf Martinique als ein sicheres Heilmittel ${ }^{4}$ ).

\section{Lauraceae.}

Laurus nobilis L. Man machte bei Schlangenbiss Umschläge mit den Blättern und der Rinde des Lorbeerbaumes und trank dic Beeren in Wein ${ }^{5}$ ). Avicenna empfichlt auch das L orbecröl.

3) Colsus, De medicina. V. Cap. 27.

2) Spix 1. v. Martius, Reise in Brisilien. I. S. 279 11.

3) v. Martius, Syst. mat. med. Brasil. p. 93.

4) La nessan J. c. j. 433.

") I'l in iur, Hist. nat. XX'HI. 80. 
Auch das von L. officinalis L. (Sassafras officinarum Nees) stammende Sassafrasöl gilt als Gegenmittel, besonders gegen den Biss von Trigonocephalus.

Cinnamomum zeylanicum Nees und andere Zimmtarten wurden ebenfalls früher angewandt ${ }^{1}$ ).

\section{Loranthaceae.}

Von Loranthus americanus Jacq. gilt der Saft der Rinde und der Früchte auf Martinique als Antidot ${ }^{2}$ ).

\section{Euphorbiaceae.}

Euphorbia officinarum L. Plinius ${ }^{3}$ ) empfiehit den Saft der Euphorbia als ein ausgezeichnetes Gegengift gegen Schlangenbiss und räth, auf dem Scheitel des Kopfes einen Einschnitt zu machen und dort das Mittel einzuführen, ebenso Dioscorides.

E. neriifolia L. (E. Ligularia Roxb.), Schadidacalli, Katak-kalli, Daun-susu-sudu (Mal.), Shadraykullie (Tam.), Manasá-sij, Munsa-sij (Beng.) ist der indischen Schlangengottheit Manasá (Munsa) geweiht. Die Eingeborenen von Indien gebrauchen die Wurzel mit schwarzem Pfeffer innerlich und äusserlich. An jedem Dienstag und Donnerstag der Monate Juli und August bringen sie den Baum zugleich mit Gaben von Reis, Milch und Zucker der Gottheit dar und beten zu ihr um Befreiung von den Schlangenbissen ${ }^{4}$ ).

E. Antiquorum L., Elak-kalli (Mal.), Ilaik-kalli (Tam.), Sehund, Thokar (Hind.) wird in Vorderindien in derselben Weise angewandt wie die vorige ${ }^{5}$ ).

E. thymifolia L., Sittra paládi (Tam.), Chhoti dudhi, Nigáchúni (Hind.). Der ausgepresste Saft oder

1) Celsus l. c.

2) Lanessan 1. c. p. 462.

3) Plinius, Hist. nat. XXV. 38.

4) Madras Quart. Journ. III. 1861. - Drury l. c. p. 205.

5) Pharmacographia indica. V. 253. 
die gepulverte Pflanze wird in Indien mit Wein innerlich genommen und auch äusserlich auf den gebissenen Theil applicirt. Das ätherische Extract der Pflanze enthält ein Alkaloid.

E. Guyoniana Boiss. et Reut. wird in Algier gegen Schlangenbiss benutzt. Tissaire ${ }^{1}$ ) empfiehlt den frischen Milchsaft, der Pflanze zu 8-10 Tropfen in Wasser zu nehmen, nach einer Stunde nochmals 5 Tropfen und nach 2-3 Stunden weitere 5 Tropfen zu nehmen; in den Zwischenräumen verordnet er Stinulantien und Diaphoretica mit etwas Ammoniumacetat, eventuell noch zwei weitere Dosen von 5 Tropfen in Pausen ron $3^{1}{ }_{12}$ bis 4 Stunden. Wenn keine frischen Pflanzen da sind, so soll man ein Decoct der trockenen anwenden.

E. pilulifera L. (E. hirta L., E. capitata Lam.) ist auf Martinique und anderen Antillen als Malnommée bekaunt. Die auf die Wunde gelegte gekaute Pflanze soll den Schmerz lindern, das Gift neutralisiren und die Bisswunde heilen. Etwas von der gepulverten Pflanze innerlich genommen soll das Herz stärken und die durch das Schlangengift verloren gegangenen Kräfte wieder lierstellen. Auch in Brasilien wird die Pflanze bei Schlangenbiss angewandt ${ }^{2}$ ).

E. prostrata Ait. wird in Nordamerika gegen Schlangenbiss gebraucht.

Der Milchsaft der Euphorbien wirkt äusserlich angewandt als Reizmittel, innerlich genommen aber als Catharticum.

Croton oblongifolius Roxb., Arjuna (Hind.), Kote, Putol (Mal.) in Indien. Die Pflanze enthält einen alkaloidischen Stoff $\left.{ }^{3}\right)$.

C. Tiglium L., Jumalghota (Hind.), Cadel-avanaeu, Neervaula, Pantjahar (Mal.). Nervalum (Tam.), AdalAdal (Javan.), wird ebenfalls in Indien benutzt. Man legt ein Pulver der getrockneten Blätter auf die Bisswunde ${ }^{-1}$.

1) Annuaire de therapeutique. 1859. p. 263. - T'issaire, litudes sur la vipère comue (bicorne) de l'Algérie du Sud. Alger 18:58.

2) Rufz, Enquâte. - Bisschop Grevelink l. c. p. 42 f.

3) Pharmacographia indica. V. 286.

") Thhede, Hort. Malahar. II. 62. 
Croton Tiglium ist auch ein Bestandtheil der Tanjore-Pillen. Der wirksame Bestandtheil der Pflanze ist das Crotonöl, welches äusserlich hautreizend, innerlich dagegen stark drastisch wirkt.

C.antisyphiliticus Mart. (Erva mular, Curraleira, Pé de perdis, Alcanfora). Die Blätter werden in Brasilien theils äusserlich als Foment auf die Bissstelle applicirt, theils in Form eines Infuses innerlich gegeben. Die Wirkung soll eine diaphoretische, diuretische und excitirende $\operatorname{sein}^{1}$ ).

Antidesma Alexiteria L. und

A. Bunius Spr., A mitee (Hind.), Nolei-tali (Tam.), Nuli-tali (Mal.), Hoenie (Jav.) werden in Indien und auf Java gegen Schlangenbiss gebraucht und wirken diaphoretisch ${ }^{2}$ ).

Rottlera tinctoria Roxb. (Mallotus philippinensis Müll.), Kamal (Hind.), Capilapodì (Tam.), Ponnagam (Mal.). Blätter und Früchte werden in Indien angewendet ${ }^{3}$ ). Der wirksame Stoff ist wahrscheinlich das Rottlerin.

Jatropha opifera Mart. (Adenoropium opiferum) in Brasilien (Herva de lagarto ${ }^{4}$ ).

\section{Urticaceae.}

Schon Plinius erwähnt eine Urtica, deren Samen die von einer Schlange Gebissenen mit Schildkrötenbrühe trinken sollen ${ }^{5}$ ), und noch jetzt soll von den nordamerikanischen Indianern eine Nessel bei Schlangenbiss angewandt werden ${ }^{6}$ ). Die Nesselarten enthalten in ihren Drüsenhaaren vielleicht

1) v. Martius l. c. p. 85 .

2) Madras Quart. Journ. IV. p. 12. - Bisschop Grevelink 1. c. p. 427 .

3) Rheede, Hort. Malabar. V. 42.

$\left.{ }^{4}\right)$ L e op. J. W eiss, Beiträge zur Kenntniss der südbrasilianischen Provinz Paraná. Curityba 1886. S. 21.

5) Plinius, Hist. nat. XXII. 15.

6) Germer 1. c. 
neben noch anderen wirksamen Stoffen freie Ameisensäure, welche die hautröthende Wirkung dieser Pflanzen verursacht. Auch Ficus Sycomorus L. (Blätter), Morus alba L. und M. nigra L. (Saft) wurden zuweilen gegen Schlangenbiss angewandt.

Dorstenia brasilieusis Lam. (Contrayerva, Caiapiá) wird in Brasilien benutzt und soll in frischem Zustande noch kräftiger wirken als die berühmte Serpentaria, ihre heilsamen Eigenschaften jedoch schneller verlieren ${ }^{1}$ ).

D. tubicina R. P. gilt in Chile und Peru als Mittel gegen Schlangenbiss ${ }^{2}$ ).

D. Contrayerva L. (M ano de sapo, Krötenhand) ist in Mexiko. Central- und Südamerika in Gebrauch. Die Curadores de culebras in Mexiko impfen den Saft der Pflanze zum Schutze gegen Schlangenbiss ein und geben dann dem Geimpften die Wurzel in einer starken Dosis Branntwein innerlich. Die Pflanze bewirkt Sinken der Körpertemperatur und der Pulsfrequenz, sowie Erbrechen ${ }^{3}$ ); ausserdem soll sie diuretisch, diaphoretisch und excitirend wirken. Wässrige Aufgüsse und Abkochungen sind unwirksam. Alkoholische oder wässrig-alkoholische lassen die excitirende Wirkung auf Herz, Gehirn und Rückenmark hervortreten.

Girardina palmata Gandich., in Indien.

\section{Plantanaceae.}

Platanus oriental is L. wurde im Alterthum und Mittelalter, und

Pl. occidentalis L. wird noch jetzt in Nordamerika von den Eingeborenen benutzt ${ }^{1}$ ). Die Knospen der ersteren enthalten Asparagin und Allantoin.

1) Spix u. v. Martius, Reise in Brasilien. I. S. 279 fl.

2) P'̈ploig, Keise in C'hile und Peru.

a) Jacolot, Arrh. de uned. navale. 1867. VII. 1. 390.

if rigrmer 1. ". 


\section{Juglandeae.}

Juglans alba L. und

J. nigra L. werden in Nordamerika gegen Schlangenbiss gebraucht.

\section{Cupuliferae.}

Quercus Robur L. und Q. sessiliflora Sm. Man nahm theils die Eicheln innerlich, theils legte man die in Milch abgekochte Rinde auf die Bissstelle ${ }^{1}$ ).

Q. n igra L. gilt in Nordamerika als Mittel gegen Schlangenbiss.

\section{Zingiberaceae.}

Curcuma aromatica Salisb., Jangli-haldi, Banhaldi (Hind.), Kashturi-manjal (Tam.) wird in Südindien gebraucht ${ }^{2}$ ). Die Wurzel hat tonische Wirkungen.

Amomum Grana paradisi L. (Guianapfeffer) und

Maranta arundinacea L. werden auf Martinique mit mehreren anderen Pflanzen zusammen, wie Erythrina ciralodendron, Aristolochia triloba und einer Anagallis, gegen den Biss der Lanzenschlange angewandt. Der Guianapfeffer bildet überhaupt den wesentlichsten Bestandtheil der meisten auf jener Insel von den Negern gebrauchten, in der Regel aus vielen Pflanzen und anderen Dingen zusammengesetzten Heilmittel gegen Schlangenbiss ${ }^{3}$ ). Die Maranta wird übrigens auch in Indien benutzt.

\section{Musaceae.}

Musa paradisiaca L. und

M. sapientium L. Der Saft der Bananenwurzel wird ebenfalls auf Martinique innerlich und äusserlich angewandt ${ }^{4}$ ).

1) Plinius, Hist. nat. XXIV. 3.

2) Pharmacographia indica. VI. 396.

3) Rufz, Enquête. p. 117 ff.

4) Ibid. p. 166. 


\section{$-1.57-$ \\ Lividear.}

Ton Gladiolus segetum Gawl. (Hyacintlus) gab man im Alterthum den Gebissenen die Samen zusammen mit Abrotonum ein ${ }^{1}$ ).

Iris florentina L. und I. germanica L. (Iris rufa) wurde mit saurem Wein getrunken ${ }^{2}$ ).

Ton Pardanthus chinensis Ker. (Belemcanda punctata Mönch.) werden in Indien die Blätter bei Cobrabiss gegeben ${ }^{3}$ ).

\section{Amaryllideae.}

Hypoxis erecta L. gilt in Nordamerika als Mittel gegen Schlangenbiss.

Von Agave rirginica Lam. legen die Mexikaner die gekaute Wurzel auf die Bissstelle und gebrauchen dieselbe zugleich innerlich ${ }^{4}$ ). Die Wirkung ist wahrscheinlich eine diuretische.

Von A. mexicana Lam. bereitet man in Mexiko einen Branntwein („mescal"), den man dem Gebissenen bis zur Trunkenheit eingiebt, während man zugleich die Wunde mit einem Pflaster aus dem Saft der Pflanze und schwarzem Pfeffer verbindet ${ }^{5}$ ).

Von Polianthus tuberosa L. (Margueritas) gebraucht man in Peru theils innerlich einen Aufguss, theils legt man die durchschnittene Wurzel auf die Bisswunde ${ }^{6}$ ).

Crinum asiaticum L., Belutta pola-tali (Mal.), Veshi Moonghee (Tam.) ist ein Bestandtheil der TanjorePillen und soll emetische Eigenschaften haben. Nan legt

1) Plinius, Hist. nat. XXI. 97.

$\left.{ }^{2}\right)$ lbid. XXI. 8:;.

3) Pheedr, Hort. Malahar. XI. 74.

4) C'roft, Chromical News. XIVI. p. 165. $18 \times 2$.

5) Nayhegyi, l'hilad. med, a. surg. Rec. XVIIl. 12. p. 249. 1869.

") Pöplpig, Reigr in Clile u. I'cru. II. S. 230 ft. - v. 'I'schudi, J'Eru. $\$ .43 .3$. 
auch einen Theil der gekauten Wurzel auf die Bisswunde und nimmt den anderen innerlich ${ }^{1}$ ).

\section{Liliaceae.}

Im Alterthum waren folgende Allium-Arten beliebte Mittel gegen Schlangenbiss:

Allium sativum L., der Knoblauch. Derselbe soll schon durch seinen Geruch die Schlangen vertreiben (noch jetzt bestreicht man in Indien häufig Thüren und Fenster damit, um die Schlangen fernzuhalten), und aufgelegt oder gegessen den Biss aller Thiere heilen. Ganz besonders sollte er gegen die Schlange Hämorrhois wirksam sein, wenn man den Wein, in welchem man ihn zu sich genommen hat, durch Erbrechen wieder von sich gab ${ }^{2}$ ).

A. Cepa L., die Zwiebel, sollte ebenso wirken und wurde ebenfalls innerlich und äusserlich bei Schlangenbiss angewandt. Russell stellte jedoch fest, dass die Schlangen keineswegs eine besondere Abneigung gegen Knoblauch und Zwiebeln zeigen.

A. Porrum L., Porree.

A. Schoenoprasum L., Schnittlauch, und A. carinatum L. wurden in ähnlicher Weise gebraucht.

Von Asphodelus ramosus L. benutzte man die Samen, Stengel und Knollen ${ }^{3}$ ).

Von Scilla maritima L. wurden die in Essig gekochten Zwiebeln aufgelegt.

Anthericum graecum L. (Lloyda graeca Salisb., Phalangitis, Phalangion, Leucanthe mum, Leucantha) wurde in Form von Kataplasmen und Abkochungsn angewandt; man benutzte davon die Blätter, Blüthen und Samen ${ }^{4}$ ).

Lilium Martagon L. (Hemerocallis) u. a. Lilienarten galten auch als Mittel gegen Schlangenbiss.

1) Lanessan 1. c. p. 784 .

$\left.{ }^{2}\right)$ Plinius, Hist. nat. XX. 23.

3) Ibid. XXII. 32.

$\left.{ }^{4}\right)$ Ibid. XXVII. 98. 
Gloriosa superba L., Kalihári, Languli (Hind.), Kalaipai-kizhangu, Caateejan (Tam.) wird in Madras als Specificun gegen Schlaugenbiss gebraucht ${ }^{1}$ ). Warden fand in der Wurzel einen Gerbstoff und einen dem Scillain der Meerzwiebeln verwandten bitteren, giftigen Stoff, "Superbin“. Eine Frau, die eine Quantität der gepulverten Wurzel einnahm, bekan nach einer halben Stunde heftiges Erbrechen, Krämpfe, Verdrehungen des Körpers, verbunden mit furchtbaren Schmerzen, und starb nach vier Stunden. Die Section ergab Congestion im Gehirn und seinen Häuten mit Blutextrarasaten, sowie Congestionen in Lungen, Leber, Nieren und Entzündung der Magenschleimhaut.

Asparagus officinalis L., der Spargel, gilt in Persien als Antidot gegen Schlangenbiss; man nennt ihn daselbst Márchubeh oder Márgiyeh, d. h. Schlangenkraut ${ }^{2}$ ). Der Spargel enthält als wirksamsten Bestandtheil das A sparagin.

Uvularia perfoliata L.,

U. grandiflora Smith und

Veratrum luteum L. werden in Nordamerika bei Schlangenbiss benutzt; die letztere Pflanze enthält wahrscheinlich ähnliche giftige Alkaloide wie V. album und V. viride.

\section{Commelinaceae.}

Aneilema tuberosum Ham. Die Knollen werden von den Eingeborenen in Ostindien als Antidot gegen Schlangenbiss gebraucht ${ }^{3}$ ).

\section{Pulmacere.}

Kunthia montana H. B. soll in Neugranada wegen ihres zuckerhaltigen Stammes gegen Schlangenbiss angewandt werden ${ }^{s}$ ).

1) Tharmacographia indica. Vf. $480 \mathrm{fl}$.

$\left.{ }^{2}\right)$ It,id. VT, 48f.

3) D) rury l. c. p. 42.

4) L, en\%, Schlangenkunde. 


\section{Typhaceae.}

Von Sparganium ramosum L. wurde im Alterthum die $W$ urzel gebraucht ${ }^{1}$ ).

Aroideae.

Von den im Alterthum bei Schlangenbiss benutzten ArumArten ist ausser Arum maculatum L., A. italicum Mill. und A. Dioscoridis Sibth. vor Allem

Arum Dracunculus L. (Dracunculus vulgaris Schott) zu erwähnen, auf dessen Bedeutung als Mittel gegen Schlangenbiss schon die alten Namen Dracontium, Dracunculus, Viperina hinweisen. Namen und Gebrauch der Pflanze sind wohl zurückzuführen auf die schlangenartigen Flecke ihrer Wurzel. Der Saft der letzteren hat scharfe, ätzende Eigenschaften.

A. Colocasia L. (Tayove) wird in Cayenne benutzt. Caladium helleborinum Vent. in Chile und Peru.

Quebitea guianensis Aubl. und

Dracontium dubium Kth. in Britisch-Guyana.

D. polyphyllum L. (Jiraraca) in Brasilien und auf Martinique ${ }^{2}$ ). Die Pflanze wirkt stark stimulirend, die Wurzel purgirend.

Arisaema Pythonium Blume (Erva de Santa Maria) in Brasilien ${ }^{3}$ ).

Typhonium orixense Schott, Ghekul (Hind.), und

Scindapsus pertusus Sweet. in Ostindien. Der Saft der letzteren Pflanze wird mit schwarzem Pfeffer beim Biss der Daboia innerlich gegeben und mit dem Saft der Wurzeln von Croton oblongifolius und von der Frucht von Momordica Charantia auch auf den gebissenen Theil gelegt ${ }^{4}$ ).

1) Plinius, Hist. nat. XXV. 63.

2) Lanessan l. c. p. 486.

$\left.{ }^{3}\right)$ v. Martius l. c. p. 95,96 .

4) Pharmacographia indica. VI. 544. - Madras Quart. Journ. IV. p. 12. 


\section{$-161-$
Cyperaceue.}

Yon Cyperus longus L. und C. rotundus L. galt die Wurzel bei den Alten als Mittel gegen Schlangenbiss ${ }^{1}$ ).

\section{Gramineae.}

Von Panicum miliaceum L. und von der Gerste wurden Mehlumschläge um die Bissstelle gemacht²).

Ob die als Schoenus oder Juncus odoratus ${ }^{3}$ ) bezeichnete Pflanze Andropogon laniger Desf. ist oder $\mathrm{C}_{Y}$ perus rotundus L. erscheint zweifelhaft.

Saccharum officinarum L. Der Saft des Zuckerrohres steht bei den Eingeborenen von Amerika, besonders von Brasilien, in hohem Ansehen als Antidot gegen Schlangengift und wird von denselben innerlich und äusserlich angewandt. Grössere Gaben davon sollen purgirend wirken, während ihm bei äusserer Anwendung eine blutstillende Wirkung zukommen soll ${ }^{\text {)}}$.

\section{Coniferae.}

Taxus baccata L. war im Alterthum sehr berühnt als Mittel gegren Schlangenbiss, und der Kaiser Claudius soll sogar in einem Edicte den Saft der Eibe für das wirksamste von allen bei Schlangenbiss angewandten Heilmitteln erklärt haben ${ }^{5}$ ). Sie enthält ein narkotisch wirkendes Alkaloid Taxin.

Von Juniperus communis L., dem Wachholder, wird von Dioscorides der Saft gegen Schlangenbiss empfohlen. Auch sollen Räucherungen nit Wachholderlaub die Schlangen vertreiben, ein Glauben, der sich bis auf die Neuzeit erhalten hat. Die diuretisch wirkenden Beeren wurden ebenfalls gebraucht.

1) Plinius, Hist. nat. XXI. 70.

2) Ibid. XXII. 62.

3) Scribonius Iargus, De compositionibus medicamentorum. Cap. 167.

") Ruf\%, Enquistr. p. $16 \%$.

c) Mlercurialis, De venenir.

Branning, Mon Vergiftumgen durch Schkengen. 
Cupressus sempervirens L. wird auch von älteren Autoren erwähnt; ebenso das besonders aus Kiefern und Fichten gewonnene Kienöl.

Henzel in Südafrika behauptet aus dem Safte der sogenannten schwarzen Edeltanne ein unfehlbares Mittel hergestellt $\mathrm{zu}$ haben, durch welches von 500 von giftigen Schlangen gebissenen Negern 487 vom sicheren Tode gerettet seien ${ }^{1}$ ).

\section{Cryptogamen.}

Salvinia natans All. (Lenticula) wird von Paulus Aegineta, ein Adianton (Kallitrichon, Polytrichon) und ein Agaricus (vielleicht Boletus igniarius) von Plinius ${ }^{2}$ ) erwähnt.

Osmunda virginica(?).

Adianthum pedatum L. und

Hypnum crista castrensis L. werden in Nordamerika gegen Schlangenbiss angewandt ${ }^{3}$ ).

Ausser den genannten Pflanzen werden noch eine Anzahl anderer angewandt, deren wissenschaftliche Namen sich nicht haben ermitteln lassen. So gebraucht man bei Cantagallo in Brasilien eine ammoniakalische Tinctur, welche der Apotheker Peckolt aus einer von den Eingeborenen gegen Schlangenbiss benutzten unbekannten Pflanze der Urwälder bereitet und unter dem Namen "Polygonaton" in den Handel gebracht hat. Dieser Tinctur wird ein Schröpfkopf aus vulcanisirtem Kautschuk beigegeben, um ihn nach Unterbindung des Gliedes sogleich auf die durch einige Einschnitte erweiterte Wunde zu setzen. Die Tinctur wird je nach der Intensität der Erscheinungen in kürzeren oder längeren Zwischenräumen tropfenweise eingenommen. Dieses Mittel hat in der Umgegend von Cantagallo in mehr als 70 Fällen den ausgezeichnetsten Er-

1) Globus. Nr. 61. S. 61.1892.

$\left.{ }^{2}\right)$ Plinius, Hist. nat. XXII. 30 u. XXV. 50.

3) Schöpf, Reisen. 
folg gehabt. Selbst wenn es sehr spät zur Anwendung kam, die Vergiftungssymptome den bedrohlichsten Charaliter angenommen hatten, und das so gefährliche Blutbrechen eingetreten war, führte es noch einen günstigen Ausgang der Krankheit herbei. Die grösste Zahl ron Schlangenbissen in dieser Gegend rührt ron der Jararacá her ${ }^{1}$ ).

In Columbien, Venezuela und anderen südamerikanischen Staaten ist unter dem Namen Curarina de Juan Salas $\mathrm{Nieto}$ ein allgemein beliebtes Volksmittel verbreitet, das als Specificum gegen Bisse von Giftschlangen, Skorpionen und tollen Hunden. sowie gegen Sumpf- und gelbes Fieber, gegen Durchfall und Menstruationsbeschwerden gilt. Es stellt eine bräunlichgelbe, etwas trübe Flüssigkeit dar, welche wahrscheinlich ein mit Rum hergestellter Pflanzenauszug ist. Die übliche Dosis ist 1 Theelöffel bis 2 Esslöffel ").

Un noch einige andere nur unter den einheimischen Namen bekannte Pflanzen zu erwähnen, so gebraucht man in Guatemala gegen Schlangenbiss eine Pflanze "Algalia" ${ }^{3}$ ), in Mexiko äusserlich eine Abkochung der narkotisch wirkenden -mala mujer" (ytlohomakil), die für so giftig gilt, dass die Indianer nicht unter ihrem Schatten zu schlafen wagen ${ }^{1}$ ), in Surinam eine "sabanaboontje" 5), in Südafrika eine .Herrenbohne", in Südamerika eine "Astrilobata" und .Maporite chequita" "). auf Martinique eine "Nhandiroba" (..Noix de Serpent") ete. Von unbekannten indischen Pflanzen fülırt Waring ') eine ganze Reihe auf, nämlich: A melpodi. Ben-moenja, Belutta-amelpodi, Maravara tsjembo, hussuwndje, Kokid, Uck, Naglee, Toore, Nangale Wal. Kird, Gogaree.

1) v. 'I'schudi, Reisrnn durch Südamerika. III. S. $160 \mathrm{ff}$.

$\left.{ }^{2}\right)$ Pharmac. Centralhalle. N. F. XV. Nr. 39. 27. Sept. 1884. S. 551.

4) liatta de fiuatemala. 29. Nov. 1799.

4) Napliegyi l. r.

) Virtin a. a. 0 .

") II a ncock, Arch. A. I'larm. XXXVII. IX:3I. p. t55.

7) Vadran (Qnart. Journ. IV. j. $14 \mathrm{f}$. 
Es ist nicht zu bezweifeln, dass von den Eingeborenen der verschiedenen, besonders tropischer Gebiete, gegen Schlangenbiss nocb andere Pflanzen gebraucht werden, deren Kenntniss sich bisher den Nachforschungen der Reisenden entzogen hat.

Ein geheimes Mittel gegen Schlangenbiss will auch ein gewisser van Tol, ein Mischling, in Surinam entdeckt haben ${ }^{1}$ ). Derselbe ritzt den Leuten die Haut an beiden Händen oberhalb des Gelenkes durch drei an der linken und zwei an der rechten Seite gemachte leichte Einschnitte auf, in welche er sein Pulver einreibt, das nach seiner Angabe aus zu Kohle verbrannten, nur ihm allein bekannten heilkräftigen Kräutern bestehen soll. Darauf muss der Betreffende eine kleine Menge des Pulvers mit Branntwein gemengt zu sich nehmen. Diese Procedur wird jährlich wiederholt und dient zur Prophylaxe. Auch nach dem Bisse behauptet van Tol durch seine Methode heilen zu können. Salkowski fand in einer von Joest nach Berlin gebrachten Probe des Pulvers Eisen, Kalk, Magnesia, Kali, Spuren von Natron, Kohlensäure, Phosphorsäure und etwas Sand; giftige Metallverbindungen fehlen darin. Es ist nach diesem Befund möglich, dass das Mittel nichts weiter ist als eine durch Sand verunreinigte Kohle. Versuche an Kaninchen und Meerschweinchen, die mit dem Mittel in der vorgeschriebenen Weise behandelt waren, zeigten die Werthlosigkeit desselben gegen Schlangenbiss. Die damit geimpften Thiere starben durch den Biss der Klapperschlange und der Puffotter ebenso wie nicht geimpfte.

Aehnlich mag es sich mit anderen mehr oder minder zusammengesetzten Heilmitteln gegen Schlangenbiss verhalten. Diese alle hier anzuführen unterlasse ich, weil die Bestandtheile zum Theil unbekannt sind. Sind sie aber bekannt, so vermag man nicht den wirksamen Antheil eines solchen Gemisches zu bezeichnen. Von der Mannigfaltigkeit solcher Compositionen giebt die Mittheilung von $\mathrm{Rufz}^{2}$ ) eine Vorstellung,

$\left.{ }^{1}\right)$ W. Joest, Ueber ein angebliches Mittel gegen Schlangengift aus Surinam. Globus. Nr. 59. S. 358. 1891. Nr.61. S. 61.1892.

2) Rufz, Enquête. p. 132. 
wonach die ganze Flora der Antillen in den auf Martinique gebrauchten zusammengesetzten Arzneien rorkommen soll.

Auch im Alterthum hatte man das Bestreben, möglichst viele Stoffe, besonders Pflanzen, zu einem Heilmittel zu vereinigen, das dann als Universalmittel gegen alle möglichen Krankheiten, besonders auch gegen Vergiftungen angewandt wurde. Einen Hauptbestandtheil solcher Mittel bildeten vielfach, wie schon oben erwähnt, Theile von Vipern. Derartige zusarnmengesetzte Mittel wurden auch gegen Schlangenbisse empfohlen, z. B. ron Avicenna der Theriak Alfuruk, die Latwerge des Hurmus, die des Aristomachus, ron Galen die Theriaca Andromachi ex viperis ${ }^{1}$ ), das Antidotum Zopyrium ${ }^{2}$ ), das Antidotum Antipatri ${ }^{3}$ ) und das des Democrates ${ }^{4}$ ). Galen berichtet auch, dass man absichtlich Thiere von Vipern beissen liess und ihnen dann Theriak gab, um sich von der Güte des Mittels zu überzeugen.

\section{Impfung mit Schlangengift.}

Es bleibt noch eine Methode zu besprechen übrig, welche angesichts der günstigen Resultate, die man in der neueren Zeit mit der Einimpfung von Krankheitsgiften, z. B. bei Pocken, Hundswuth, Diphtheritis, erzielt hat, vielleicht eine grössere Zukunft hat als alle bisher besprochenen Mittel, nämlich die Impfung mit Schlangengrift zum Schutze gegen die Vergiftung durch Schlangenbiss. Zwar war schon im Alterthum, wie bereits in dem Kapitel über thierische Antidota hervorgehoben wurde, das Bestreben vorhanden, sich durch Genuss von Viperntheilen, besonders von Vipernküpfen, gegen Schlangenhiss zu sichern, indessen ist die bewusste $A$ nwendung

'G Galen, 1\% Antidotis. Liber 1. Cary. 6-7.

") Jbid. litger HI. Cap. 8.

$\left.{ }^{3}\right)$ Ibid. Cap. 10.

4) Ibid. ('ap. 15. 
der Impfung doch erst der neueren Zeit vorbehalten gewesen. Es ist auffallend, dass wir dieses Mittel bei den Eingeborenen der verschiedensten Länder bereits zu einer Zeit in Gebrauch finden, in welcher bei uns selbst die Pockenimpfung noch völlig unbekannt war. Freilich die Art und Weise, wie diese Impfung von manchen Eingeborenen vorgenommen wird, macht es zweifelhaft, ob dieselbe immer den Geimpften deu gewünschten Schutz gegen die schädlichen Folgen eines etwaigen Bisses verleiht - jedenfalls hegen die so Behandelten eine feste Zuversicht zu der Schutzkraft dieses Mittels, und nach den Berichten von Reisenden zu urtheilen, müsste dieselbe in der That im Allgemeinen eine ziemlich sichere sein.

Ich erinnere hier noch einmal an die Schlangenbeschwörer, welche sich aller Wahrscheinlichkeit nach wenigstens in manchen Ländern theilweise durch Impfung mit Schlangengift immun gegen die Bisse der Giftschlangen gemacht haben. In Südamerika, besonders in Brasilien, ist seit alten Zeiten der Glaube weit verbreitet, dass man sich gegen Schlangenbisse schützen könne, wenn man sich den Rücken mit dem Giftzahne einer Schlange kreuz und quer zerkratzen lasse. In ähnlicher Weise macht man in Französisch-Guyana mit dem Zahne einer Giftschlange drei ca. $3 \mathrm{~cm}$ lange Einschnitte auf dem Fussrücken und lässt die Wunden eine Minute lang bluten. Sodann werden dieselben mit einem schwärzlichen Pulver behandelt, das aus Leber und Galle des Thieres besteht, welche an der Sonne getrocknet und mit den Giftdrüsen zusammen zerrieben sind; das Blut hört danach auf zu rinnen. Der Indianer, der die Operation vornimmt, kaut darauf Baumblätter mit diesem Pulver und bringt soviel Speichel, wie er produciren kann, auf die Wunde. Damit ist die Impfung beendet. Die dadurch angeblich erlangte Immunität soll nach dem Glauben der Eingeborenen sogar in mehreren Generationen erblich sein. Ein französischer Reisender, welcher einer solchen Impfung beizuwohnen Gelegenheit hatte, liess dieselbe auch an sich selbst vollziehen und behauptet, seitdem $7 \mathrm{Mal}$ von verschiedenen, theilweise sehr 
gefährlichen Giftschlangen gebissen worden zu sein, ohne auch nur einen Fieberanfall davongetragen zu laaben ${ }^{1}$ ).

$\mathrm{Da}$ bei der beschriebenen Operation mit der zerriebenen Giftdrüse unzweifelhaft auch etwas von dem darin enthaltenen Gifte in das Blut gelangen kann, so scheint es sich hier in der That um eine wirkliche Impfung mit Schlaugengift zu handeln. An dem zum Ritzen der Haut gebrauchten Giftzahne dürfte sich wohl in den meisten Fällen kein Gift mehr befinden, es sei denn, dass er einer frisch getödteten Schlange entnommen und nicht schon früher zur Impfung benutzt wurde.

Recht interessant ist auch das in manchen Gegenden Mexikos geübte Verfahren, Menschen gegen Schlangenbiss immun zu machen $\left.{ }^{2}\right)$. Hier spielen aber wieder durch abergläubische Vorstellungen beeinflusste äusserliche Formalitäten eine Hauptrolle. Zunächst darf die Impfung nur an einem f'reitage vorgenommen werden. Vor derselben muss der Betreffende zur Vorbereitung 5-15 Knollen von der "Mano dle sapo" genannten Pflanze (Dorstenia Contrayerva L.) essen. und zwar nur in ungerader Zahl (also $5,7,9 \ldots 15$ ), je nach der Toleranz des Individuums. Am besten sollen die Pflanzen sein, welche am ersten Freitag des Monates März gepflückt sind. Auch im getrockneten Zustande sind sie noch geeignet zur Vorbereitung der Impfung. Die physiologische Wirkung der Pflanze besteht darin, dass die Circulation des Blutes etwas verlangsamt wird, und ein Kältegefüll, oft auch Uebelkeit und Erbrechen eintritt. Gegen letzteres muss man nach Möglichkeit ankämpfen, denn wenn die genossenen Wurzeln wieder ausgebrochen werden, soll es gefährlich sein, sich der Impfung zu unterwerfen.

Zur Impfung selbst, die noch an demselben Tage von einem "Curador de culebras" vorgenommen wird, wird ein grosser Giftzahn von den giftigsten Schlangen benutzt. Diese müssen an einem Freitag getödtet sein, und die /ä̈bne noch

1) Archives d'anthropologie criminelle. Janv. 1892.

2) Jacolot, Arch. de méd. navale. 1867. p. 390. 
an demselben Tage herausgenommen sein. Ein und derselbe Zahn kann mehrere Jahre lang zu Impfungen dienen. Zunächst wird mit dem Zahne auf dem linken Fussrücken die Haut in Form eines Viereckes geritzt, so dass es etwas blutet; man muss sich dabei hüten, eine Vene zu verletzen. Sodann kommen das rechte Handgelenk, der rechte Fussrücken, das linke Handgelenk, der linke Schenkel, der rechte Arm, der rechte Schenkel, der linke Arm, die Mitte des Brustbeins, der Nacken, die Stirn an die Reihe, so dass im Ganzen elf Inoculationen gemacht werden; den Schluss bildet endlich eine sinnbildliche Incision auf der Zunge. Vor der Impfung muss der Betreffende viel Branntwein trinken, während derselben darf er weder rauchen noch Tabak kauen, weil das Gift sonst durch den Speichel entwischen könnte.

Mindestens sieben solcher Impfungen sind nöthig, um einen Menschen sicher gegen Schlangenbiss zu schützen und ihm die Fähigkeit zu verleihen, Bisswunden auszusaugen; denn nur Geimpfte sollen im Stande sein, dies ohne Gefahr zu thun. In jedem Falle aber soll der Aussaugende seinen Mund mit Tabak gefüllt haben, da sonst die Zähne ausfallen und sogar der Tod eintreten kann. Der Gebissene dagegen soll nach dem Aussaugen Knollen von der "Mano de sapo" essen und auch davon Cataplasmen machen. Manche lassen sich bis 15 Mal impfen (stets ist auch hier eine ungerade Zahl vorgeschrieben), sollen dann aber so von Schlangengift gesättigt sein, dass sie zuweilen wahnsinnig werden. In der Regel sind sonst während der Impfzeit nur unerhebliche Störungen, wie Kopfschmerz, geringe Erregung etc. vorhanden, aber bei Vollmond soll die Geimpften eine furchtbare Wuth ergreifen, der Speichel soll ihnen in Strömen aus dem Munde fliessen, sie sollen das Bedürfniss haben zu beissen, und, um nicht Menschen zu beissen, in die Wälder fliehen und in die Bäume beissen, welche in Folge dessen absterben. Der Biss eines solchen Geimpften soll für Menschen eben so gefährlich sein wie der Biss einer Giftschlange.

Dass in diesem Berichte über die Wirkung der Impfung 
etwas Wahrheit mit viel Aberglauben, Mysticismus und Uebertreibungen rerbrämt ist, wird ohue Weiteres klar. Wenn man bedenkt, dass ein Giftzahn mehrere Jahre lang zu den Impfungen gebraucht wird, während welcher Zeit sicher jede Spur von Gift von seiner die Haut verletzenden Spitze verschwunden sein müsste, so ist es doch sehr fraglich, ob man diesem ganzen Verfahren überhaupt noch einen Werth zuschreiben darf und es nicht vielmehr als eine bewusste Täuschung von Impfenden und eine Suggestivtäuschung der Geimpften bezeichnen soll.

In Afrika tragen die Eingebỏrenen von Namaqua, Damara, Kalahari, sowie die Buschmänner stets getrocknete Giftdrüsen bei sich, machen, falls sie gebissen sind, an der betreffenden Stelle kleine Einschnitte und legen Stückchen des getrockneten Inhaltes der Drüsen hinein. Zuvor legen sie eine Ligatur um das gebissene Glied und saugen die Wunde aus. Auch suchen sie die Schlange zu tödten, schneiden die Giftdrüse heraus und trinken den Inhalt derselben aus. Manche verwenden übrigens statt der getrockneten Giftdrüse in derselben Weise den getrockneten Körper einer giftigen Eidechse "t'nobo". Bolton. der sich zwei Jahre lang in jenen Gegenden aufhielt, will sich durch wiederholte Beobachtungen an den Einwohnern und an europäischen Reisenden von der vollkommen sicheren Wirkung dieser Heilmethorle überzeugt haben. So sah er z. B. einen Eingeborenen, der "Gifttrinker" und Schlangenfänger war, seine Hand in einen Behälter mit giftigen Schlangen stecken und, trotzdem er ernstlich gebissen wurde, doch völlig gesund bleiben. Die einzige Folge des Bisses soll eine leichte örtliche Entzündung sein ${ }^{1}$ ).

Eq handelt sich also hier um eine wirkliche Inoculation des Schlangengiftes, die aber im Gegensatze zu den bisher mitgetheilten Beobachtungen nicht als Präiventivmittel vor Jem Bisse, sondern erst nach geschehenem Bisse angewandt wird. $/ \mathrm{hu}$ der bereits durch diesen in den Körper linein-

1) Sancat. 7. Jan. 1886\% 1. 92. 
gelangten Giftmenge wird also auf demselben Wege noch eine neue, wenn auch nur geringe Quantität gefügt, wodurch doch die Wirkung des Giftes der landläufigen Auffassung nach eher verstärkt als abgeschwächt werden müsste. Auf welche Weise hier der angebliche Erfolg der Impfung zu erklären ist, dürfte vorläufig deductiv schwer zu ermitteln sein. Möglicherweise spielt dabei die gleichzeitige innere Anwendung des Schlangengiftes eine Rolle. Es ist nämlich denkbar, dass bei genügender Menge von saurem Magensafte eine Modification des Giftstoffes zu Stande kommt, welche die Fähigkeit hat, die Herzthätigkeit und zugleich die Ausscheidung durch Haut und Nieren stark anzuregen; wenigstens soll dem innerlich genommenen Schlangengift eine die Herzaction sehr beschleunigende Wirkung zukommen ${ }^{1}$ ). Dieser Meinung widerspricht jedoch die Beobachtung, dass Magensaft die Wirkung des Giftes nicht zerstört, sondern bei Thieren noch um das Doppelte verstärkt ${ }^{2}$ ).

Vor einiger Zeit suchte man von zoologischer Seite die medicinischen Kreise Deutschlands für die innere Anwendung des Schlangengiftes gegen Schlangenbiss zu gewinnen ${ }^{3}$ ). Der Empfehlende hatte in Aegypten nach jedem Bisse ein paar Tropfen Schlangengift, das er stets in einem Fläschchen bei sich trug, innerlich genommen und war stets von allen schweren Erscheinungen frei geblieben. Als er einstmals bei einer Demonstration in Alexandrien von einer sehr giftigen Schlange gebissen worden war, und sich alsbald Angstgefühl, starke Schwellung der Hand und Ohnmacht eingestellt hatte, so dass ihn Alle für verloren hielten, wurden ihm ein paar Tropfen von seinem Schlangengift in Cognac eingeflösst. Schon nach kurzer Zeit folgte ein colossaler Schweissausbruch, das Bewusstsein kehrte allmälig wieder, und nach einer Stunde konnte er sich bereits auf die Strasse begeben.

$\mathrm{Ob}$ in diesem Falle wirklich dem Schlangengifte oder

1) Ziem, Allg. Med. Central-Zeitg. XCIV. 1886. p. 1597.

$\left.{ }^{2}\right)$ Gautier, Bull. de l'Acad. de méd. 2. sér. X. 1881. p. 950.

3) Ziem 1. c. 
nicht vielmehr dem gleichzeitig verabreichten Cognnac der Erfolg zuzuschreiben ist, erscheint mindestens sehr zweifelhaft. Auch in Schlesien soll ein Schuhflicker, der wegen zahlreicher glücklicher Curen bei Kreuzotterbissen berühnt war, seine Erfolge der Anwendung von gefangenen Thieren abgenommenem Schlangengifte verdankt haben.

In manchen Gegenden Afrikas soll man sogar kleine Kinder von weniger gefährlichen Giftschlangen beissen lassen. um sie gegen den Biss grösserer zu schützen.

Wissenschaftliche Untersuchungen über Immunisirung von M enschen gegen Schlangenbiss durch Schlangengift selbst scheinen bisher noch nicht angestellt worden zu sein. Dagegen liegen eine Reihe von Beobachtungen vor, welche zeigen, dass es bei Thieren möglich ist, wenn auch keine absolute, so doch eine relative Immunität gegen Schlangengift herrorzubringen, und zwar in der Weise, dass successive Giftinoculationen den Thieren grössere Widerstandsfähigkeit gegen stärkere Giftdosen ertheilen, besonders wenn letztere an demselben Punkte applicirt werden wie die ersteren ${ }^{1}$ ).

Nach den neuesten in Frankreich angestellten Untersuchungen ${ }^{2}$ ) erwiesen sich folgende Methoden als geeignet zur Immunisirung von Thieren gegen Schlangengift:

1. Man gewöhnt die Thiere an progressiv wachsende Dosen verdünnten Schlangengiftes. Zuerst injicirt man dem Thiere die Hälfte der tödtlichen Giftdosis, also z. B. einem Kaninchen von $2 \mathrm{~kg}$ Gewicht $0,25 \mathrm{mg}$ Cobra-Gift; nach 12-15 Tagen verabfolgt man ihm dieselbe Dosis noch einmal, nach ij Tagen bereits die doppelte Dosis ron

1) M. Ka u fmann, Du venin de la vipère. Paris 1889.

$\left.{ }^{2}\right)$ M. Kaufinann, Compt. rend. de la soc. de biologie. 9. sér. VI. 1894. p. 113. - A. Calmetíe, Annales de l'institut l'asteur. 1892. p. 160. 1894. p. 275; Compt. rend. de la soc. de biologie. 9. sér. VI. 1894. p. 120. 10. sér. 1894. p. 204; Compt. rend. de l'Acad. des seiences. CXVIII. 1894. p. 720, 1004. - C. Phisalix et G. Bertrand, Compt. rend. de l'Acad. des sciencer. CXVIII. 1494. p. 288, 356; Arch. de phy*iol. 5. ger. VI. :3. 1894. p.567, 611; Compt. rend. de la soe. de biol. 9. หล́r. VI. 1894. 1. 111, 124. 
$0,5 \mathrm{mg}$, nach weiteren 6 Tagen $0,75 \mathrm{mg}$, schliesslich $1 \mathrm{mg}$. Von da an kann man jedesmal die Menge des injicirten Giftes um $1 \mathrm{mg}$ steigern, und in 2 Monaten verträgt das Thier bereits $6 \mathrm{mg}$, also eine sonst 12 fach tödtliche Dosis.

2. Injectionen von Chlorkalklösung oder anderen, das Schlangengift abschwächenden Substanzen einige Zeit nach den Giftinoculationen. Hierdurch wird ein Thier nach 2 Wochen gegen die tödtliche Dosis von $0,5 \mathrm{mg}$ Schlangengift immun. Man darf jedoch das betreffende Mittel nicht zu früh nach der Giftinoculation einspritzen.

3. Man inoculirt den Thieren alle 5 Tage ein Gemisch von $2 \mathrm{mg}$ Cobra-Gift mit einer Lösung von Chlorkalk oder Natriumhypochlorid in einer Concentration von 1: 60, wovon man bei jeder folgenden Einspritzung eine immer geringere Menge zum Gifte hinzufügt. Nach Verlauf eines Monats ist eine Immunität gegen $2 \mathrm{mg}$ reinen Giftes vorhanden, welche man noch dadurch steigern kann, dass man alle 8-10 Tage jedesmal um $1-2 \mathrm{mg}$ steigende Giftinjectionen macht. Es soll sogar genügen, Kaninchen $4-5$ Tage lang jedesmal $6-8 \mathrm{~cm}$ einer Chlorkalklösung $(1: 60)$ subcutan zu injiciren, um sie gegen eine zweifach tödtliche Giftmenge zu immunisiren.

4. Injectionen von durch Erhitzen abgeschwächtem Schlangengifte. Wenn man Viperngift eine Viertelstunde lang bei $75^{\circ}$ erhitzt, so tödtet es nicht mehr; erhitzt man es $15-20$ Minuten lang bei $100^{\circ}$, so bringt es überhaupt. keine Vergiftungserscheinungen mehr hervor.

Fünf Minuten langes Erhitzen auf $80^{\circ}$ soll ebenfalls das Gift abschwächen, und zwar in der Weise, dass die Localwirkungen desselben ganz aufgehoben werden, während die Allgemeinwirkungen nur gemildert werden. Impft man nun ein derartig abgeschwächtes Gift Meerschweinchen ein, so sollen dieselben schon nach 2 Tagen gegen eine tödtliche Dosis des ursprünglichen Giftes immun sein.

5. Injection von Blut oder Blutserum von durch Schlangengift immunisirten Thieren. Dasselbe wirkt 
antitoxisch und vermag andere Thiere nicht nur gegen gleiches Schlangengift, sondern auch gegen andere Arten immun zu machen, so dass also z. B. das Serum von gegen Viperngift immunen Thieren auch gegen Cobra-Gift prïventiv und therapeutisch angewandt werden kann.

Auch das Serum von mit Chlorkalk behandelten Thieren soll in derselben Weise antitoxisch wirken. Die mit antitoxischem Serum immunisirten Thiere behalten ihre Immunität ziemlich lange. Dieselbe tritt übrigens nicht sofort nach der Inoculation, sondern erst nach einiger Zeit (24 bis 48 Stunden) ein und wird nicht direct durch den Impfstoff hervorgebracht, sondern ist eine Folge der Reaction des Organismus, indem der Giftstoff im Blute angeblich die Bildung einer antitoxischen Substanz hervorruft, welche physiologisch die Wirkungen des Giftes neutralisirt und welche von einer chemischen Wirkung des Impfstoffes auf einen der Blutbestandtheile herzurühren scheint. Was die Menge des nöthigen Impfstoffes betrifft. so sollen 0,3 mg Vaccine gegen die gleiche Menge Schlangengift schützen können.

Man vollzieht die Impfung mit Serun in der Weise, dass man $1-1^{1 / 2}$ Stunden nach der Giftinoculation und dem Auftreten der ersten Vergiftungserscheinungen $6-8 \mathrm{ccm}$ Serum intraperitoneal und subcutan injicirt. Selbst mit einem schwachen Impfserum kann man hierdurch nicht nur die Thiere heilen, sondern auch gegen weitere Giftinoculationen immun machen.

Die antitoxischen Eigenschaften des Serums verschwinden, wenn man letzteres auf $(60-7)^{\circ}$ erhitzt, indem durch die Hitze das Antitoxin alterirt wird.

Uebrigens kann man auch theilweise das Serum von Giftschlangen selbst zur Impfung benutzen. Wenn man z. B. eine nicht tödtliche Dosis von frischem Serum von Naja lıaje einem Thiere einimpft, so verträgt das letztere naclı 4 'lagen eine tödtliche Dosis dieses Giftes.

Mit Cobra-Serum scheint sich jedoch eine ähnliche Immunität nicht "rzielen $\% u$ lassen.

Dagegen scheint das Blut von Varanus Bengalensis, 
der gegen den Biss der Brillenschlange unempfindlich sein soll, bei Thieren die Wirkung des Schlangengiftes, wenn es zugleich mit diesem injicirt wird, abzuschwächen, d. h. die Thiere lebten längere Zeit als nach der Injection des Giftes allein ${ }^{1}$ ).

Neuerdings hat man auch die Entdeckung gemacht, dass sogar das Serum von gegen Tetanus oder Hundswuth immun gemachten Thieren im Stande ist, andere Thiere gegen nachfolgende Vergiftung durch Cobra-Gift zu schützen, und dass gegen Wuth geimpfte Kaninchen eine 4-5fach tödtliche Dosis von Schlangengift ertragen können. Und was noch wunderbarer ist, das Serum von Kaninchen, welche gegen Abrin, den wirksamen Bestandtheil der Jequirity-Bohnen, immunisirt sind, macht andere Thiere resistenter gegen Schlangengift, und umgekelırt macht das Serum von gegen Schlangengift immunen Thieren andere resistenter gegen Abrin ${ }^{2}$ ).

Es wäre voreilig, wollte man, vorausgesetzt, dass diese Mittheilungen als sichere Thatsachen angesehen werden können, von diesen bei Thieren günstigen Resultaten der Impfung mit Schlangengift sofort auf eine gleich günstige Wirkung derselben bei Menschen schliessen. Indessen die Beobachtungen bei den wilden Völkerschaften und die wissenschaftlichen Untersuchungen der neuesten Zeit über die Schutzkraft der Impfung bei verschiedenen anderen Krankheiten, namentlich die jetzigen Erfolge der Serumtherapie bei der Diphtheritis, machen es doch sehr wahrscheinlich, dass es schliesslich gelingen wird, auch die Menschen nicht nur nach erfolgten Bissen von Giftschlangen sicher zu heilen, sondern sie auch gegen Schlangengift zu immunisiren, was für jene Länder, in denen die Giftschlangen die furchtbarste Plage bilden, selbstverständlich von der allergrössten Bedeutung sein würde.

Solange dieses Ziel aber noch nicht erreicht ist, muss man sich eben damit begnügen, abgesehen von der möglichst frühzeitigen, Anwendung geeigneter Heilmittel, von denen

1) Kanthack, Journ. of Physiol. XIII. 3. 4. 1892. p. 272.

2) R oux, Ann. de l'inst. Pasteur. 1894. Nr. 10. p. 722. 
die mechanischen. besonders Ligatur, Ausschneiden, Aussaugen und Aetzen der IVunde, vorliuufig inmer noch die sichersten sind, die Bisse so viel als möglich überhaupt $\mathrm{zu}$ verhindern. Dazu ist zunächst die grösste Vorsicht an Orten, wo sich Giftschlangen aufhalten, erforderlich, wie Tragen einer festen, für die Gittzähne undurchdringlichen Fussbekleidung u. dgl. Sodann müssen die Giftschlangen überall energisch verfolgt und getödtet werdell. und womöglich von Staats wegen Prämien dafür ausgesetzt werden, wie es schon in manchen Ländern, so in Britisch-Indien und auch bei uns, der Fall ist. Auch soll man alle solche Thiere, welche als Schlangenfeinde bekannt sind, wic Igel. Iltis, Wiesel, Dachs, Bussard, Storch, Eichelhäher. schonen. Auch die Schweine sollen die Schlangen durclı Aufwühlen ihrer Höhlen vertreiben. Zum Fernhalten der Giftschlangen von den Wohnungen emptiehlt Fayrer, die Wände init Carbolsäure oder mit Kohlentheer zu bestreichen, da die Schlangen den grïssten Widerwillen gegen den Phenolgeruch besitzen: auch durch Knoblauch sucht man in Indien, wie schon oben erwähnt, die Schlangen fernzuhalten.

Es empfiehlt sich auch in Ländern, welche an Giftschlangen reich sind, besondere Versuchsstationen für Schlangengift einzurichten. So existirt bereits in Calcutta neben einem Schlangenhause ein Laboratorium behufs genauer Untersuchungen über die pathologischen Folgen von Schlangenbissen. Es sollen in diesem Institute auch alle diejenigen Mittel auf ihre Wirksamkeit und Leistungsfähigkeit untersucht werden, welche man bisher gregen Schlangenbisse empfohlen hat.

Mïgre sich diese Einrichtung nicht nur für Ostindien, sonilern für alle an der Giftschlangenplage leidenden Länder als eine erfolg- und segensreiche erweisen. 



\section{Grundriss der pathologischen Anatomie.}

Von Dr. E. Grerdes.

Mit $6 \mathrm{Abbildungen.} \mathrm{8.} \mathrm{1893.} \mathrm{geh.} \mathrm{M.} \mathrm{6.} \mathrm{-}$

Lehrbuch der

\section{Bakteriologischen Untersuchung}

\section{und Diagnostik.}

Eine Anleitung zur Ausführung bakteriologischer Arbeiten

und zur Einrichtung bakteriologischer Arbeitstätten mit zahlreichen, vielfach nach Originalphotogrammen hergestellten Abbildungen und mit 8 Tafeln in

Lichtdruck, enthaltend 50 Photogramme von llikroorganismen.

Von Doc. Dr. L. Heim.

gr. 8. 1894. geh. M. 16.-

\section{Lehrbuch der Z oologie. \\ Von Prof. Dr. J. Kennel.}

Mit 310 Abbildungen im 'Text, entlaaltend gegen 1000 Einzeldarstellungen. gr. 8. 1893. geh. M. 18.-

\section{Compendium der Arzneiverordnungslehre}

für Studirende und Aerzte

Prof. Dr. R. Kobert.

Zweite erweiterte Auflage. Mit 121 Abbildungen.

8. 1893. gel. 11. 7.-

\section{Compendium der praktischen Toxikologie}

zum Gebrauche fiir praktische Aerzte und Studierende.

Von Prof. Dr. R. Kobert.

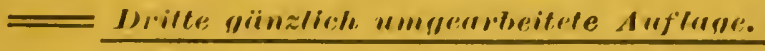

Mit 22 Tabellen. 8. 1894. geh. M. 4.80.

\section{Lehrbuch der Intoxikationen. Von Prof. Dr. R. Kobert.}

Mit $6: 3$ Abtildungen irn Text. gr. 8. 1×93. gel. M. 16.- 
Ueber Areca Catechu, Chavica Betle und das

Hetelkaue n

von

Docent Dr. L. Lewin.

Mit 2 lithograph. Tafeln. gr. 8. 1889. geh. M. 6. -

Versuch einer Theorie der

\section{Septischen Krankheiten.}

Auf Grund experimenteller Untersuchungen.

Von Dr. A. Marmorek.

8. 1894. geh. M. 4.-

\section{Synopsis Plantarum diaphoricarum.}

Systematische Uebersicht

der

Heil-, Nutz- und Giftpflanzen aller Länder. Von

Professor Dr. D. A. Rosenthal. gr. 8. 1861-1862. geh. M. 18.20.

\section{Lehrbuch der pathologischen Anatomie} mit Berücksichtigung der

allgemeinen Pathologie.

\section{$z$ wei Theile.}

I. Theil: Allgemeine pathologische Anatomie mit Berücksichtigung der allgemeinen Pathologie.

Von Professor Dr. R. Thoma.

Mit 436 Abbildungen und 4 Tafeln. gr. 8. 1894. geh. M. 18. -

\section{Lehrbuch \\ des \\ öffentlichen Gesundheitswesens. \\ Von}

Dr. A. Wernich und Dr. R. Wehmer. gr. 8. 1894. geh. M. 18. - 




\section{COLUMBIA UNIVERSITY}

This book is due on the date indicated below, or at the expiration of a definite period after the date of borrowing, as provided by the rules of the Library or by special arrangement with the Librarian in charge.

\begin{tabular}{|c|c|c|c|}
\hline DATE BORROWED & DATE DUE & DATE BORROWED & DATE DUE \\
\hline & What ? & & \\
\hline & & & \\
\hline & & & \\
\hline & " & & \\
\hline & & & \\
\hline & & & \\
\hline & & & \\
\hline & & & \\
\hline & & & \\
\hline & & & \\
\hline & & & \\
\hline & & & \\
\hline & & & \\
\hline & & & \\
\hline & & & \\
\hline & & & \\
\hline G28(538)M 50 & & & \\
\hline
\end{tabular}




\section{Brenning}

Die vergiftungen durch schlangen

AUG 101938

BINDERY

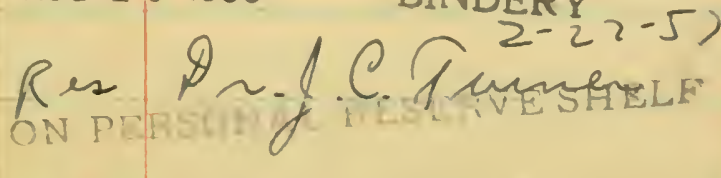

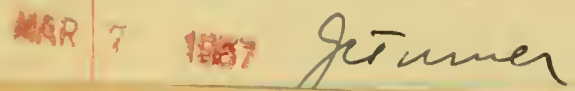


